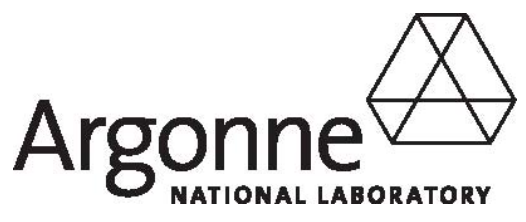

ANL-GenIV-077

\title{
CONTROL ROD STUDIES FOR ENIGMA CONFIGURATIONS
}

Nuclear Engineering Division 


\section{About Argonne National Laboratory}

Argonne is a U.S. Department of Energy laboratory managed by The University of Chicago under contract W-31-109-Eng-38. The Laboratory's main facility is outside Chicago, at 9700 South Cass Avenue, Argonne, Illinois 60439. For information about Argonne,

see www.anl.gov

\section{Availability of This Report}

This report is available, at no cost, at http://www.osti.gov/bridge. It is also available

On paper to the U.S. Department of Energy and its contractors, for a processing fee, from:

U.S. Department of Energy

Office of Scientific and technical Information

P.O. Box 62

Oak Ridge, TN 37831-0062

phone (865) 576-8401

fax (865) 576-5728

reports@adonis.osti.gov

This report was prepared as an account of work sponsored by an agency of the United States Government. Neither the United States Government nor any agency thereof, nor The University of Chicago, nor any of their employees or officers, makes any warranty, express or implied, or assumes any legal liability or responsibility for the accuracy, completeness, or usefulness of any information, apparatus, product, or process disclosed, or represents that its use would not infringe privately owned rights. Reference herein to any specific commercial product, process, or service by trade name, trademark, manufacturer, or otherwise, does not necessarily constitute or imply its endorsement, recommendation, or favoring by the United States Government or any agency thereof. The views and opinions of document authors expressed herein do not necessarily state or reflect those of the United State Government or any agency thereof, Argonne National Laboratory, or The University of Chicago. 


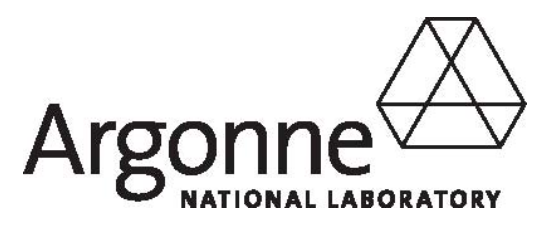

ANL-GenIV-077

Control Rod Studies for ENIGMA Configurations

by

G. Aliberti

T. A. Taiwo

G. Palmiotti

Nuclear Engineering Division, Argonne National Laboratory

and

J. Tommasi and R. Jacqmin

CEA-Cadarache,

St.-Paul-Lex-Durance (FRANCE)

August 31, 2006 


\section{TABLE OF CONTENTS}

ABSTRACT VIII

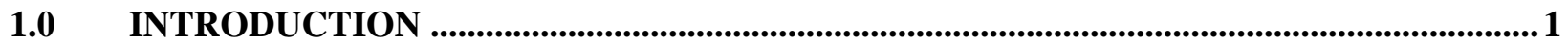

2.0 REFERENCE CORE CONFIGURATION AND PROPOSED EXPERIMENTS ................... 3

2.1 Reference Configuration for Experiments ............................................................. 3

2.2 Proposed Phases for Central Control Experiments .............................................. 6

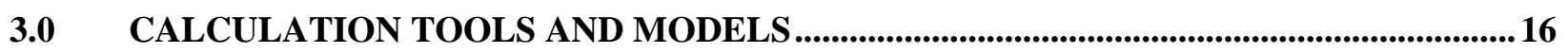

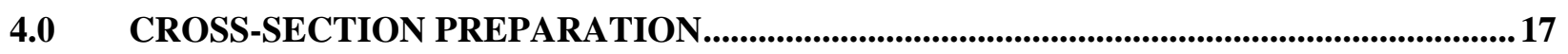

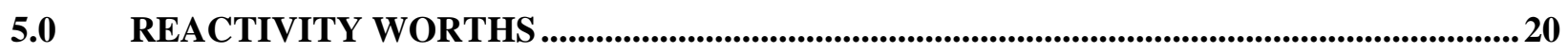

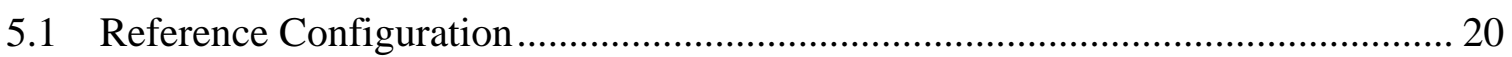

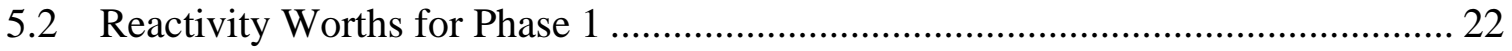

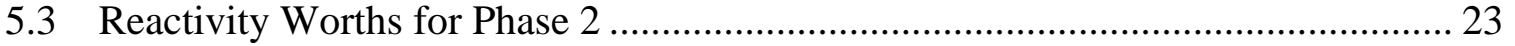

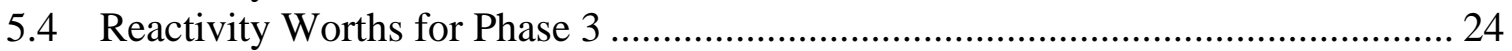

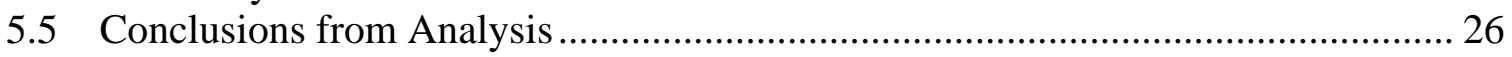

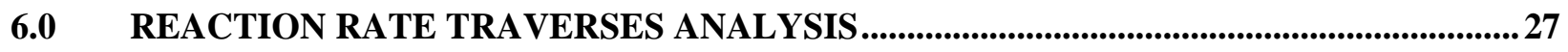

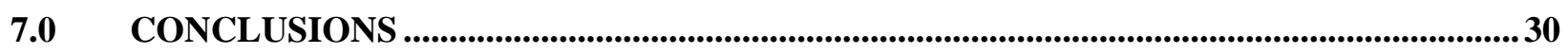

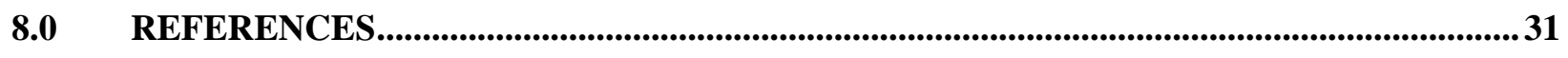

9.0 APPENDIX A. FLUX AND REACTION RATE TRAVERSES ............................................. 32 


\section{LIST OF FIGURES}

Figure 1. Reference Configuration (XY Layout)................................................................... 3

Figure 2. Reference Configuration (RZ Model)............................................................... 3

Figure 3. ENIGMA Reference Fuel Assembly..................................................................... 4

Figure 4. Reference Configuration with Void Transition Zone................................................ 4

Figure 5. Reference Configuration with Void Transition Zone (RZ Model). .............................. 4

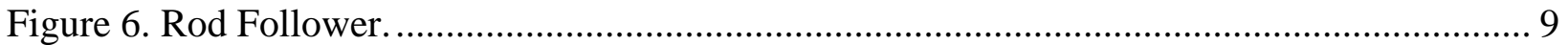

Figure 7. 4 Absorber Rodlets: Compact Absorber Pattern. ...................................................... 9

Figure 8. 4 Absorber Pattern: Dispersed Absorber Pattern........................................................ 10

Figure 9. 12 Absorber Rodlets: Compact Absorber Pattern. .................................................. 10

Figure 10. 12 Absorber Rodlets: Dispersed Absorber Pattern................................................. 11

Figure 11. 32 Absorber Rodlets: Compact Absorber Pattern. ................................................... 11

Figure 12. 32 Absorber Rodlets: Dispersed Pattern \#1 (4 Absorber Rods)................................. 12

Figure 13. 32 Absorber Rodlets: Dispersed Pattern \#2 (8 Absorber Rods)................................. 12

Figure 14. 32 Absorber Rodlets: Dispersed Pattern \#3 (32 Absorber Rods).............................. 13

Figure 15. 32 Absorber Rodlets: Dispersed Pattern \#4 (Absorber Ring). .................................. 13

Figure 16. 52 Absorber Rodlets: Compact Absorber Pattern. .................................................. 14

Figure 17. 52 Absorber Rodlets: Dispersed Pattern \#1 (4 Rods)............................................... 14

Figure 18. 52 Absorber Rodlets : Dispersed Pattern \#2 (8+1 Absorber Rods). ........................... 15

Figure 19. 52 Absorber Rodlets : Dispersed Pattern \#3 (8+4+1 Absorber Rods). ...................... 15

Figure 20. Cell for Void Rodlet Cross-Section Processing. ................................................... 17

Figure 21. Cell for Boron Rodlet Cross-Section Processing. ................................................. 17

Figure 22. Details of the Void Zone at ENIGMA Core Center............................................... 19

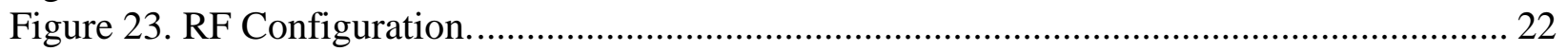

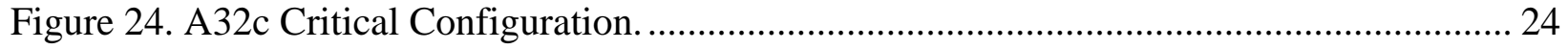

Figure 25. A52c Critical Configuration .................................................................................. 25

Figure 26. Channel Location in Reference Configuration With Void Zone and Inside Void Zone............................................................................................. 27

Figure 27. Direct and Adjoint Flux Spectra at Core Center. .................................................. 29

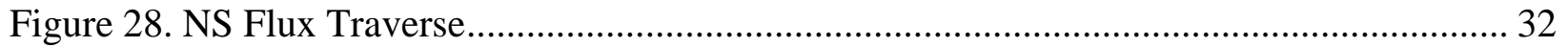

Figure 29. NS Flux Traverse inside the Void Region....................................................... 32

Figure 30. NS U-235 Fission Traverse .............................................................................. 32

Figure 31. NS U-235 Fission Traverse inside the Void Region ............................................. 32

Figure 32. NS U-238 Fission Traverse ........................................................................... 32

Figure 33. NS U-238 Fission Traverse inside the Void Region ........................................... 32

Figure 34. NS Np-237 Fission Traverse .......................................................................... 33

Figure 35. NS Np-237 Fission Traverse Inside the Void Region ............................................. 33

Figure 36. NS Pu-239 Fission Traverse .......................................................................... 33

Figure 37. NS Pu-239 Fission Traverse Inside the Void Region............................................ 33

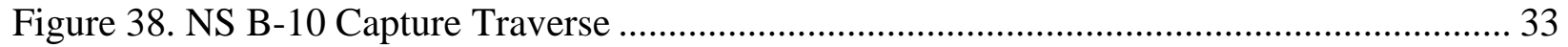

Figure 39. NS B-10 Capture Traverse Inside the Void Region ............................................... 33

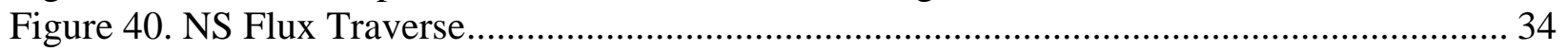

Figure 41. NS Flux Traverse Inside the Void Region ...................................................... 34

Figure 42. NS U-235 Fission Traverse ............................................................................... 34

Figure 43. NS U-235 Fission Traverse Inside the Void Region ............................................ 34 


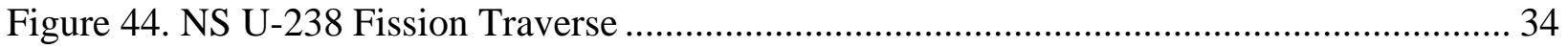

Figure 45. NS U-238 Fission Traverse Inside the Void Region ............................................. 34

Figure 46. NS Np-237 Fission Traverse ................................................................................ 35

Figure 47. NS Np-237 Fission Traverse Inside the Void Region ............................................ 35

Figure 48. NS Pu-239 Fission Traverse .............................................................................. 35

Figure 49. NS Pu-239 Fission Traverse Inside the Void Region.............................................. 35

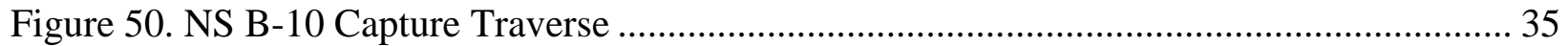

Figure 51. NS B-10 Capture Traverse Inside the Void Region .............................................. 35

Figure 52. NS Flux Traverse ........................................................................................ 36

Figure 53. NS Flux Traverse Inside the Void Region ....................................................... 36

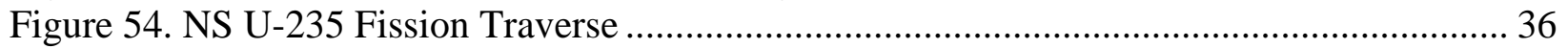

Figure 55. NS U-235 Fission Traverse Inside the Void Region ............................................ 36

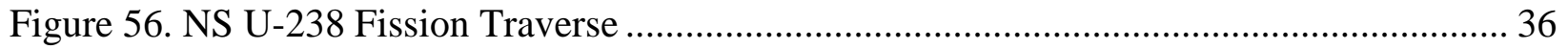

Figure 57. NS U-238 Fission Traverse Inside the Void Region ............................................ 36

Figure 58. NS Np-237 Fission Traverse ......................................................................... 37

Figure 59. NS Np-237 Fission Traverse Inside the Void Region ........................................... 37

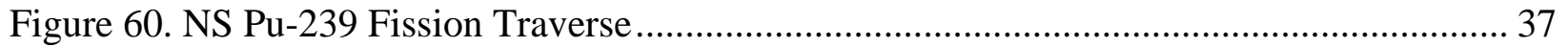

Figure 61. NS Pu-239 Fission Traverse Inside the Void Region............................................ 37

Figure 62. NS B-10 Capture Traverse .............................................................................. 37

Figure 63. NS B-10 Capture Traverse Inside the Void Region ............................................. 37

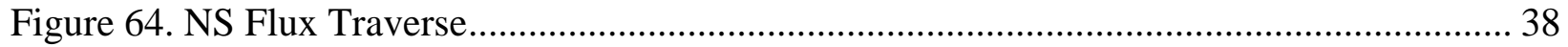

Figure 65. NS Flux Traverse Inside the Void Region ........................................................ 38

Figure 66. NS U-235 Fission Traverse ........................................................................... 38

Figure 67. NS U-235 Fission Traverse Inside the Void Region ............................................ 38

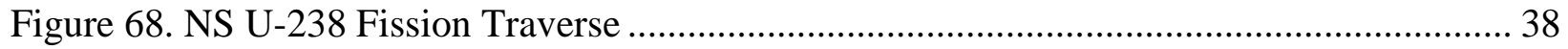

Figure 69. NS U-238 Fission Traverse Inside the Void Region ............................................. 38

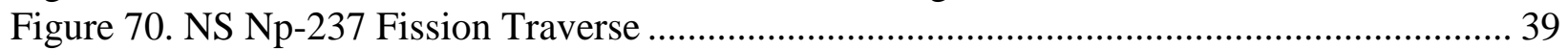

Figure 71. NS Np-237 Fission Traverse Inside the Void Region ............................................ 39

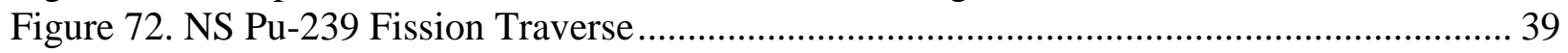

Figure 73. NS Pu-239 Fission Traverse Inside the Void Region............................................. 39

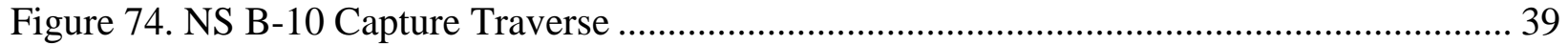

Figure 75. NS B-10 Capture Traverse Inside the Void Region ............................................... 39

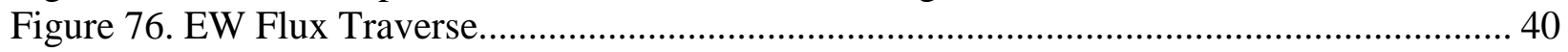

Figure 77. EW Flux Traverse Inside the Void Region ........................................................ 40

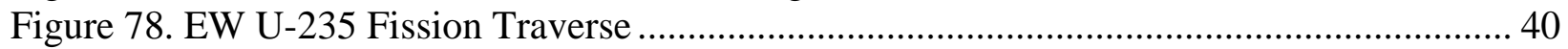

Figure 79. EW U-235 Fission Traverse Inside the Void Region ........................................... 40

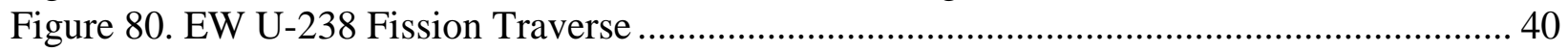

Figure 81. EW U-238 Fission Traverse Inside the Void Region ............................................ 40

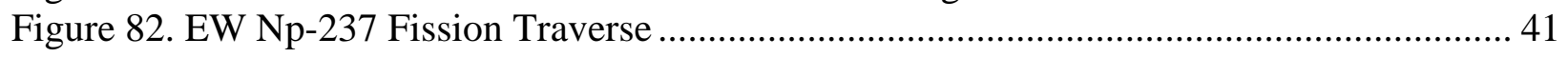

Figure 83. EW Np-237 Fission Traverse Inside the Void Region........................................... 41

Figure 84. EW Pu-239 Fission Traverse.......................................................................... 41

Figure 85. EW Pu-239 Fission Traverse Inside the Void Region........................................... 41

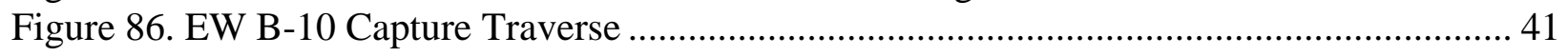

Figure 87. EW B-10 Capture Traverse Inside the Void Region ............................................. 41

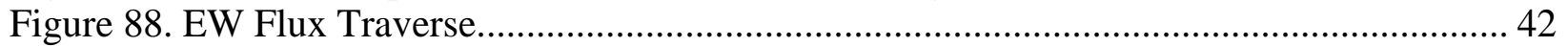

Figure 89. EW Flux Traverse Inside the Void Region ...................................................... 42 


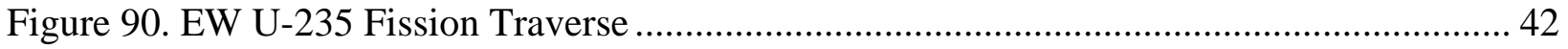

Figure 91. EW U-235 Fission Traverse Inside the Void Region ........................................... 42

Figure 92. EW U-238 Fission Traverse ........................................................................... 42

Figure 93. EW U-238 Fission Traverse Inside the Void Region ............................................. 42

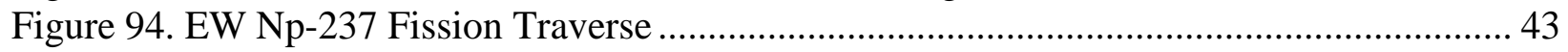

Figure 95. EW Np-237 Fission Traverse Inside the Void Region.......................................... 43

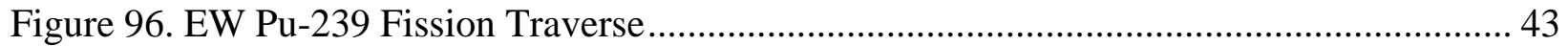

Figure 97. EW Pu-239 Fission Traverse Inside the Void Region............................................. 43

Figure 98. EW B-10 Capture Traverse ................................................................................. 43

Figure 99. EW B-10 Capture Traverse Inside the Void Region ............................................. 43

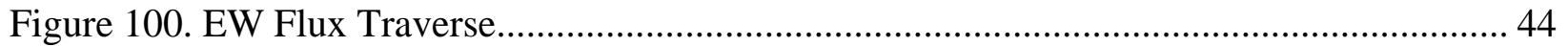

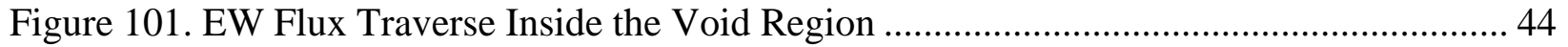

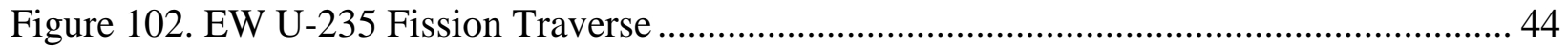

Figure 103. EW U-235 Fission Traverse Inside the Void Region........................................... 44

Figure 104. EW U-238 Fission Traverse ............................................................................ 44

Figure 105. EW U-238 Fission Traverse Inside the Void Region............................................ 44

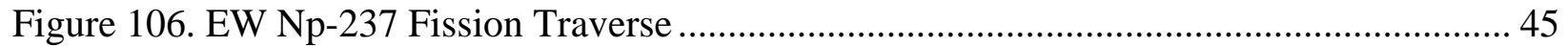

Figure 107. EW Np-237 Fission Traverse Inside the Void Region ......................................... 45

Figure 108. EW Pu-239 Fission Traverse........................................................................ 45

Figure 109. EW Pu-239 Fission Traverse Inside the Void Region.......................................... 45

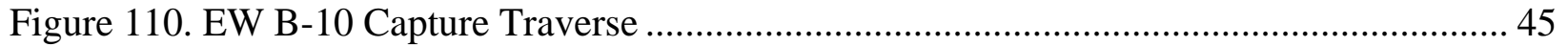

Figure 111. EW B-10 Capture Traverse Inside the Void Region ............................................ 45

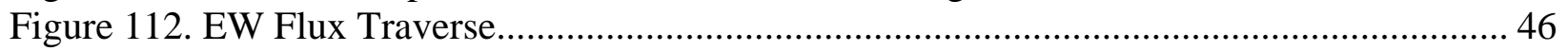

Figure 113. EW Flux Traverse Inside the Void Region ................................................... 46

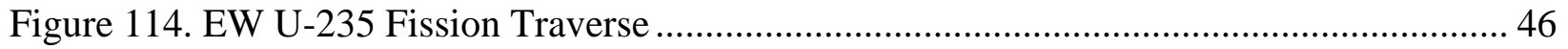

Figure 115. EW U-235 Fission Traverse Inside the Void Region........................................... 46

Figure 116. EW U-238 Fission Traverse ...................................................................... 46

Figure 117. EW U-238 Fission Traverse Inside the Void Region........................................... 46

Figure 118. EW Np-237 Fission Traverse ...................................................................... 47

Figure 119. EW Np-237 Fission Traverse Inside the Void Region ........................................ 47

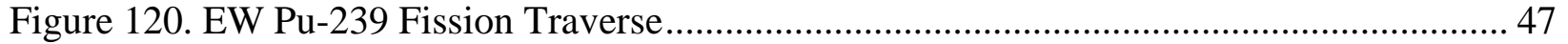

Figure 121. EW Pu-239 Fission Traverse Inside the Void Region......................................... 47

Figure 122. EW B-10 Capture Traverse ........................................................................... 47

Figure 123. EW B-10 Capture Traverse Inside the Void Region ........................................... 47 


\section{LIST OF TABLES}

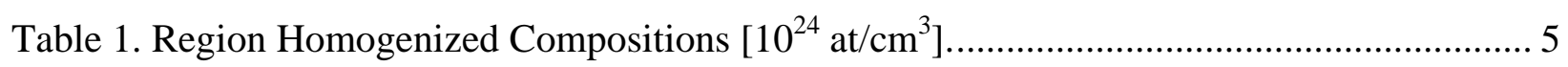

Table 2. Summary of Planned Configurations....................................................................... 8

Table 3. Calculated Reactivity Values for ENIGMA Reference Configuration. ........................ 20

Table 4. Reactivity [pcm] of Reference Configuration Before and After Introduction of Void Region................................................................................................... 21

Table 5. Reactivity [pcm] of Reference Configuration Before and After Introduction of Void Region in Simplified 2-D Problem.............................................................. 22

Table 6. Reactivity Worths [pcm] of $\mathrm{B}_{4} \mathrm{C}$ Rodlets in Phase 1 Configurations............................ 23

Table 7. Reactivity Worths [pcm] of $\mathrm{B}_{4} \mathrm{C}$ Rodlets in Phase 2 Configurations........................... 24

Table 8. Reactivity Worths [pcm] of $\mathrm{B}_{4} \mathrm{C}$ Rodlets in Phase 3 Configurations............................ 25 


\begin{abstract}
Collaboration is underway between Argonne and the CEA-Cadarache on the preparation of experiments for the ENIGMA program dedicated to the reactor physics experiments supporting the development of gas-cooled fast reactors. Specifications have been defined for the study of control rods in the central void zone of ENIGMA configurations. Deterministic calculations of the rodded configurations have been performed using the ERANOS code system. The various core criticality states for the different phases of the control rod experiments have been determined by specifying the number of additional fuel assemblies required to restore criticality. Control rod worths, flux distributions, and reactions rate distributions for a few nuclides have been analyzed. The study revealed the significant impact of spatial heterogeneity in the rod configurations used for the experiments, indicating flexibility for the control rod experiments.
\end{abstract}




\subsection{INTRODUCTION}

Planning is underway at CEA-Cadarache for experiments [1] that will investigate the core physics characteristics of gas-cooled fast reactor (GFR) designs being considered under the Generation IV International Forum. This effort, designated Experimental Neutronic Investigation of Gas-Cooled Configurations at MAsurca (ENIGMA), has the objectives of defining MASURCA configurations that are similar in their neutronic characteristics to the candidate GFR designs and extending the validation domain of the neutronics tools to design and licensing calculations of future GFRs.

The CEA and ANL have been collaborating in an International Nuclear Energy Research Initiative (I-NERI) project centered on the ENIGMA program. An objective of the I-NERI project is to jointly participate in the justification, and definition and design of experiments for ENIGMA, and additionally evaluate experimental results for the purpose of improving analytical models for GFRs. Towards these goals, joint studies have been performed (1) to give justifications for the planned experiments, and (2) to evaluate the feasibility of simulating a series of proposed gas-cooled fast systems with harder or softer spectrum in the ENIGMA configurations. [2, 3]

As part of the ongoing collaboration, the two institutions have recently defined potential control rod experimental configurations for ENIGMA. These cases have focused on the insertion of control rods in the center of the MASURCA core. The neutron spectrum in candidate GFR designs is somewhat softer than in classical sodium-cooled fast reactors. This may result in larger heterogeneity effects inside control rod subassemblies. The control rod experimental patterns considered in the ENIGMA program have been designed to check calculational results of control rod worth and reaction rate distributions against experimental values, in gas-cooled reactor spectral conditions. It is envisioned that a subset of these proposed experiments would be performed in the MASURCA facility. The purpose of this report is to document the core neutronic calculation results for these configurations. These calculations have included determination of (1) control rod reactivity worths, (2) the amount of additional fuel assemblies to restore core criticality when voided positions are provided or when the amount of control rodlets in the core are increased, and (3) flux and reaction rate spatial distributions for selected nuclides in the rodded configurations. 
For the current study, the pertinent neutronic parameters were calculated using the deterministic codes that are typically used for analyzing fast reactor cores and experiments at CEA (the same code package has been used for analyzing experiments at ANL).

In Section 2.0, the reference ENIGMA core configuration is presented along with the proposed experimental configurations for the control rod experiments. The sequence of calculations that are required is also provided. The calculation tools and models used for the analysis of the proposed experiments are summarized in Section 3.0. The cross section generation approaches are discussed in Section 4.0. In Section 5.0, the results of the reactivity worth calculations are presented. The analysis results of flux and reaction rate distributions are summarized in Section 6.0. Finally, conclusions from the work are presented in Section 7.0. 


\subsection{REFERENCE CORE CONFIGURATION AND PROPOSED EXPERIMENTS}

Three distinct phases of the central control rod measurements have been defined and are presented in this section, along with the calculation sequences for the cases. The phases include experiments for the core configurations with few absorber rodlets and cases with 32 and 52 absorber rodlets that can be used for studying heterogeneity effects. In addition, the reference configuration for the experiments is provided.

\subsection{Reference Configuration for Experiments}

The reference configuration for the ENIGMA first core (see Figures 1 and 2) is uniformly loaded with 85 fuel subassemblies (PIT assemblies). Each PIT assembly contains 8x8 rodlet positions and is square with a side dimension of $10.6 \mathrm{~cm}$. Based on previous studies, it is assumed that the reference PIT assembly will contain $24 \mathrm{UPuO}_{2}, 8 \mathrm{UO}_{2}, 16$ graphite (C) and 16 void rodlets (see MASURCA fuel assembly in Figure 3). The active core height is $91.44 \mathrm{~cm}$. Graphite is used in the subassembly to imitate carbide fuel and to represent matrix and structural elements; there is no plan to manufacture new fuel forms in early phases of the ENIGMA project, so existing materials are used in representative proportions. The fueled zone is surrounded radially and axially by a reflector zone and an outer shield zone (stainless steel).

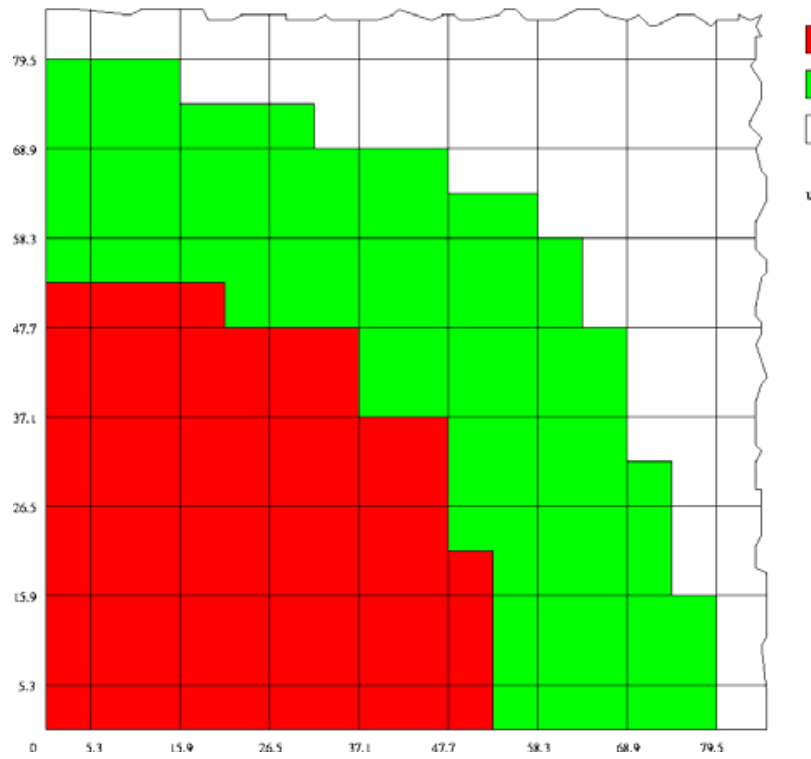

Figure 1. Reference Configuration (XY Layout). Figure 2. Reference Configuration (RZ Model). 


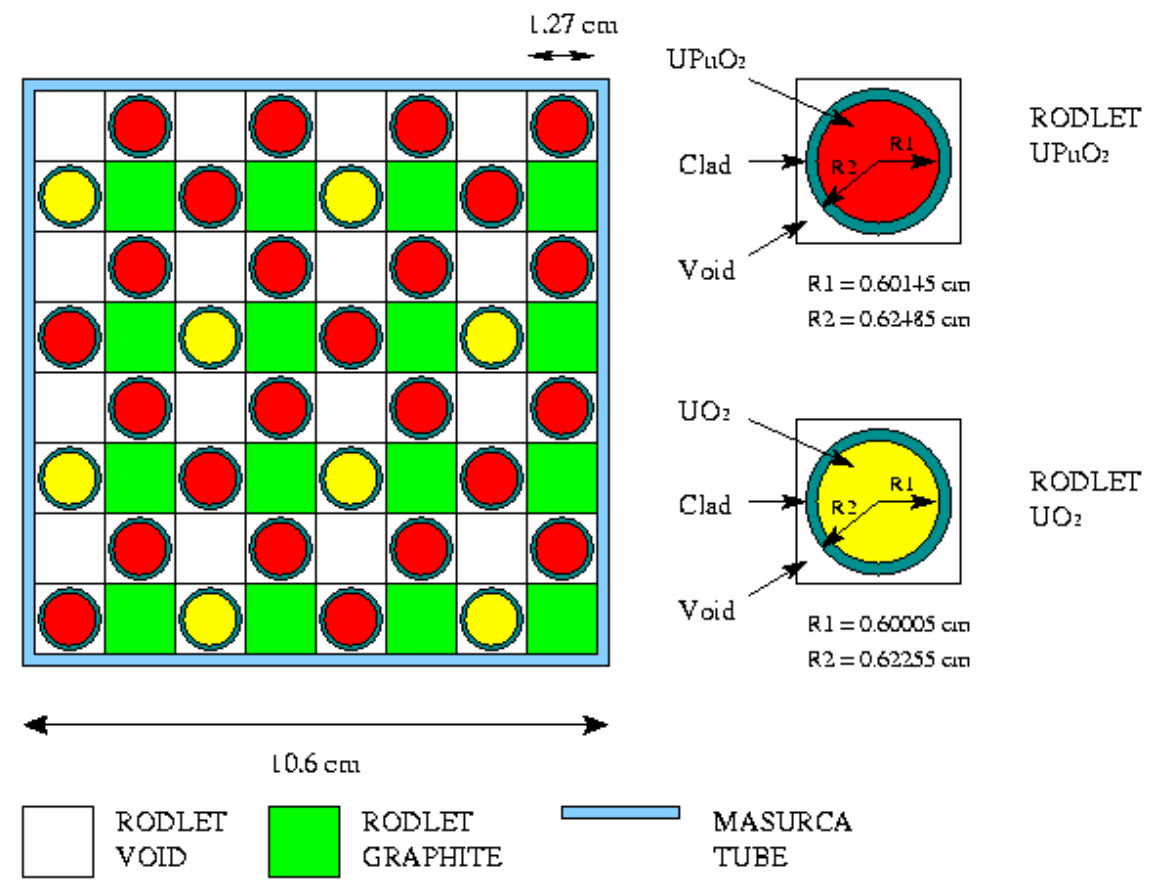

Figure 3. ENIGMA Reference Fuel Assembly.

For the purpose of this study, it is assumed that the transition zone would be at the core center and comprises 172 rodlets of the central nine fuel assemblies (1 full assembly plus fractions of the surrounding 8 assemblies) as shown in Figures 4 and 5, for the quarter-core.

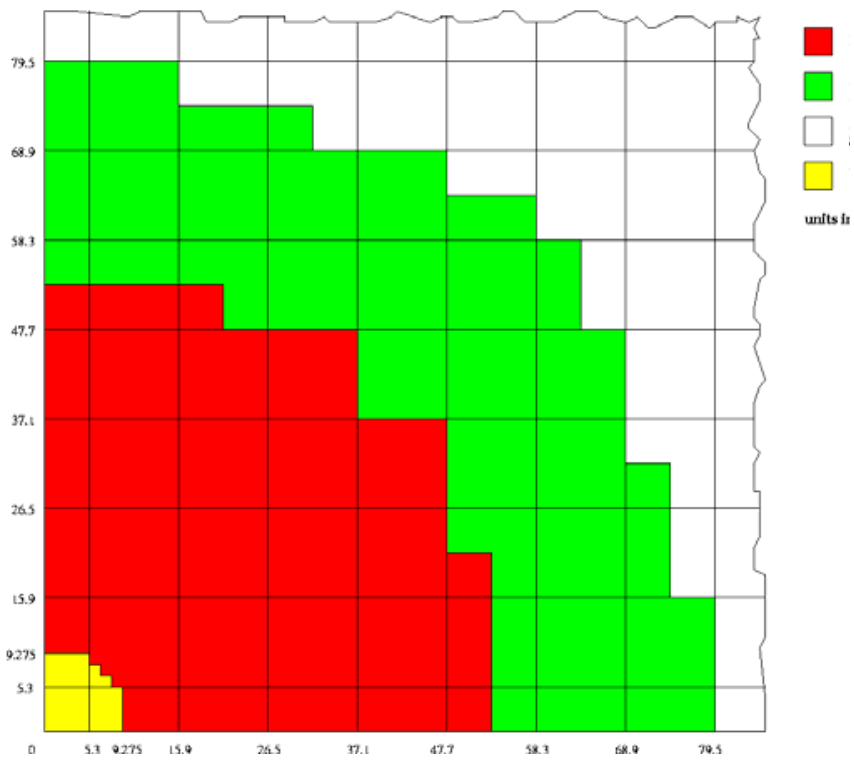

Figure 4. Reference Configuration with Void Transition Zone.

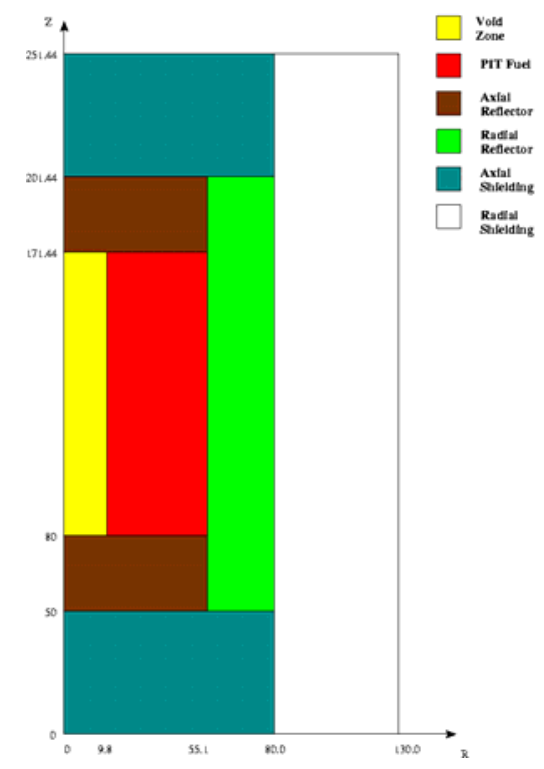

Figure 5. Reference Configuration with Void Transition Zone (RZ Model). 
The homogeneous compositions for the core and experimental regions are summarized in Table 1.

Table 1. Region Homogenized Compositions $\left[10^{24} \mathrm{at} / \mathrm{cm}^{3}\right]$.

\begin{tabular}{|c|c|c|c|c|c|c|c|c|c|}
\hline & Fuel & R1_Fuel & $\begin{array}{c}\text { Axial } \\
\text { Reflector }\end{array}$ & $\begin{array}{c}\text { Radial } \\
\text { Reflector }\end{array}$ & $\begin{array}{l}\text { Axial } \\
\text { Shield }\end{array}$ & $\begin{array}{l}\text { Radial } \\
\text { Shield }\end{array}$ & Void Region & \begin{tabular}{|c|} 
Natural \\
Boron Rodlet
\end{tabular} & \begin{tabular}{|c|} 
Enriched \\
Boron Rodlet
\end{tabular} \\
\hline U234 & $6.26220 \mathrm{E}-7$ & & & & & & & & \\
\hline U236 & $1.27430 \mathrm{E}-6$ & & & & & & & & \\
\hline U235 & $2.75384 \mathrm{E}-5$ & 1.89713E-3 & & & & & & & \\
\hline U238 & $5.79480 \mathrm{E}-3$ & $6.98491 \mathrm{E}-3$ & & & & & & & \\
\hline Np237 & $1.65462 \mathrm{E}-6$ & & & & & & & & \\
\hline Pu238 & 2.08333E-6 & & & & & & & & \\
\hline Pu239 & 1.14127E-3 & & & & & & & & \\
\hline Pu240 & 2.76141E-4 & & & & & & & & \\
\hline Pu241 & $1.28586 \mathrm{E}-5$ & & & & & & & & \\
\hline Pu242 & $9.95066 \mathrm{E}-6$ & & & & & & & & \\
\hline Am241 & $5.05871 \mathrm{E}-5$ & & & & & & & & \\
\hline Fe54 & 3.54712E-4 & $6.09275 \mathrm{E}-4$ & $2.61766 \mathrm{E}-3$ & $2.61766 \mathrm{E}-3$ & $3.23041 \mathrm{E}-3$ & 4.57985E-3 & 4.36155E-4 & 4.36155E-4 & 4.36155E-4 \\
\hline Fe56 & $5.56821 \mathrm{E}-3$ & $9.56431 \mathrm{E}-3$ & 4.10917E-2 & 4.10917E-2 & $5.10739 \mathrm{E}-2$ & $7.24090 \mathrm{E}-2$ & $6.84670 \mathrm{E}-3$ & 6.84670E-3 & $6.84670 \mathrm{E}-3$ \\
\hline Fe57 & $1.28595 \mathrm{E}-4$ & $2.21438 \mathrm{E}-4$ & $9.48984 \mathrm{E}-4$ & $9.48984 \mathrm{E}-4$ & $1.22533 \mathrm{E}-3$ & $1.73718 \mathrm{E}-3$ & $1.58120 \mathrm{E}-4$ & $1.58120 \mathrm{E}-4$ & $1.58120 \mathrm{E}-4$ \\
\hline Fe58 & $1.71135 \mathrm{E}-5$ & $2.93953 E-5$ & $1.26292 \mathrm{E}-4$ & $1.26292 \mathrm{E}-4$ & $1.67090 \mathrm{E}-4$ & $2.36889 \mathrm{E}-4$ & $2.10429 \mathrm{E}-5$ & $2.10429 \mathrm{E}-5$ & $2.10429 E-5$ \\
\hline Cr50 & 7.21863E-5 & $1.22724 \mathrm{E}-4$ & $5.25611 \mathrm{E}-4$ & $5.25611 \mathrm{E}-4$ & 6.52073E-4 & 3.88182E-5 & 8.76952E-5 & 8.76952E-5 & 8.76952E-5 \\
\hline Cr52 & $1.39204 \mathrm{E}-3$ & $2.36660 \mathrm{E}-3$ & $1.01359 \mathrm{E}-2$ & $1.01359 \mathrm{E}-2$ & $1.25603 \mathrm{E}-2$ & 7.47719E-4 & $1.69111 \mathrm{E}-3$ & $1.69111 \mathrm{E}-3$ & $1.69111 \mathrm{E}-3$ \\
\hline Cr53 & $1.57846 \mathrm{E}-4$ & $2.68354 \mathrm{E}-4$ & 1.14933E-3 & 1.14933E-3 & $1.42407 \mathrm{E}-3$ & $8.47754 \mathrm{E}-5$ & $1.91758 \mathrm{E}-4$ & $1.91758 \mathrm{E}-4$ & $1.91758 \mathrm{E}-4$ \\
\hline Cr54 & 3.92913E-5 & 6.67989E-5 & $2.86092 \mathrm{E}-4$ & $2.86092 \mathrm{E}-4$ & $3.53768 \mathrm{E}-4$ & $2.10600 \mathrm{E}-5$ & 4.77328E-5 & 4.77328E-5 & $4.77328 \mathrm{E}-5$ \\
\hline Ni58 & $5.47945 \mathrm{E}-4$ & $1.17069 \mathrm{E}-3$ & $4.31294 \mathrm{E}-3$ & $4.31294 \mathrm{E}-3$ & $5.01450 \mathrm{E}-3$ & $7.44874 \mathrm{E}-4$ & 6.66570E-4 & $6.66570 \mathrm{E}-4$ & $6.66570 \mathrm{E}-4$ \\
\hline $\mathrm{Ni60}$ & $2.11068 \mathrm{E}-4$ & $4.50946 \mathrm{E}-4$ & $1.66134 \mathrm{E}-3$ & $1.66134 \mathrm{E}-3$ & $1.91707 \mathrm{E}-3$ & $2.84770 \mathrm{E}-4$ & $2.56762 \mathrm{E}-4$ & $2.56762 \mathrm{E}-4$ & $2.56762 \mathrm{E}-4$ \\
\hline Ni61 & 9.17496E-6 & 1.96023E-5 & $7.22172 \mathrm{E}-5$ & $7.22172 \mathrm{E}-5$ & $8.29996 \mathrm{E}-5$ & $1.23291 \mathrm{E}-5$ & 1.11613E-5 & $1.11613 \mathrm{E}-5$ & 1.11613E-5 \\
\hline $\mathrm{Ni62}$ & $2.92538 \mathrm{E}-5$ & $6.25008 \mathrm{E}-5$ & $2.30260 \mathrm{E}-4$ & $2.30260 \mathrm{E}-4$ & $2.63689 \mathrm{E}-4$ & $3.91694 \mathrm{E}-5$ & 3.55869E-5 & 3.55869E-5 & 3.55869E-5 \\
\hline $\mathrm{Ni64}$ & 7.45007E-6 & $1.59171 \mathrm{E}-5$ & $5.86404 \mathrm{E}-5$ & $5.86404 \mathrm{E}-5$ & $6.68404 \mathrm{E}-5$ & $9.92875 \mathrm{E}-6$ & 9.06293E-6 & 9.06293E-6 & 9.06293E-6 \\
\hline $\mathrm{O}$ & $1.45532 \mathrm{E}-2$ & $1.19223 \mathrm{E}-2$ & & & & & & & \\
\hline $\mathrm{C}$ & $1.96036 \mathrm{E}-2$ & 1.91213E-2 & $1.21638 \mathrm{E}-4$ & $1.21638 \mathrm{E}-4$ & $5.19968 \mathrm{E}-6$ & $2.90417 \mathrm{E}-3$ & 2.68951E-5 & $2.10550 \mathrm{E}-2$ & 2.00992E-2 \\
\hline $\mathrm{Al}$ & 6.01452E-7 & & & & & & & & \\
\hline $\mathrm{Mn}$ & $1.00717 \mathrm{E}-4$ & $6.41424 \mathrm{E}-5$ & $9.13875 \mathrm{E}-4$ & $9.13875 \mathrm{E}-4$ & & & $1.23488 \mathrm{E}-4$ & $1.23488 \mathrm{E}-4$ & $1.23488 \mathrm{E}-4$ \\
\hline Mo & $1.59449 \mathrm{E}-5$ & $1.60624 \mathrm{E}-5$ & $2.66176 \mathrm{E}-5$ & $2.66176 \mathrm{E}-5$ & $3.49181 \mathrm{E}-6$ & $3.49181 \mathrm{E}-6$ & $1.66293 \mathrm{E}-5$ & $1.66293 \mathrm{E}-5$ & $1.66293 \mathrm{E}-5$ \\
\hline $\mathrm{Si}$ & $8.22729 \mathrm{E}-5$ & $5.92179 \mathrm{E}-5$ & 7.16529E-4 & $7.16529 \mathrm{E}-4$ & $2.81155 \mathrm{E}-5$ & $2.81155 \mathrm{E}-5$ & 9.81093E-5 & $9.81093 \mathrm{E}-5$ & $9.81093 \mathrm{E}-5$ \\
\hline $\mathrm{Ti}$ & $6.90972 \mathrm{E}-7$ & 1.79753E-6 & $2.97681 \mathrm{E}-6$ & $2.97681 \mathrm{E}-6$ & 4.99779E-7 & 4.99779E-7 & 7.87692E-7 & 7.87692E-7 & 7.87692E-7 \\
\hline $\mathrm{Cu}$ & $1.95177 \mathrm{E}-6$ & $3.45471 \mathrm{E}-6$ & $3.14028 \mathrm{E}-5$ & 3.14028E-5 & 7.71376E-5 & $7.05761 \mathrm{E}-4$ & 3.12474E-6 & $3.12474 \mathrm{E}-6$ & 3.12474E-6 \\
\hline $\mathrm{Zr}$ & 8.17728E-12 & & 6.25169E-12 & 6.25169E-12 & & & 6.25170E-12 & 6.25170E-12 & 6.25170E-12 \\
\hline $\mathrm{B} 10$ & 1.40240E-12 & $1.93887 \mathrm{E}-7$ & & & $1.00000 \mathrm{E}-15$ & 1.00000E-15 & & 1.66511E-2 & 7.25787E-2 \\
\hline B11 & & & & & & & & 6.75309E-2 & 7.79637E-3 \\
\hline Co59 & & 4.54173E-6 & 7.15335E-5 & 7.15335E-5 & & & & & \\
\hline $\mathrm{V}$ & & & $1.84606 \mathrm{E}-5$ & $1.84606 \mathrm{E}-5$ & & & & & \\
\hline $\mathrm{bdH}$ & & & & & $1.63827 \mathrm{E}-6$ & $1.63827 \mathrm{E}-6$ & & & \\
\hline Nb93 & & & & & 7.72677E-7 & 7.72677E-7 & & & \\
\hline
\end{tabular}




\subsection{Proposed Phases for Central Control Experiments}

The three distinct phases of the central control rod measurements are discussed in this section. According to the experimental approach envisaged for the absorber rodlets study, after the introduction of the void region at the center of the reference configuration, it is planned to restore core criticality by adding enough fuel assemblies at the core periphery. Then, for a given number of fixed $\mathrm{B}_{4} \mathrm{C}$ rodlets, different configurations of the rodlets will be introduced in the void region. Following the set of experiments for a given number of fixed rodlets, a higher number of rodlets will be introduced at the core center, and the core criticality will be re-established by addition of more assemblies. This pattern is followed to the end of the cases.

Because of insufficient materials for the reference PIT-type assemblies used in the ENIGMA core, it is currently envisioned that the "R1-type" (U-fueled) assemblies will be used to restore core criticality.

The set of calculations requested to support the control rod experimental phases are summarized in the following sub-sections.

\section{Phase 1: Reactivity Worths of Absorber Patterns with "Few" Absorber Rodlets}

The following calculation sequence should be followed for Phase 1:

1) Start from the ENIGMA reference, critical core (85 fuel S/As, $91.44 \mathrm{~cm}$ fuel height).

2) Establish rod follower configuration: replace at core center all rodlets by void rodlets, according to Figure 6 (representing the central subassembly and part of the adjacent subassemblies). Restore criticality by adding adequate number of ENIGMA R1-type fuel assemblies at the core periphery. Determine the critical core radius and number of U-fuelled subassemblies required to restore criticality.

3) Establish absorber patterns with 4 absorber rodlets. Compact (Figure 7) and dispersed (Figure 8) patterns should be considered. Perform calculations for the subcritical measurement state, relative to step 2, with no modification of the core contour. For these states, study separately the cases using natural and enriched boron $\left(90 \%{ }^{10} \mathrm{~B}\right)$ in the absorber rodlets. 
4) Establish absorber patterns with 12 absorber rodlets. Again compact (Figure 9) and dispersed (Figure 10) patterns are to be considered. Perform calculations for the subcritical states (with no modification of the core contour). The impact of using enriched boron $\left(90 \%{ }^{10} \mathrm{~B}\right)$ instead of natural boron should be evaluated.

\section{Phase 2: Heterogeneity Effects of Patterns with 32 Absorber Rodlets}

For phases 2 and 3, consider only enriched boron rodlets.

1) Consider first the compact pattern in Figure 11. Restore criticality by adding adequate number of ENIGMA R1-type fuel assemblies at the core periphery. Determine the critical core radius and the number of U-fuelled required to restore criticality.

2) Then analyze the dispersed pattern \#1 (Figure 12, 4 rods modeled). Determine the subcritical measurement state relative to step 1 (no core contour modification).

3) Analyze dispersed pattern \#2 (Figure 13, a ring of 8 rods modeled). Determine the subcritical measurement state relative to step 1 (no core contour modification).

4) Consider the dispersed pattern \#3 (Figure 14, 32 small rods modeled). Determine the subcritical measurement state relative to step 1 (no core contour modification).

5) Finally, evaluate the dispersed pattern \#4 (Figure 15, absorber ring modeled). Determine the subcritical measurement state relative to step 1 (no core contour modification).

\section{Phase 3: Heterogeneity Effects on Patterns with 52 Absorber Rodlets}

1) Compact pattern (Figure 16). Restore criticality by adding adequate number of ENIGMA R1-type fuel assemblies at the core periphery. Determine the critical core radius and the number of U-fuelled required to restore criticality.

2) Dispersed pattern \#1 (Figure 17, 4 rods modeled). Perform subcritical measurement calculation relative to step 1 (no core contour modification).

3) Dispersed pattern \#2 (Figure 18, $8+1$ rods modeled). Determine the subcritical measurement state relative to step 1 (no core contour modification). 
4) Dispersed pattern \#4 (Figure 19, 8+4+1 rods modeled). Determine the subcritical measurement state relative to step 1 (no core contour modification).

Table 2 summarizes the various planned configurations, enumerated above. It also gives the number of subassemblies (S/A) that must be extracted, opened and re-built from one step to the next. Names have also been assigned to the different cases, for easy referencing during subsequent discussions below.

The homogeneous compositions for the core and experimental regions given in Table 1 include compositions of the $\mathrm{B}_{4} \mathrm{C}$ and void rodlets.

In addition to the calculation of the critical mass and control rod worths implied by the steps specified for Phases 1 to 3, it is desirable to evaluate flux and reactions rate distributions. The radial and axial traverses of ${ }^{235} \mathrm{U}(\mathrm{n}, \mathrm{f}),{ }^{238} \mathrm{U}(\mathrm{n}, \mathrm{f}),{ }^{237} \mathrm{~Np}(\mathrm{n}, \mathrm{f}),{ }^{239} \mathrm{Pu}(\mathrm{n}, \mathrm{f}),{ }^{238} \mathrm{U}(\mathrm{n}, \gamma)$ and ${ }^{10} \mathrm{~B}(\mathrm{n}, \alpha)$, should be evaluated. Computing “realistic” traverses or pin-by-pin reaction rate maps would require a fine XYZ geometrical description of the central zone of the core.

Table 2. Summary of Planned Configurations.

\begin{tabular}{|c|c|c|c|c|c|}
\hline $\begin{array}{c}\text { Config. } \\
\text { name }\end{array}$ & $\begin{array}{c}\text { Fig. } \\
\#\end{array}$ & $\begin{array}{c}\text { \# Abs. } \\
\text { rodlets }\end{array}$ & $\begin{array}{c}\text { Abs. rod } \\
\text { pattern }\end{array}$ & $\begin{array}{c}\text { \# S/A } \\
\text { moved }\end{array}$ & Comments \\
\hline ENIGMA & - & - & - & - & Reference ENIGMA core \\
\hline RF & 1 & 0 & 0 & 9 & Rod follower - critical contour with ENIGMA R1 fuel \\
\hline A4c & 2 & 4 & 1 & 1 & Subcritical measurements \\
\hline A4d & 3 & 4 & 4 & 1 & Subcritical measurements \\
\hline A12c & 4 & 12 & 1 & 1 & Subcritical measurements \\
\hline A12d & 5 & 12 & 12 & 1 & Subcritical measurements \\
\hline A32c & 6 & 32 & 1 & 1 & Critical contour with ENIGMA R1 fuel \\
\hline A32i4 & 7 & 32 & 4 & 1 & Subcritical measurements \\
\hline A32i8 & 8 & 32 & 8 & 5 & Subcritical measurements \\
\hline A32d & 9 & 32 & 32 & 5 & Subcritical measurements \\
\hline A32r & 10 & 32 & ring & 9 & Subcritical measurements \\
\hline A52c & 11 & 52 & 1 & 9 & Critical contour with ENIGMA R1 fuel \\
\hline A52i4 & 12 & 52 & 4 & 5 & Subcritical measurements \\
\hline A52i9 & 13 & 52 & $8+1$ & 5 & Subcritical measurements \\
\hline A52i13 & 14 & 52 & $8+4+1$ & 5 & Subcritical measurements \\
\hline
\end{tabular}

*Configuration names: $\mathrm{A}+$ number of $\mathrm{B}_{4} \mathrm{C}$ rodlets + letter $(\mathrm{c}=$ compact, $\mathrm{i}=$ intermediate, $\mathrm{d}=$ dispersed $)$ $+($ only if letter $=i)$ number or rods modeled 


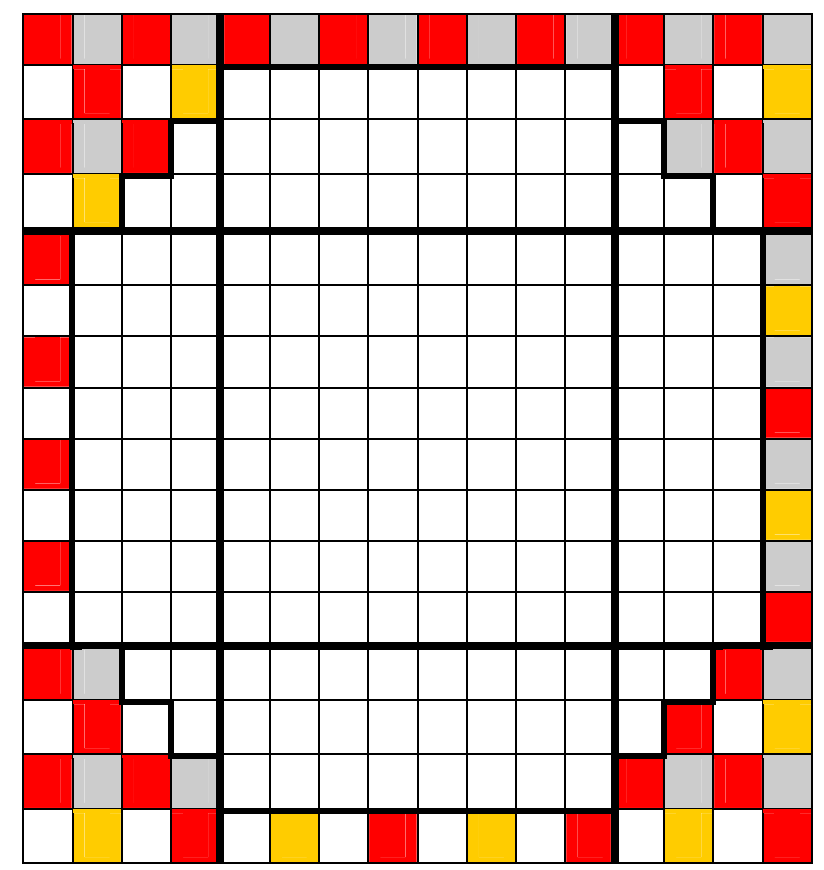

\section{(U,Pu) $\mathrm{O}_{2}$ (cylinder)}

$\mathrm{UO}_{2}$ (cylinder)

$\mathrm{C}$ (square)

void (square)

$\mathrm{B}_{4} \mathrm{C}$ (square)

Figure 6. Rod Follower.

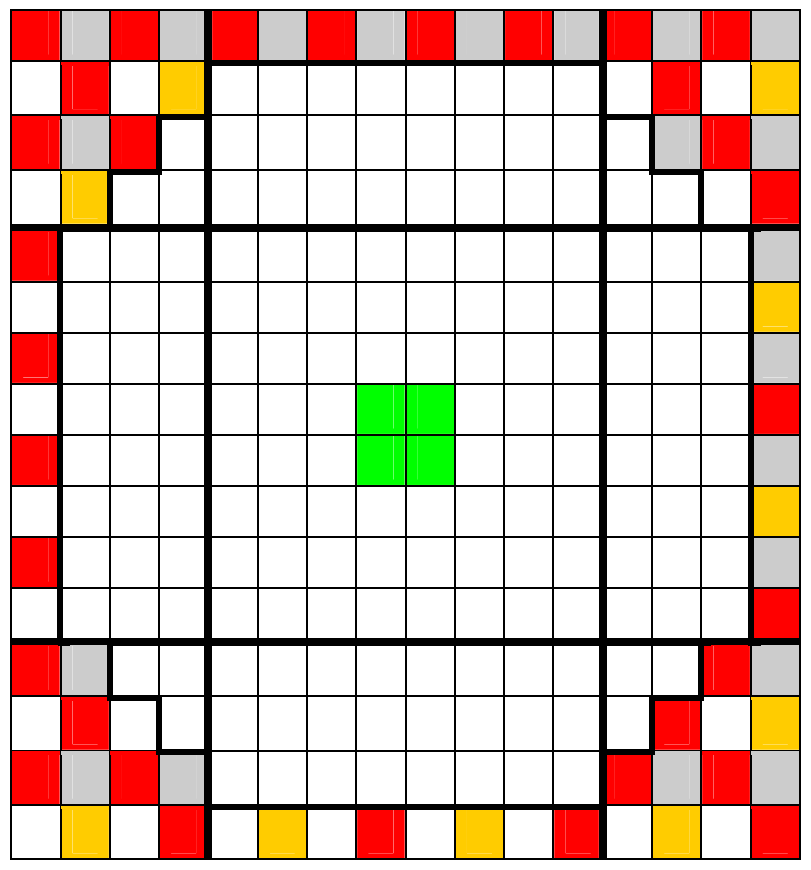

(U,Pu) $\mathrm{O}_{2}$ (cylinder)

$\mathrm{UO}_{2}$ (cylinder)

$\mathrm{C}$ (square)

void (square)

$\mathrm{B}_{4} \mathrm{C}$ (square)

Figure 7. 4 Absorber Rodlets: Compact Absorber Pattern. 


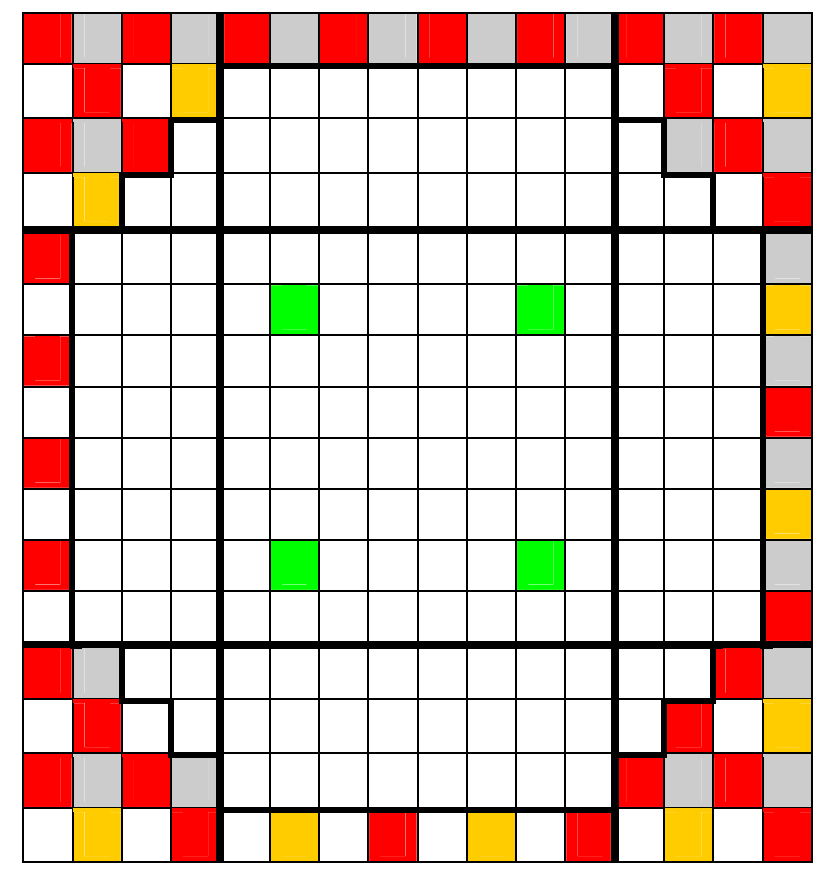

\section{(U,Pu) $\mathrm{O}_{2}$ (cylinder)}

$\mathrm{UO}_{2}$ (cylinder)

$\mathrm{C}$ (square)

void (square)

$\mathrm{B}_{4} \mathrm{C}$ (square)

Figure 8. 4 Absorber Pattern: Dispersed Absorber Pattern.

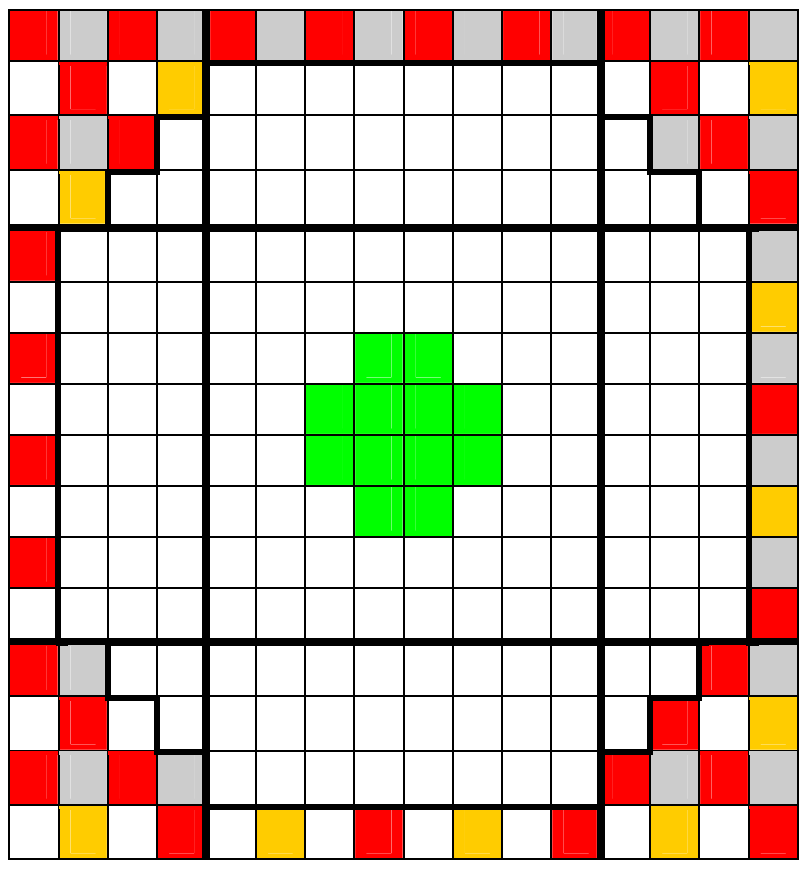

(U,Pu) $\mathrm{O}_{2}$ (cylinder)

$\mathrm{UO}_{2}$ (cylinder)

$\mathrm{C}$ (square)

void (square)

$\mathrm{B}_{4} \mathrm{C}$ (square)

Figure 9. 12 Absorber Rodlets: Compact Absorber Pattern. 


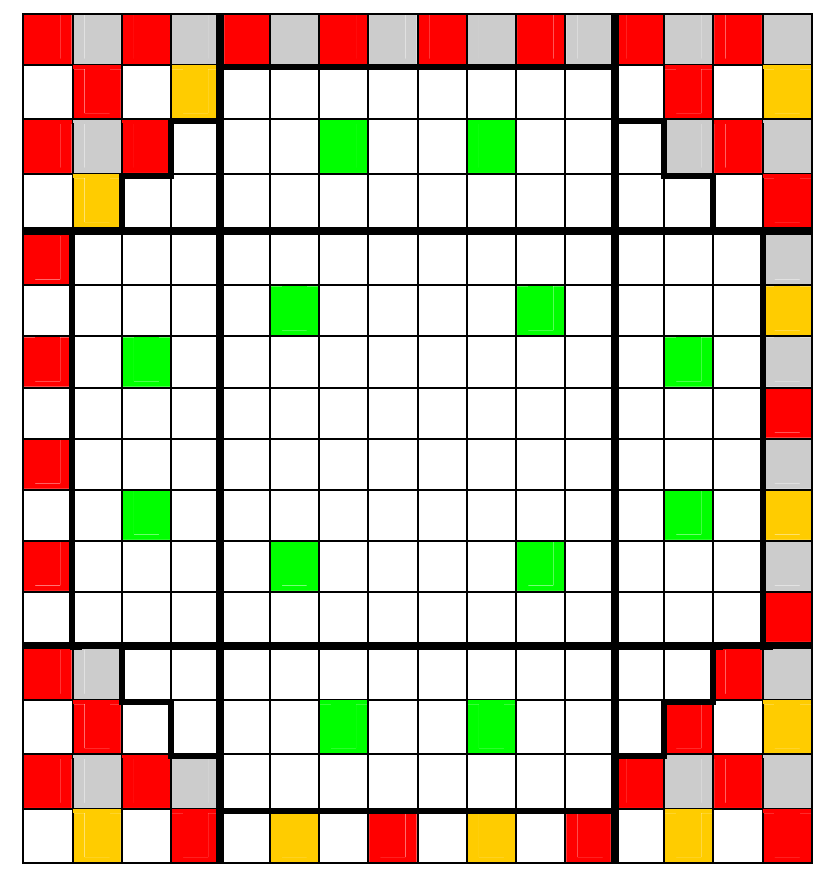

(U,Pu) $\mathrm{O}_{2}$ (cylinder)

$\mathrm{UO}_{2}$ (cylinder)

$\mathrm{C}$ (square)

void (square)

$\mathrm{B}_{4} \mathrm{C}$ (square)

Figure 10.12 Absorber Rodlets: Dispersed Absorber Pattern.

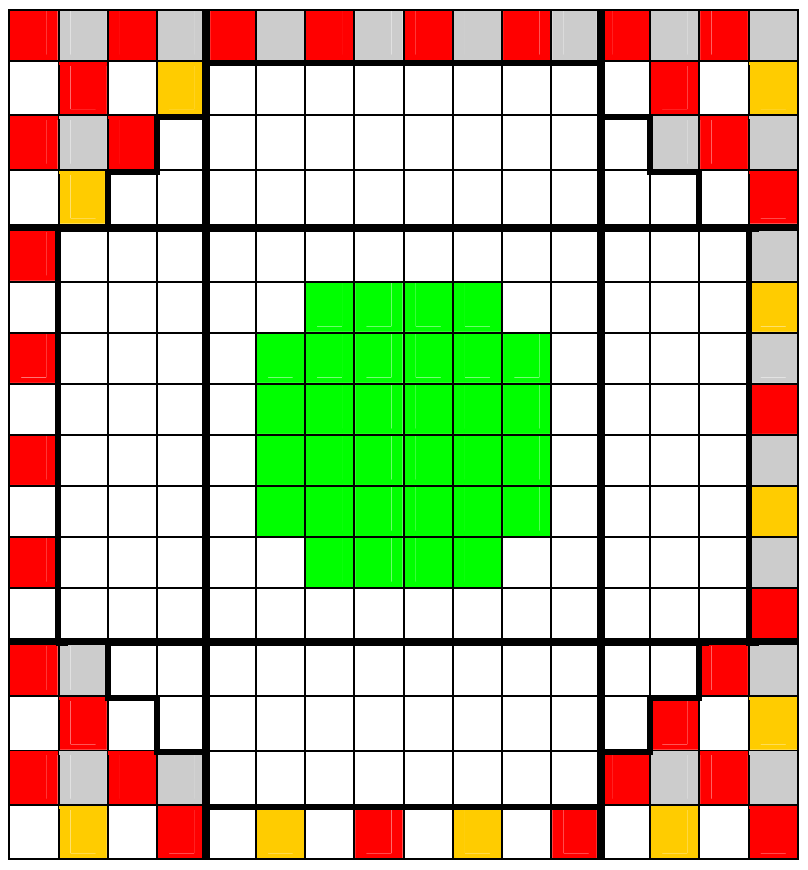

$(\mathrm{U}, \mathrm{Pu}) \mathrm{O}_{2}$ (cylinder) $\mathrm{UO}_{2}$ (cylinder)

C (square) void (square)

$\mathrm{B}_{4} \mathrm{C}$ (square)

Figure 11. 32 Absorber Rodlets: Compact Absorber Pattern. 


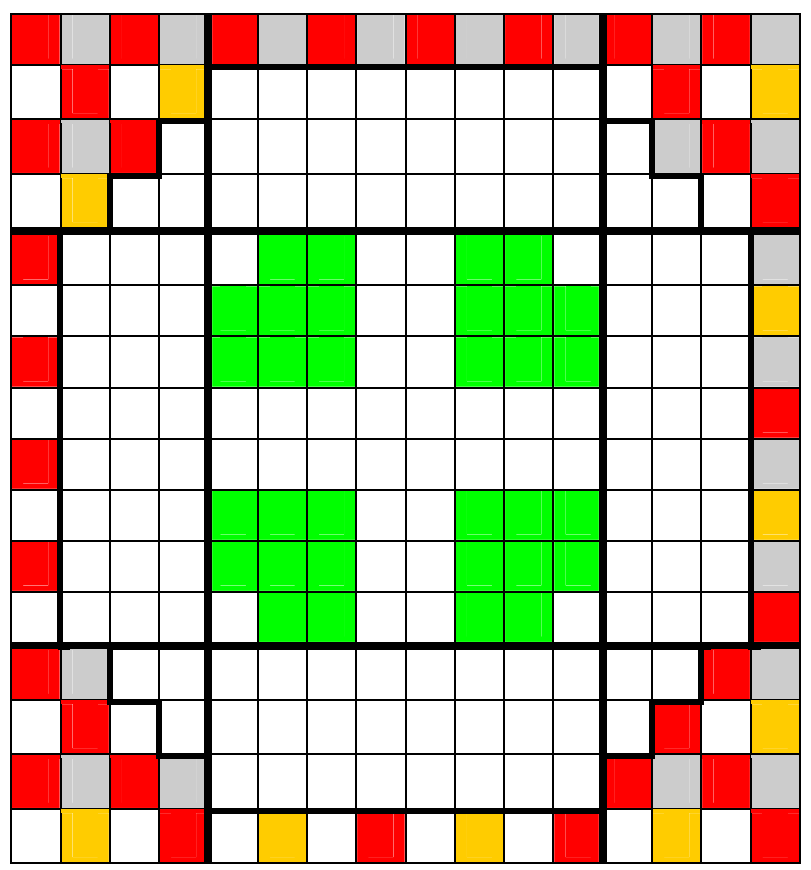

\section{(U,Pu) $\mathrm{O}_{2}$ (cylinder)}

$\mathrm{UO}_{2}$ (cylinder)

$\mathrm{C}$ (square)

void (square)

$\mathrm{B}_{4} \mathrm{C}$ (square)

Figure 12. 32 Absorber Rodlets: Dispersed Pattern \#1 (4 Absorber Rods).

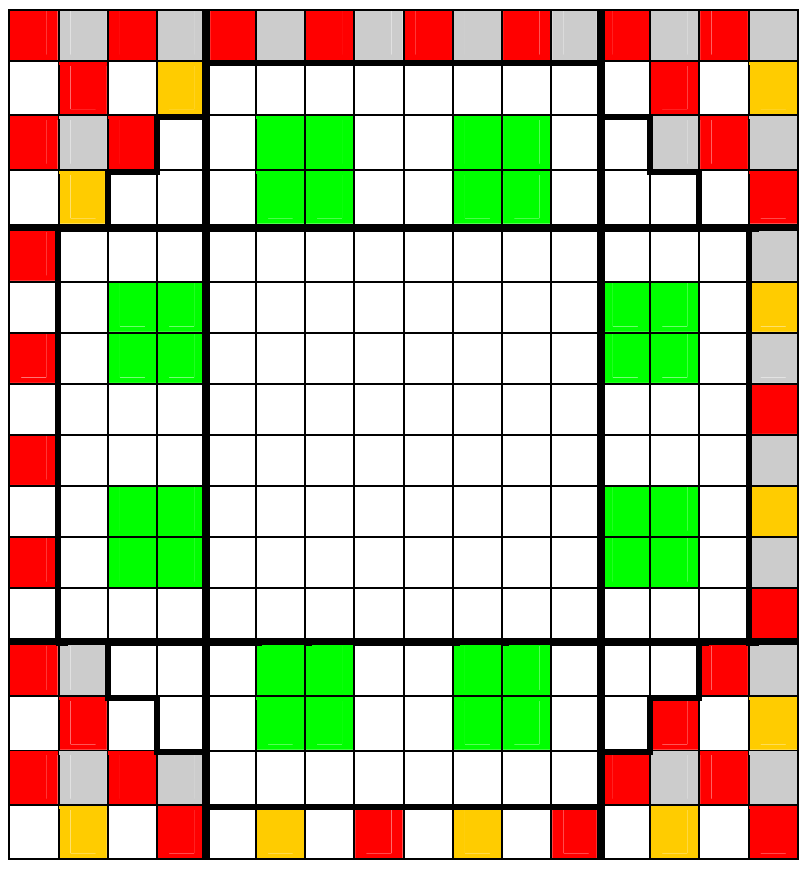

(U,Pu) $\mathrm{O}_{2}$ (cylinder) $\mathrm{UO}_{2}$ (cylinder)

C (square) void (square)

$\mathrm{B}_{4} \mathrm{C}$ (square)

Figure 13. 32 Absorber Rodlets: Dispersed Pattern \#2 (8 Absorber Rods). 


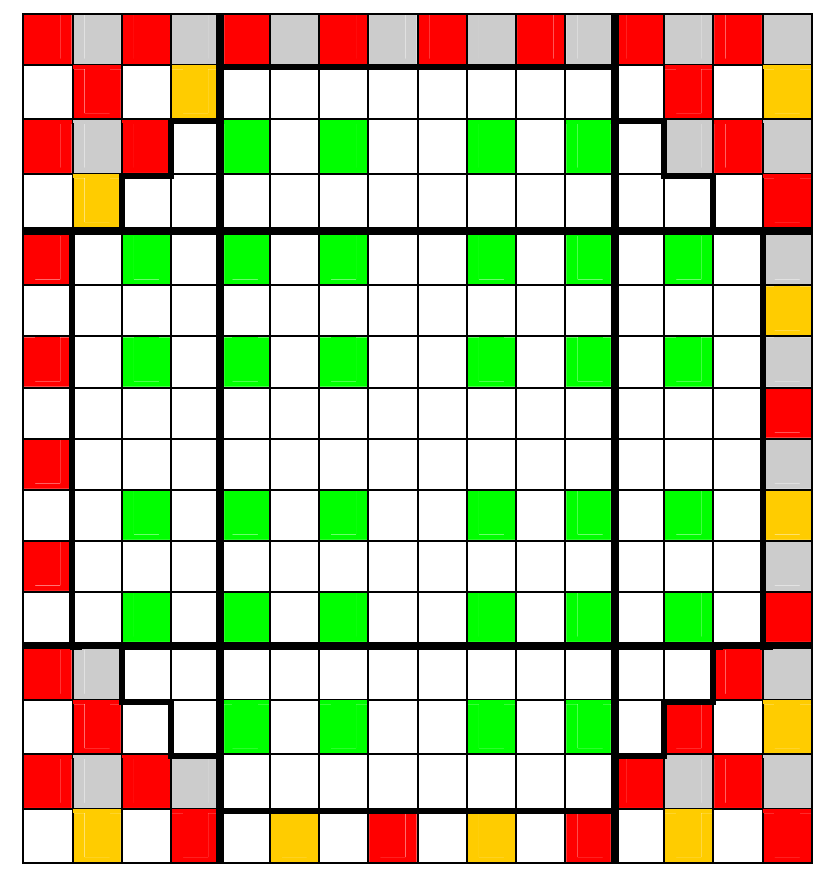

\section{(U,Pu) $\mathrm{O}_{2}$ (cylinder)}

$\mathrm{UO}_{2}$ (cylinder)

$\mathrm{C}$ (square)

void (square)

$\mathrm{B}_{4} \mathrm{C}$ (square)

Figure 14. 32 Absorber Rodlets: Dispersed Pattern \#3 (32 Absorber Rods).

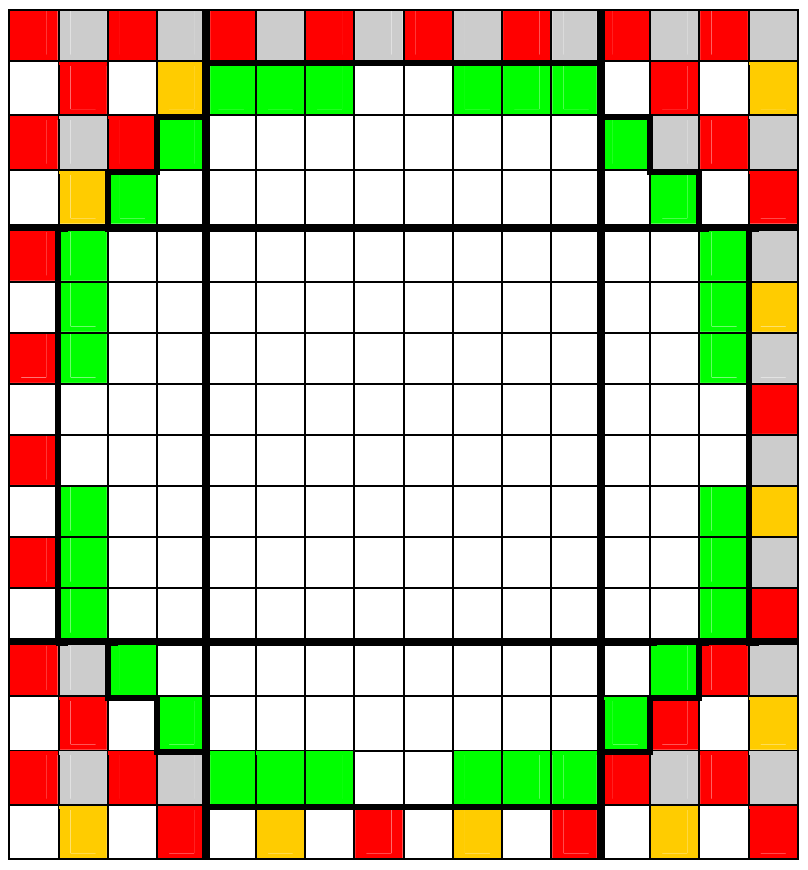

(U,Pu) $\mathrm{O}_{2}$ (cylinder)

$\mathrm{UO}_{2}$ (cylinder)

C (square)

void (square)

$\mathrm{B}_{4} \mathrm{C}$ (square)

Figure 15. 32 Absorber Rodlets: Dispersed Pattern \#4 (Absorber Ring). 


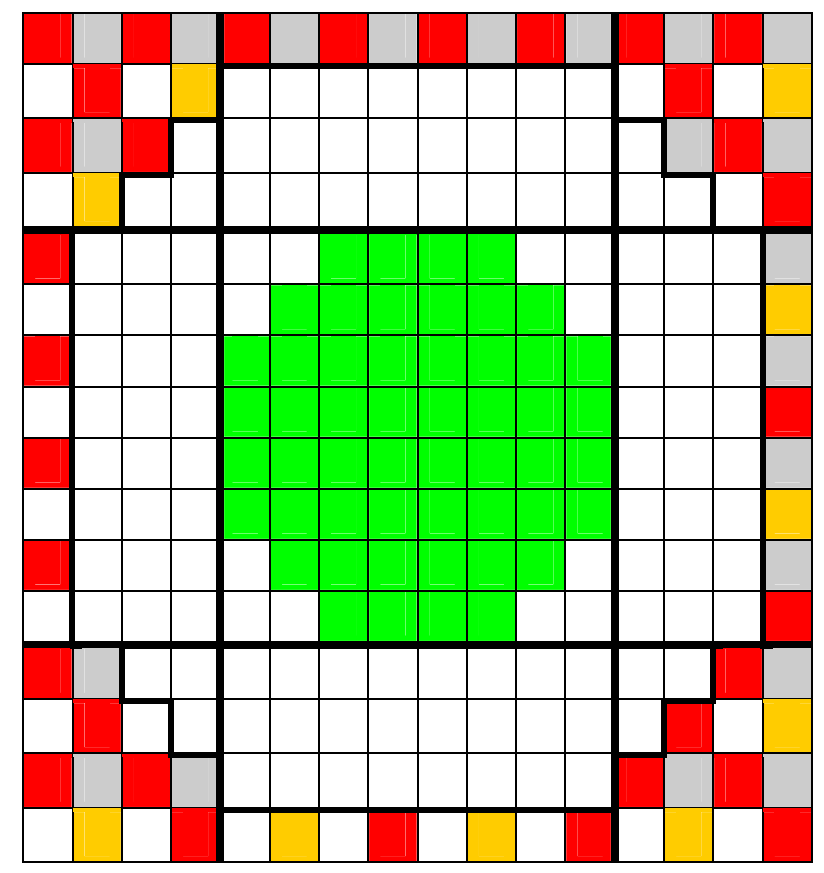

(U,Pu) $\mathrm{O}_{2}$ (cylinder)

$\mathrm{UO}_{2}$ (cylinder)

$\mathrm{C}$ (square)

void (square)

$\mathrm{B}_{4} \mathrm{C}$ (square)

Figure 16. 52 Absorber Rodlets: Compact Absorber Pattern.

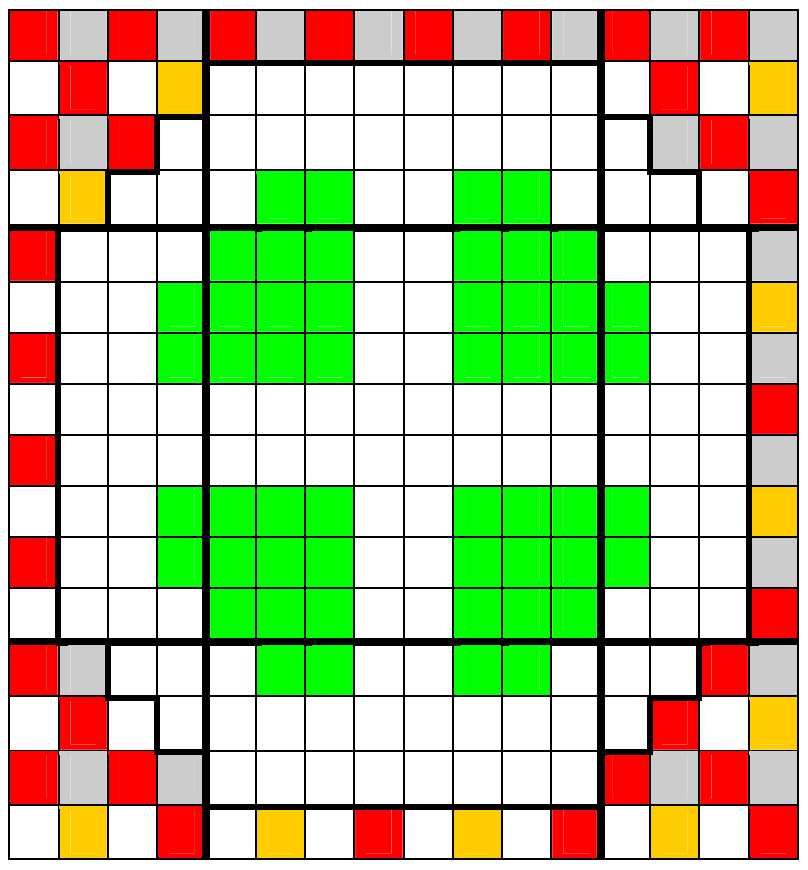

$(\mathrm{U}, \mathrm{Pu}) \mathrm{O}_{2}$ (cylinder) $\mathrm{UO}_{2}$ (cylinder)

C (square) void (square)

$\mathrm{B}_{4} \mathrm{C}$ (square)

Figure 17. 52 Absorber Rodlets: Dispersed Pattern \#1 (4 Rods). 


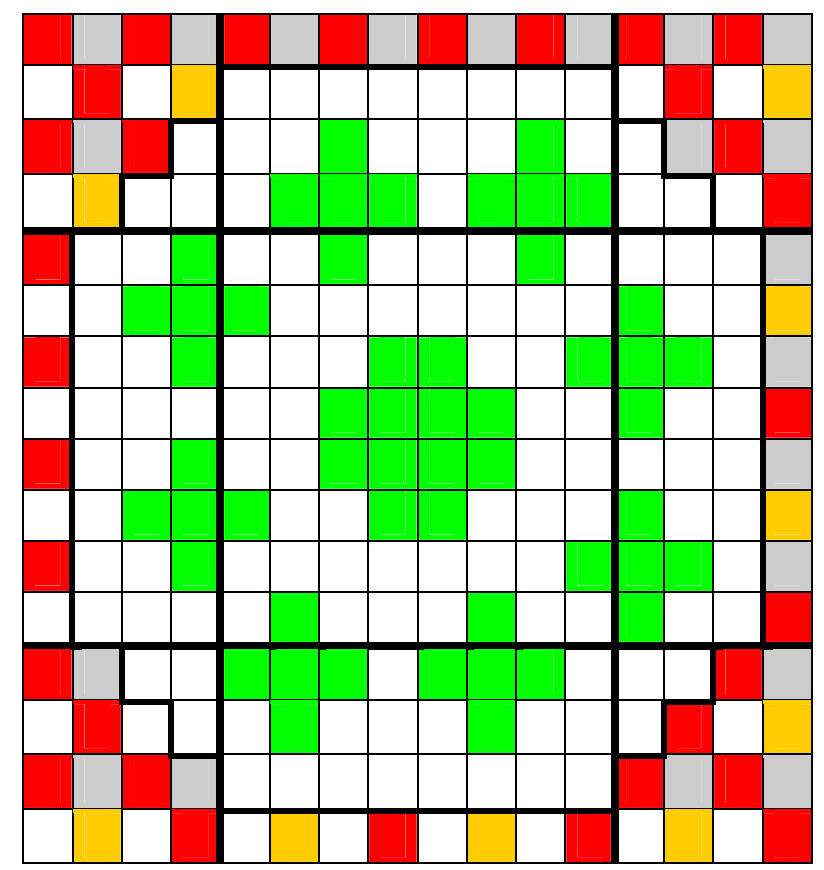

\section{(U,Pu) $\mathrm{O}_{2}$ (cylinder)}

$\mathrm{UO}_{2}$ (cylinder)

$\mathrm{C}$ (square)

void (square)

$\mathrm{B}_{4} \mathrm{C}$ (square)

Figure 18. 52 Absorber Rodlets : Dispersed Pattern \#2 (8+1 Absorber Rods).
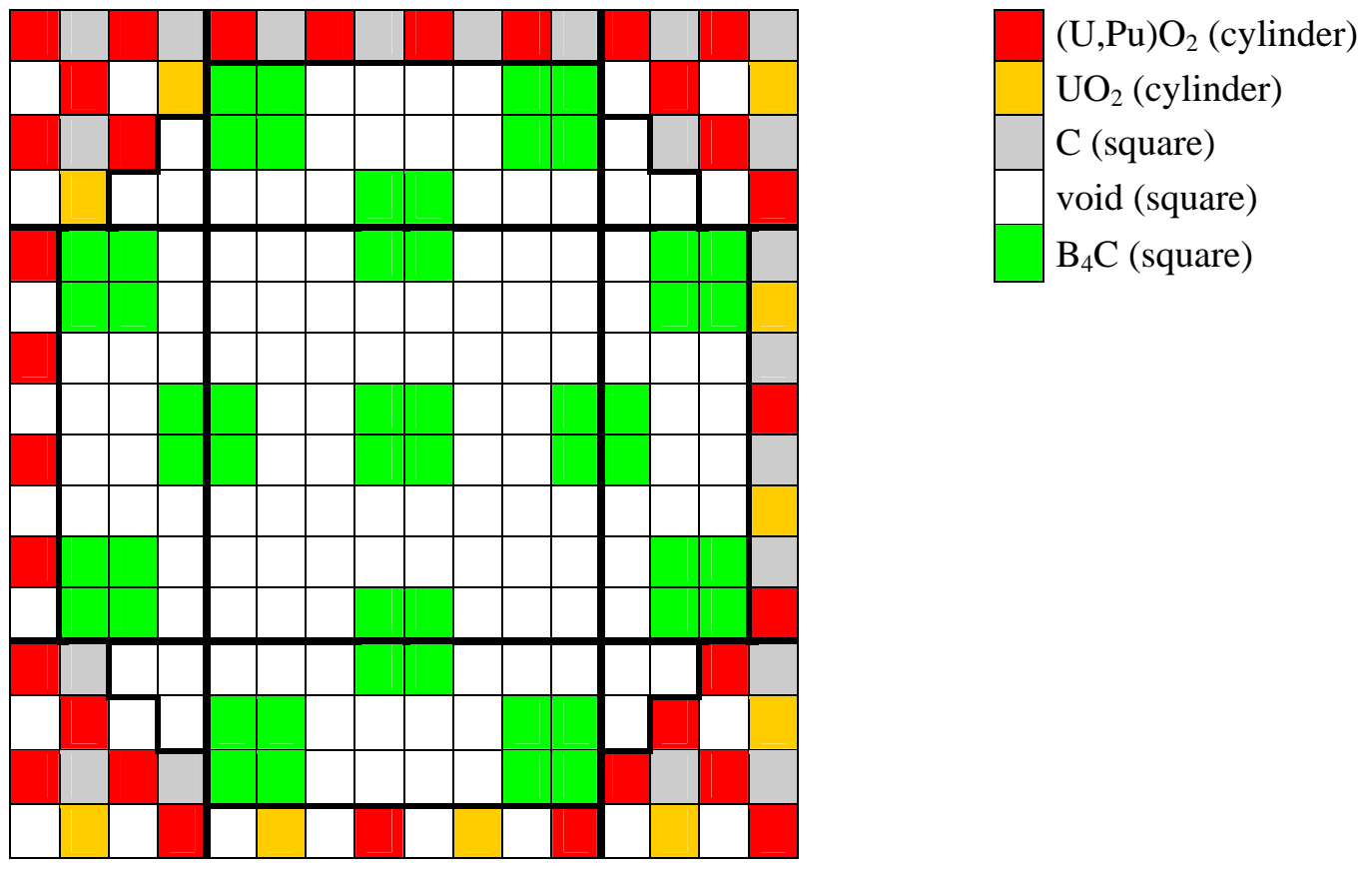

Figure 19. 52 Absorber Rodlets : Dispersed Pattern \#3 (8+4+1 Absorber Rods). 


\subsection{CALCULATION TOOLS AND MODELS}

The calculations for this study have been done using the European ERANOS code system [4]. Neutron cross-sections for the calculations were processed into a 33 multigroup energy structure using the ECCO code [5] with the ERALIB1 data library [6]. Neutron fluxes were calculated in RZ geometry using the BISTRO code [7] with the $\mathrm{S}_{16} \mathrm{P}_{1}$ approximation and in XYZ geometry using the TGV/VARIANT code [8]. For the VARIANT calculations, the effects of the anisotropic scattering order (transport versus diffusion) and of the angular flux expansion order (transport $\mathrm{P}_{3}$ versus transport $\mathrm{P}_{3}$ with simplified spherical harmonics) were investigated. Although the planned configurations have symmetry with respect to the three axes, X, Y, Z (with the exception of the A52i9 configuration), a full-core model was prepared for the calculation of the reaction rate traverses; these traverses being located very near to the symmetry axes caused problems for the interpolation routine when 1/8-core is modeled.

In order to represent exactly the absorber rodlet configurations inside the void region, the XYZ geometry model used very fine meshes at the core center (the rodlet dimensions are $1.325 \mathrm{~cm} \times 1.325 \mathrm{~cm}$ ). These meshes are smaller than the typical nodal sizes that are used for calculations in nodal codes such as VARIANT. This required that attention be paid to the VARIANT calculations: (a) because small mesh sizes require significantly more computation time and could cause solution instability, and (b) because the presence of a void zone at the core center necessitates homogenization with surrounding material (e.g., the void cans) since VARIANT cannot model an actual void zone due to the second-order transport formulation used in the code.

Using RZ geometry in BISTRO, the exact description of the absorber rodlets is not possible, and consequently, BISTRO calculations are not performed for the ENIGMA configuration containing $\mathrm{B}_{4} \mathrm{C}$ rodlets inside the void transition zone. However, for ERANOS, procedures have been developed, based on the so-called techniques of reactivity equivalence, to produce homogenized cross-sections for absorber assemblies. These modules have not been used in the present analysis, but are recommended in future efforts. Clearly, by generating the crosssections for the $\mathrm{B}_{4} \mathrm{C}$ rodlets homogenized with the void zone, it would be possible to perform BISTRO calculations for all the ENIGMA configurations with absorber zones and to avoid the long-running VARIANT simulations using fine meshes. 


\subsection{CROSS-SECTION PREPARATION}

The cross-sections for the different core zones have been processed using the ERANOS standard 33 energy group structure according to the following specifications.

The fuel assemblies have been calculated based on the heterogeneous description of the cell as shown in Figure 3 (void rodlets are homogenized with their cladding material; 93.2\% and $6.8 \%$ respectively by volume). The ECCO code performs a fine-group flux calculation using the heterogeneous geometry. Then the cross-sections are condensed to 33 energy groups and homogenized over the cell. The composition of the fuel assembly after homogenization is given in Table 1.

The cross-sections for the R1-Fuel assembly, axial and radial reflectors, and axial and radial shields have been processed with a 0-D cell calculation using the compositions presented in Table 1 and resulting from the homogenization over the MASURCA assembly.

Cross-sections for the void and $\mathrm{B}_{4} \mathrm{C}$ rodlets have been processed based on the heterogeneous description of the cell as shown in Figures 20 and 21.

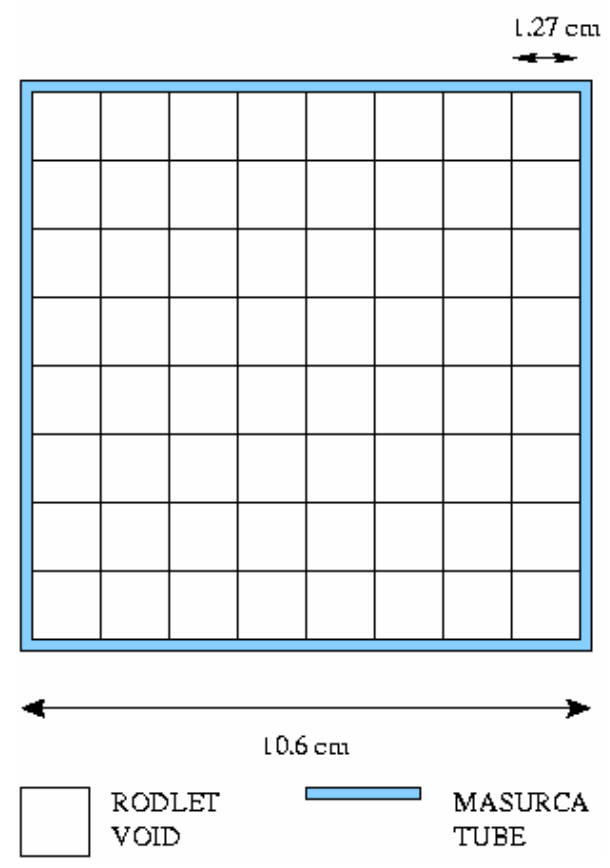

Figure 20. Cell for Void Rodlet Cross-Section Processing.

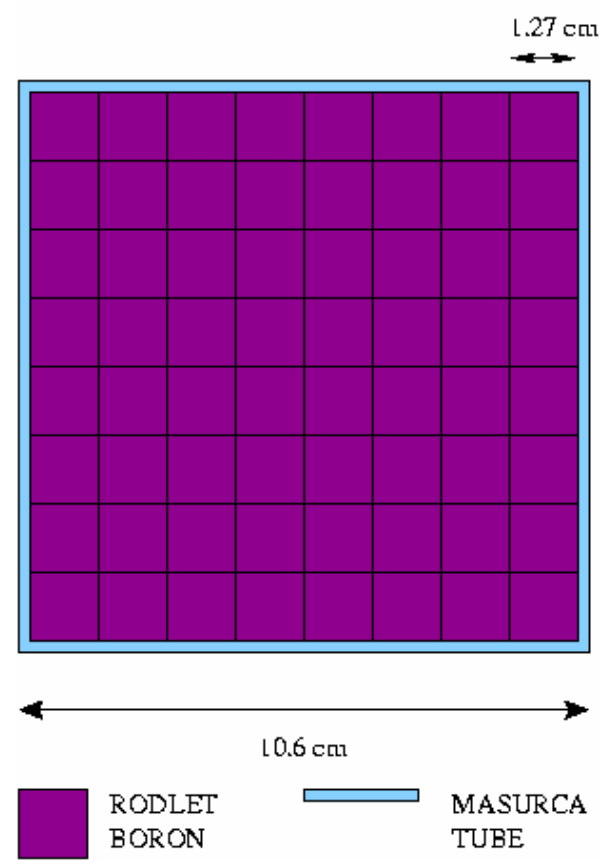

Figure 21. Cell for Boron Rodlet Cross-Section Processing. 
For each medium, cross-sections and compositions are homogenized over the MASURCA assembly, assuming that the entire assembly is filled with the same material. In some MASURCA assemblies two different materials may co-exist. In this case, when creating the geometry for the VARIANT or BISTRO spatial calculation, the homogenized cross-sections and compositions for each zone will be distributed only in the assembly sub-volume that is filled by the corresponding medium. However, this model can introduce some inconsistencies when those sub-volumes are not multiple of the unit cell of the corresponding medium.

As example, this situation occurs for the 8 assemblies defining the boundary between the void transition zone and the core, as shown in Figure 22; the sub-volumes of those assemblies extending into the core region contain for instance, a number of $\mathrm{PuO}_{2}\left(\right.$ or $\left.\mathrm{UO}_{2}\right)$ rodlets that is not consistent with the assembly homogenized compositions for which the cross-sections are produced. However, the impact of this inconsistency is assumed to be negligible for the reactivity and reaction rate results.

Additionally, because of the symmetry of the reactor, if the fuel assemblies are oriented always in the same way, the total compositions over the 8 assemblies will be preserved. In this regard, the only way to avoid any inconsistency between homogenized compositions and assembly sub-volumes is to perform a spatial calculation in which the single rodlets are separately described by the geometry model (cross-sections should also be processed for each rodlet without any assembly homogenization): the computational resources for such a calculation would be so demanding that it would be impractical. 


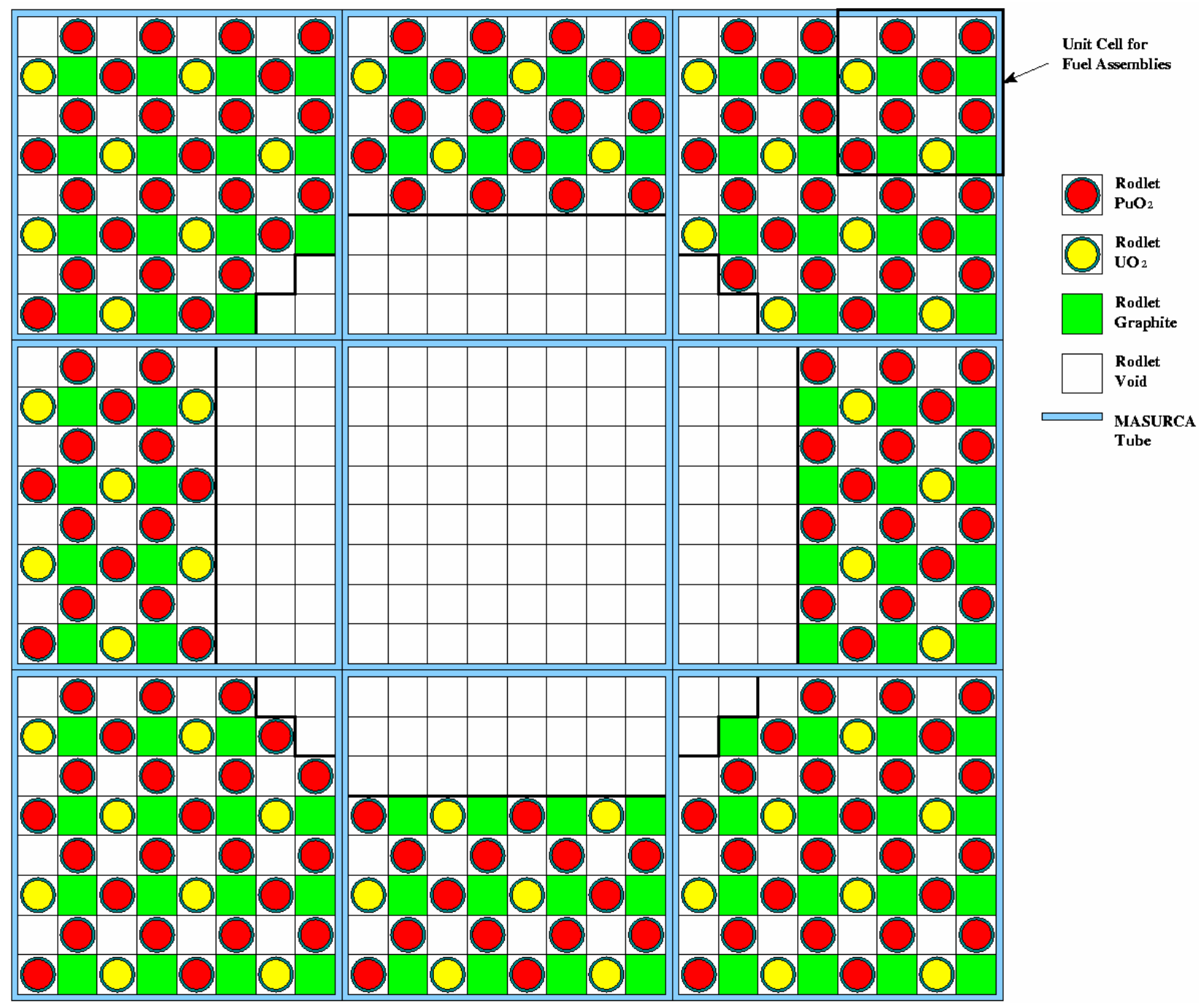

Figure 22. Details of the Void Zone at ENIGMA Core Center. 


\subsection{REACTIVITY WORTHS}

The reactivity worths for the reference configuration and the control rod experimental Phases 1, 2, and 3 are presented in the following sub-sections.

\subsection{Reference Configuration}

Analysis of the reference core criticality state has been performed. The reactivity results for the reference configuration are presented in Table 3. Both the RZ (BISTRO) and the XYZ (VARIANT) models have been used to determine the multiplication factor ( $\left.k_{\text {eff }}\right)$. The multiplication factor was then converted to reactivity using the expression $\left(\mathrm{k}_{\text {eff }}-1\right) / \mathrm{k}_{\text {eff. }}$ The BISTRO reactivity value shows a discrepancy of about $150 \mathrm{pcm}$ with respect to the VARIANT results with $\mathrm{P}_{3}-\mathrm{P}_{1}$ approximation. The observed discrepancy involves both method and cylindrization effects (see Table 5 below).

Table 3. Calculated Reactivity Values for ENIGMA Reference Configuration.

\begin{tabular}{|l|c|}
\hline Calculation type & Reactivity [pcm] \\
\hline A: RZ $\left(\mathrm{S}_{16} \mathrm{P}_{1}\right.$ BISTRO) & 297 \\
\hline B: XYZ (Diffusion VARIANT) & -203 \\
\hline C: XYZ $\left(\mathrm{SP}_{3}-\mathrm{P}_{1}{ }^{(\mathrm{a})}\right.$ VARIANT) & +230 \\
\hline D: XYZ $\left(\mathrm{P}_{3}-\mathrm{P}_{1}{ }^{\text {(b) }}\right.$ VARIANT) & +135 \\
\hline \multicolumn{2}{|c|}{${ }^{\text {(a) }}$ Anisotropic scattering order 1; Angular flux expansion order 3 with } \\
simplified spherical harmonics; \\
(b) Anisotropic scattering order 1; Angular flux expansion order 3.
\end{tabular}

The reference calculation would be the one using the VARIANT XYZ model with $\mathrm{P}_{3}-\mathrm{P}_{1}$ approximation. The order of this approximation, however, leads to convergence problems for the successive ENIGMA configurations, where a void transition zone is introduced at the core center. For this reason, the reactivity results are successively determined using the $\mathrm{SP}_{3}-\mathrm{P}_{1}$ approximation. Additionally, for the spatial expansion of flux, leakage and source the orders 4, 1 and 2, respectively, are used; these expansion orders are considered sufficiently accurate, since a more precise approximation would enormously increase the computational time and result in a negligible improvement of the result accuracy.

Table 4 summarizes the reactivity results for the ENIGMA reference configuration with the void region at the center of the core (see Figures 4 and 5). The results calculated with 
VARIANT ( $\mathrm{SP}_{3}-\mathrm{P}_{1}$ approximation) indicate that the introduction of the void region results in a 2472 pcm reduction in the core reactivity; a value of $2232 \mathrm{pcm}$ was obtained with BISTRO. It is also observed that the reactivity discrepancy between the two cases A and C of Table 4 increases from 70 to 300 pcm with the introduction of the void zone at the center of the reference configuration. The observed change is most likely due to the transport effects in the void region. In this regard, it is observed that using the VARIANT code, the reactivity discrepancy between the diffusion and $\mathrm{SP}_{3}-\mathrm{P}_{1}$ approximations increases from 430 to $520 \mathrm{pcm}$ with void region (see Tables 3 and 4).

Table 4. Reactivity [pcm] of Reference Configuration Before and After Introduction of Void Region.

\begin{tabular}{|l|c|c|c|}
\hline Calculation type & Without Void & With Void & Reactivity Effect \\
\hline A: RZ $\left(\mathrm{S}_{16} \mathrm{P}_{1}\right.$ BISTRO) & +297 & -1935 & -2232 \\
\hline B: XYZ (Diffusion VARIANT) & -203 & -2764 & -2561 \\
\hline C: XYZ $\left(\mathrm{SP}_{3}-\mathrm{P}_{1}\right.$ VARIANT) & +230 & -2242 & -2472 \\
\hline
\end{tabular}

${ }^{\text {(a) }}$ Reactivity change: with void - without void

To separate the cylindrization and transport effects in the void zone from the effects arising from differences in code methods $\left(S_{n}\right.$, BISTRO versus nodal, VARIANT), a simple spatial calculation has been performed for the horizontal section of the ENIGMA core configuration at the core midplane. The same value of the axial buckling has been employed in the VARIANT (XY) and BISTRO (R or XY) simulations. This axial buckling value was selected in order to get a nearly critical state and to eliminate leakage effects in the comparison of the results. The results of this study are summarized in Table 5. The calculations C-A and D-B show that the cylindrization effect is about 75 pcm (both in diffusion and transport approximations) if there is no void. With the void region, this effect is 93-102 pcm. It can also be seen that the transport effect increases with introduction of the void region; 329 to 503 pcm (B-A), 332 to 512 pcm (D-C), 448 to 776 pcm (F-E), 325 to 490 pcm (H-G), but only 433 to 522 pcm (VARIANT $\mathrm{SP}_{3}$ in Table 4). This confirms the importance of the transport effect arising from introduction of the void zone. From the calculations G-C and H-D it is also concluded that BISTRO and VARIANT show consistent results both with and without void. 
Table 5. Reactivity [pcm] of Reference Configuration Before and After Introduction of Void Region in Simplified 2-D Problem.

\begin{tabular}{|c|c|c|c|}
\hline Calculation type & Without Void & With Void & Reactivity Effect ${ }^{(a)}$ \\
\hline A: R (Diffusion BISTRO) & -72 & -4114 & -4042 \\
\hline $\mathrm{B}: \mathrm{R}\left(\mathrm{S}_{16} \mathrm{P}_{1} \mathrm{BISTRO}\right)$ & +257 & -3611 & -3868 \\
\hline C: XY (Diffusion BISTRO) & -148 & -4216 & -4068 \\
\hline $\mathrm{D}: \mathrm{XY}\left(\mathrm{S}_{16} \mathrm{P}_{1} \mathrm{BISTRO}\right)$ & +184 & -3704 & -3888 \\
\hline E: RZ (Diffusion BISTRO) & -151 & -2711 & -2560 \\
\hline $\mathrm{F}: \mathrm{RZ}\left(\mathrm{S}_{16} \mathrm{P}_{1} \mathrm{BISTRO}\right)$ & +297 & -1935 & -2232 \\
\hline G: XY (Diffusion VARIANT) & -143 & -4207 & -4064 \\
\hline $\mathrm{H}: \mathrm{XY}\left(\mathrm{SP}_{3}-\mathrm{P}_{1}\right.$ VARIANT $)$ & +182 & -3717 & -3899 \\
\hline $\mathrm{I}: \mathrm{XY}\left(\mathrm{P}_{3}-\mathrm{P}_{1}\right.$ VARIANT $)$ & +126 & & \\
\hline
\end{tabular}

${ }^{(a)}$ Reactivity change: with void - without void

\subsection{Reactivity Worths for Phase 1}

VARIANT $\mathrm{SP}_{3}-\mathrm{P}_{1}$ calculations have been done to determine the number of assemblies required to restore criticality following the introduction of the void zone. By iteratively introducing assemblies (or fraction of an assembly), it was determined that $9 \frac{1}{4}$ U-fueled assemblies need to be added at the core periphery. The new ENIGMA critical configuration with these additional assemblies (designated "RF" configuration) is shown in Figure 23. Note that radial reflector assemblies are also added in order to maintain a reflector thickness of about $25 \mathrm{~cm}$. The equivalent core and reflector radii change to $58.1 \mathrm{~cm}$ and to $82.9 \mathrm{~cm}$, respectively.

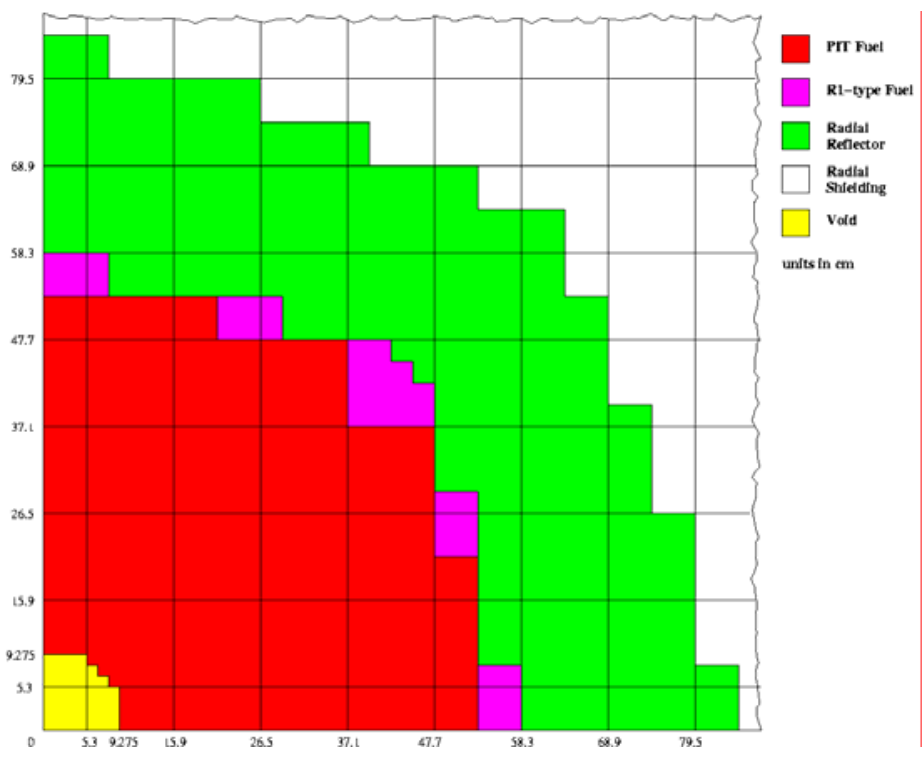

Figure 23. RF Configuration. 
Using the new $\mathrm{RF}$ configuration, the $\mathrm{B}_{4} \mathrm{C}$ rodlet configurations specified for Phase 1 (Figures 7 to 10) are successively introduced and the reactivity worth determined. Table 6 is a summary of the calculated worths that were obtained using VARIANT with the XYZ Cartesian geometry and $\mathrm{SP}_{3}-\mathrm{P}_{1}$.

Table 6. Reactivity Worths [pcm] of $\mathrm{B}_{4} \mathrm{C}$ Rodlets in Phase 1 Configurations.

\begin{tabular}{|l||c|c|c|}
\hline \multirow{2}{*}{ Configuration } & \multirow{2}{*}{$\mathrm{XYZ}_{\left(\mathrm{SP}_{3}-\mathrm{P}_{1} \text { VARIANT) }\right.}$} & \multicolumn{2}{|c|}{ Reactivity Worth $^{\text {(a) }}$} \\
\cline { 3 - 4 } & & Total & Average per rodlet \\
\hline \hline RF & 67 & - & - \\
\hline A4c with natural boron & -491 & -558 & -140 \\
\hline A4c with enriched boron & -1339 & -1406 & -352 \\
\hline A4d with natural boron & -546 & -613 & -154 \\
\hline A4d with enriched boron & -1620 & -1687 & -422 \\
\hline A12c with natural boron & -1288 & -1355 & -113 \\
\hline A12c with enriched boron & -2806 & -2873 & -239 \\
\hline A12d with natural boron & -1517 & -1584 & -132 \\
\hline A12d with enriched boron & -3643 & -3710 & -309 \\
\hline
\end{tabular}

${ }^{\text {(a) }}$ Reactivity loss with respect to the RF configuration

Results are presented for the total reactivity worth and the worth per rodlet. Data have also been given for cases using natural and enriched boron in the $\mathrm{B}_{4} \mathrm{C}$ rodlets. The conclusions from this and following analyses are given in Section 5.5.

\subsection{Reactivity Worths for Phase 2}

To establish the initial core configuration for the Phase 2 control rod experiments, the rodlet configuration A32c (Figure 11) was introduced into the void region of the RF configuration. The VARIANT calculation for this state indicated a subcriticality reactivity of $-4778 \mathrm{pcm}$ from the presence of the rodlets. Iteratively searching for the number of additional R1-type assemblies needed to restore criticality revealed that 211/4 such assemblies should be added to the core periphery of the RF configuration as shown in Figure 24; radial reflector assemblies are also added in order to maintain a reflector thickness of about $25 \mathrm{~cm}$. The equivalent core and reflector radii change to $64.3 \mathrm{~cm}$ and to $89.3 \mathrm{~cm}$, respectively. 


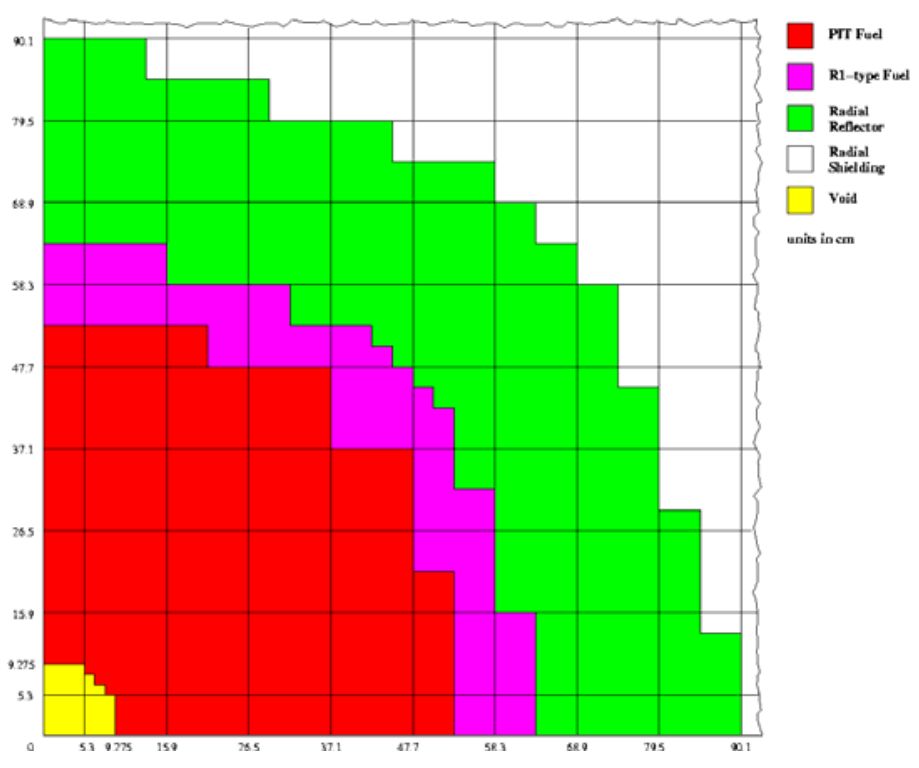

Figure 24. A32c Critical Configuration.

Using the new A32c critical configuration, reactivity calculations outlined for Phase 2 in Section 2.2 (central core zones illustrated in Figures 12 to 15) have been performed. The reactivity worths for the different cases are summarized in Table 7.

Table 7. Reactivity Worths [pcm] of $\mathrm{B}_{4} \mathrm{C}$ Rodlets in Phase 2 Configurations.

\begin{tabular}{|l|c|c|}
\hline Configuration & $\mathrm{XYZ}\left(\mathrm{SP}_{3}-\mathrm{P}_{1}\right.$ VARIANT $)$ & Reactivity Worth $^{(\mathrm{a})}$ \\
\hline A32c critical & 21 & - \\
\hline A32i4 with enriched boron & -535 & -556 \\
\hline A32i8 with enriched boron & -920 & -941 \\
\hline A32d with enriched boron & -1041 & -1062 \\
\hline A32r with enriched boron & -1147 & -1168 \\
\hline
\end{tabular}

${ }^{\text {(a) }}$ Reactivity loss with respect to the A32c critical configuration

\subsection{Reactivity Worths for Phase 3}

Following the same sequence for establishing new core critically, the rodlet configuration A52c was first modeled with the VARIANT code without modifying the core contour of the A32c critical configuration. This calculation gave a reactivity value of $-960 \mathrm{pcm}$.

By iteratively adding R1-type assemblies at the periphery of the core with the A32c configuration and checking the $\mathrm{k}_{\mathrm{eff}}$, it was found that an additional $6 \frac{1 / 4}{4}$ assemblies are required to restore core criticality, as shown in Figure 25. Additional radial reflector assemblies are also 
added in order to maintain a reflector thickness of about $25 \mathrm{~cm}$. The equivalent core and reflector radii change to $66.0 \mathrm{~cm}$ and $90.9 \mathrm{~cm}$, respectively.

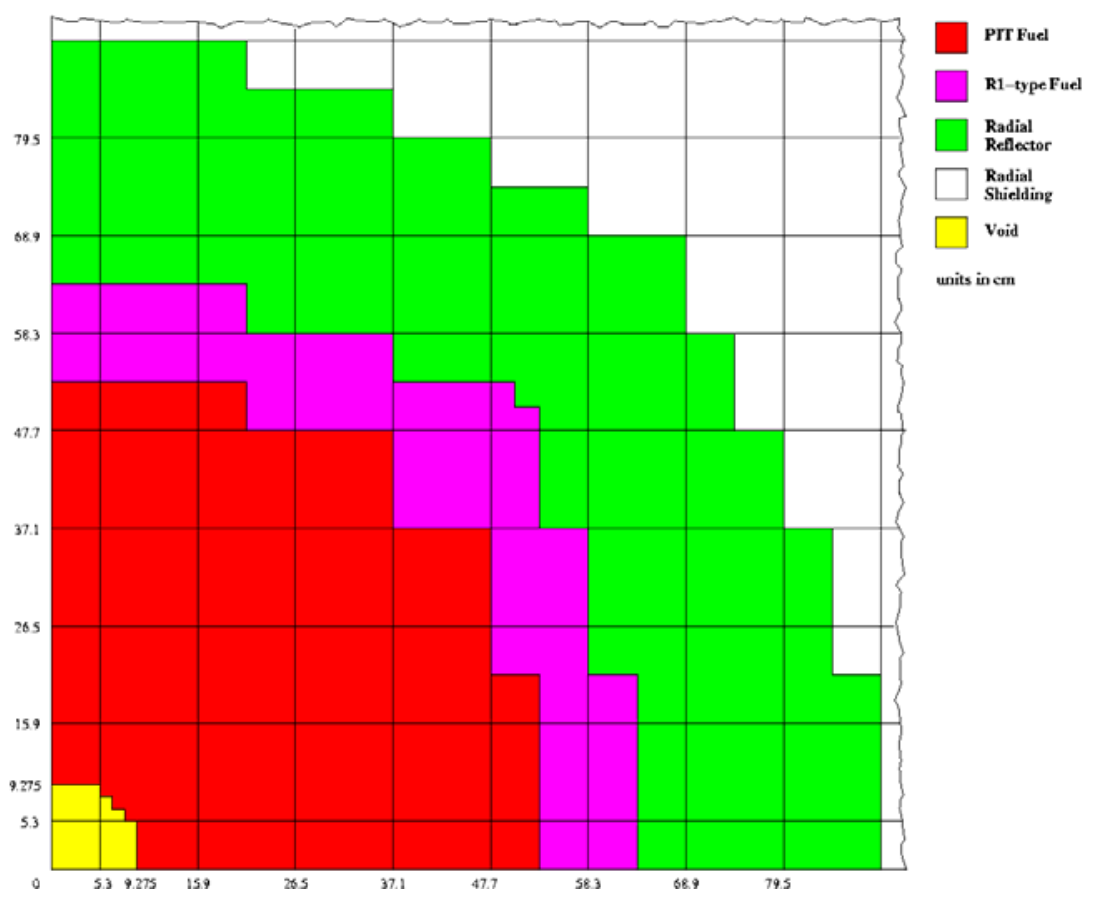

Figure 25. A52c Critical Configuration

To support the latter phases of the control rod experiments, calculations have been done with the A52c critical configuration using the rodlet configurations presented in Section 2.2 for Phase 3. Only enriched boron is used in this phase. The reactivity worths that were obtained are summarized in Table 8.

Table 8. Reactivity Worths [pcm] of $\mathrm{B}_{4} \mathrm{C}$ Rodlets in Phase 3 Configurations.

\begin{tabular}{|l|c|c|}
\hline Configuration & $\mathrm{XYZ}\left(\mathrm{SP}_{3}-\mathrm{P}_{1}\right.$ VARIANT $)$ & Reactivity Worth $^{(\mathrm{a})}$ \\
\hline A52c critical & 77 & - \\
\hline A52i4 with enriched boron & -541 & -618 \\
\hline A52i9 with enriched boron & -753 & -1065 \\
\hline A52i13 with enriched boron & -988 & -830 \\
\hline
\end{tabular}

${ }^{\text {(a) }}$ Reactivity loss with respect to the A52c critical configuration 


\subsection{Conclusions from Analysis}

Considering the results of Table 6, 7, and 8 (Sections 5.2 to 5.4), we make the following observations:

- Spatial self-shielding effect is quite important, as evident from the results for the set of cases, using 4 rodlets, 12 rodlets, 32 rodlets, and 52 rodlets. For example, depending on the arrangement of the 4 rodlets in Phase 1 , the reactivity worth per rod could be 140 pcm to 422 pcm. The dispersed arrangement gives the higher worth, compared to the compact arrangement. This shows the flexibility to obtain different worths from the same amount of absorbing material.

- The average reactivity worth of a R1-type fuel assembly added to the core periphery of the reference configuration (to restore criticality) is $250 \mathrm{pcm}$. The worth decreases to $226 \mathrm{pcm}$ when restoring criticality for the A32c configuration and to $166 \mathrm{pcm}$ in the case of the A52c configuration. This is attributed to the decrease in the neutron importance at the core periphery arising from increase in the core size to support the higher number of rodlets.

- The maximum active core radius and reflector radius required for the proposed experimental configurations are $66.0 \mathrm{~cm}$ and $90.9 \mathrm{~cm}$, respectively. 


\subsection{REACTION RATE TRAVERSES ANALYSIS}

Evaluations of the flux and reaction rate spatial distributions have been performed for the absorber rodlet configurations planned for the ENIGMA program. The ${ }^{235} \mathrm{U}$ fission, ${ }^{238} \mathrm{U}$ fission, ${ }^{237} \mathrm{~Np}$ fission, ${ }^{239} \mathrm{Pu}$ fission and ${ }^{10} \mathrm{~B}$ capture rate traverses have been selected for this purpose. The calculations were for distributions along the MASURCA experimental channel NS and along the channel EW, as indicated in Figure 26. The actual experimental channel EW is symmetric to the NS channel with respect to the $x=-y$ diagonal. Because of the core symmetry with respect to the same diagonal, it is expected that the measured EW traverses would not provide any additional information with respect to the NS ones. Consequently, for the study, it was decided to shift the EW channel by a rodlet position, as shown in Figure 26. In the axial direction, the NS and EW channels extend $6 \mathrm{~mm}$ and $95 \mathrm{~mm}$, respectively, below the core midplane. To calculate the reaction rate traverses, detector cross-sections have been generated with a separate ECCO calculation with infinite diluted isotope number densities.

For completeness, all investigated traverses are presented in Appendix A. Besides the distribution across the reactor, a zoom of the traverse inside the void transition zone is also given. Figures 28 to 75 show the traverses calculated along the NS channel, while Figures 76 to 123 are for the EW channel. The distributions have been normalized to 1 at the channel midpoint.

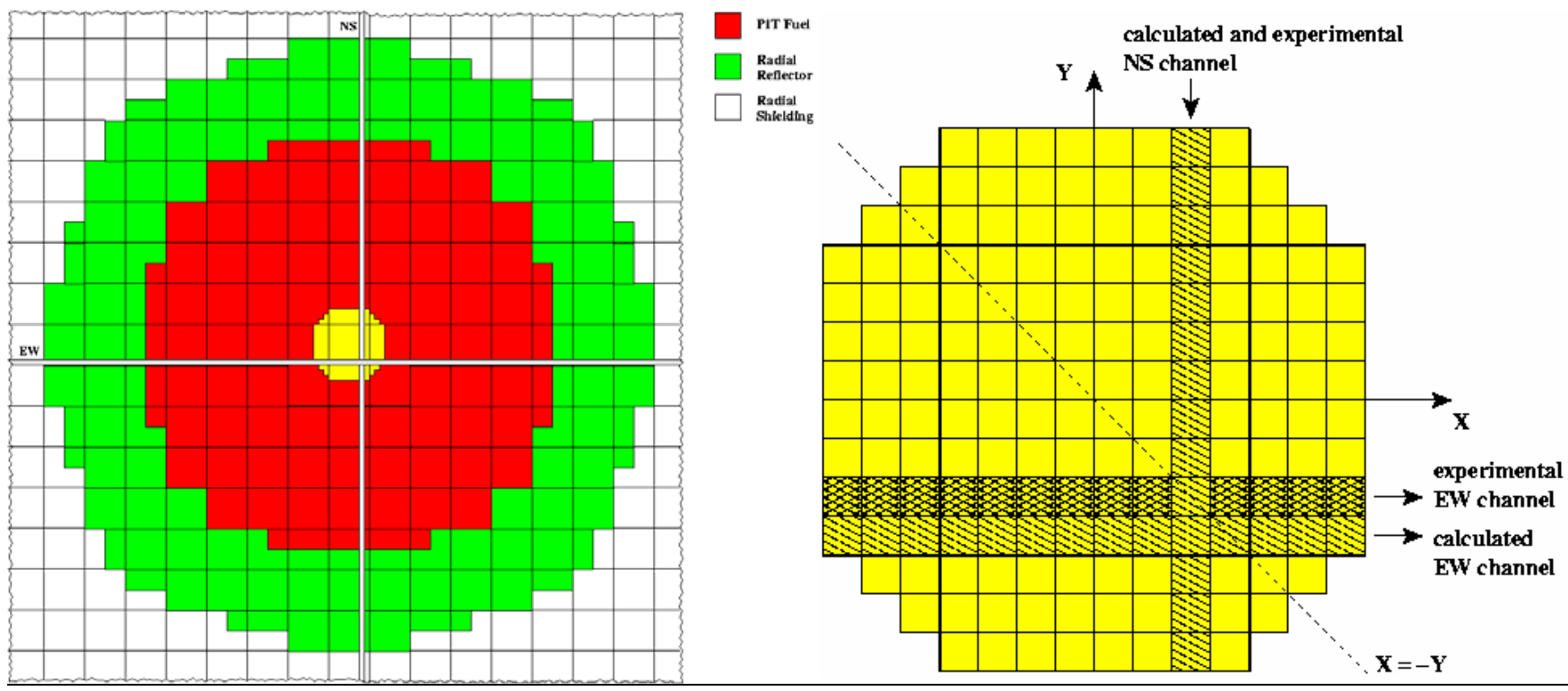

Figure 26. Channel Location in Reference Configuration With Void Zone and Inside Void Zone. 
The following is a summary of the results.

- Because of the reactor symmetry, the traverses are all symmetric with respect to the core center, with exception of the A52i9 configuration, which is the only configuration where the $\mathrm{B}_{4} \mathrm{C}$ rodlets do not have a symmetric distribution inside the void transition zone (see Figures 64 to 75 and 112 to 123).

- The NS and EW traverses for the configurations with no $\mathrm{B}_{4} \mathrm{C}$ rodlets (the reference configuration with and without void transition zone) basically have the same shape (see Figures 28 to 39 and Figures 76 to 87). For the other configurations, however, the distance of a single absorber rodlet from the channels is not the same and this impacts the shape of the traverses. For the A4d configuration, for instance, the NS channel crosses two $\mathrm{B}_{4} \mathrm{C}$ rodlets and consequently at the corresponding locations one observes a rate depression more pronounced than the EW channel, which does not cross any $\mathrm{B}_{4} \mathrm{C}$ rodlet (see e.g., Figures 43 and 91 ).

- As expected, the depression of the flux or rate distributions in the $\mathrm{B}_{4} \mathrm{C}$ rodlet locations is more pronounced if enriched boron is used instead of natural boron in the rodlets (see Figures 40 to 51 and 88 to 99).

- It was observed that the depression of the rate distributions in the $\mathrm{B}_{4} \mathrm{C}$ rodlet locations is more pronounced for the ${ }^{235} \mathrm{U}$ fission, ${ }^{239} \mathrm{Pu}$ fission and ${ }^{10} \mathrm{~B}$ capture traverses (whose detector cross-sections are more sensitive to low energy neutrons), with respect to the ${ }^{238} \mathrm{U}$ and ${ }^{237} \mathrm{~Np}$ fission traverses (see Figures 42 to 51 and 90 to 99); the $\mathrm{B}_{4} \mathrm{C}$ rodlets are effective thermal neutron absorbers. This can be seen in Figure 27, which shows the direct and adjoint flux spectra at the core center of some ENIGMA configurations. The introduction of the void transitional zone (instead of the absorbers) seems to produce a softer spectrum at the core center. However, for the configurations with absorber rodlets (configurations A4c and A4d), the flux spectrum is harder, particularly in the location of the $\mathrm{B}_{4} \mathrm{C}$ rodlets (configuration $\mathrm{A} 4 \mathrm{c}$ ). Also, assessment of the adjoint flux spectrum revealed that the thermal neutron importance at core center of configurations with absorber rodlets significantly decreases, becoming practically zero at the $\mathrm{B}_{4} \mathrm{C}$ rodlet location. 

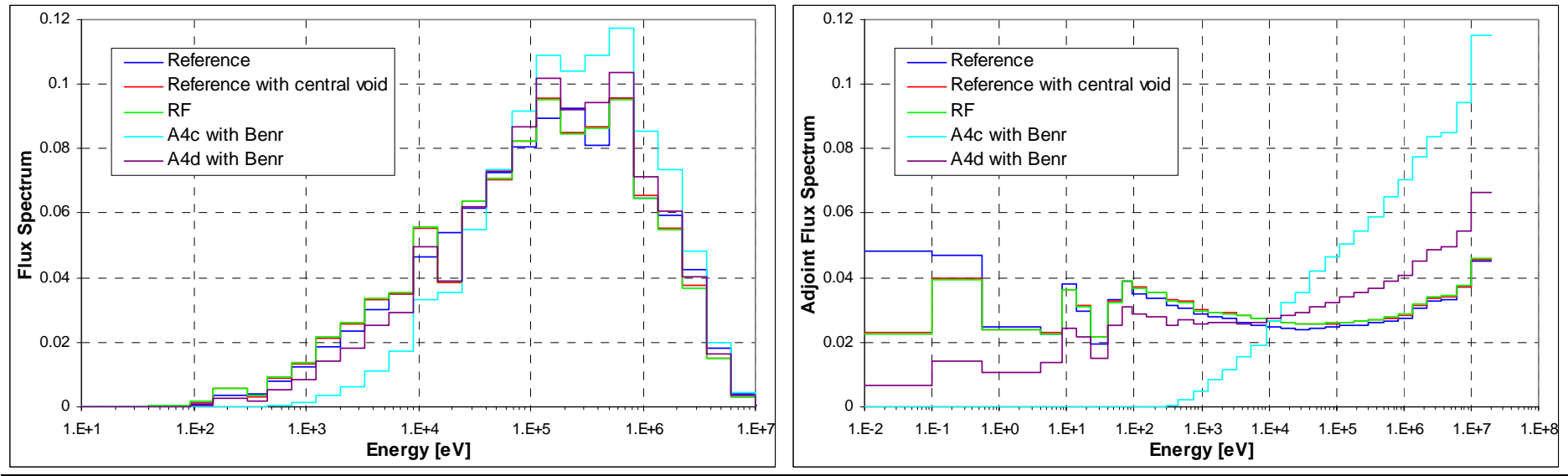

Figure 27. Direct and Adjoint Flux Spectra at Core Center. 


\subsection{CONCLUSIONS}

Central control rod experiments have been proposed for the ENIGMA program which is being planned to provide reactor physics experimental data to support the development of advanced gas-cooled fast reactors (GFRs). These experiments would be useful in characterizing GFRs in the presence of control rods and for assessing the adequacy of existing fast reactor analysis tools for the calculation of control rod worths and power distributions (distortions) near absorbers.

The various experiments that have been proposed are summarized in this report. Core physics calculations and analysis have been performed for the experimental configurations using the traditional codes, ERANOS (VARIANT and BISTRO) and ECCO, utilized for fast reactor analysis at CEA; the codes have been used for the analysis of experiments at Argonne.

In this study, the numbers of additional assemblies required to restore core criticality (or critical core radius) under various rodlet configurations were determined. Control rod worths for the different $\mathrm{B}_{4} \mathrm{C}$ rodlet configurations were analyzed. Additionally, flux distributions and reaction rate distributions for a few nuclides were presented. The results showed the need for more assemblies at the core periphery as the number of absorber rodlets introduced into the core increases. The importance of spatial heterogeneity for the control rod experiments was also quite evident from the results, indicating the flexibility available in achieving desired rod worths for the experiments.

At the current time, only deterministic calculations have been performed. It is recommended that subsets of the cases be modeled with Monte Carlo codes in the future in order to provide independent confirmation of the deterministic results. 


\subsection{REFERENCES}

1. J. Tommasi, R. Jacqmin, F. Mellier, "Gas-Cooled Fast Reactors: Motivation and Presentation of the ENIGMA Program in the MASURCA Experimental Critical Facility,” Proceedings of GLOBAL 2005, Tsukuba, Japan, October 9-13, 2005.

2. G. Aliberti, G. Palmiotti, M. Salvatores, T. Taiwo and H. Khalil (ANL), J. Tommasi, R. Jacqmin (CEA-Cadarache), "Investigation of the Similarity of Reactor Physics Experimental Configurations Planned in the CEA MASURCA Facility to Gas-Cooled Fast Reactor Concepts,” June 2004.

3. G. Aliberti, G. Palmiotti, T.A. Taiwo, J. Tommasi, "Impact of Spectral Transition Zone in Reference ENIGMA Configuration,” ANL-GenIV-053, Argonne National Laboratory, USA (August 2005).

4. G. Rimpault et al., "The ERANOS Code and Data System for Fast Reactor Neutronics Analyses”, Proc. PHYSOR 2002 Conference, Seoul (Korea), October 2002. see also G. Palmiotti, R. F. Burstall, E. Kiefhaber, W. Gebhardt, J. M. Rieunier, "New Methods Developments and Rationalization of Tools for LMFBR Design in the Frame of the European Collaboration,” FR'91 International Conference on Fast Reactors and Related Fuel Cycles, Kyoto, Japan, October 28 - November 1, 1991.

5. G. Rimpault, “Algorithmic Features of the ECCO Cell Code for Treating Heterogeneous Fast Reactor Assemblies,” International Topical Meeting on Reactor Physics and Computation, Portland - Oregon, May 1-5, 1995.

6. E. Fort, W. Assal, G. Rimpault, J. L. Rowlands, P. Smith, R. Soule, "Realization and Performance of the Adjusted Nuclear Data Library ERALIB1 for Calculating Fast Reactor Neutronics,” PHYSOR96, Mito, Japan, 1996.

7. G. Palmiotti, J. M. Rieunier, C. Gho, M. Salvatores, "BISTRO Optimized Two Dimensional Sn Transport Code”, Nucl. Sci. Eng., 104, 26 (1990).

8. G. Palmiotti, C. B. Carrico, E. E. Lewis, "Variational Nodal Transport Methods with Anisotropic Scattering,” Nucl. Sci. Eng., 115, p.233 (1993). 


\subsection{APPENDIX A. FLUX AND REACTION RATE TRAVERSES}

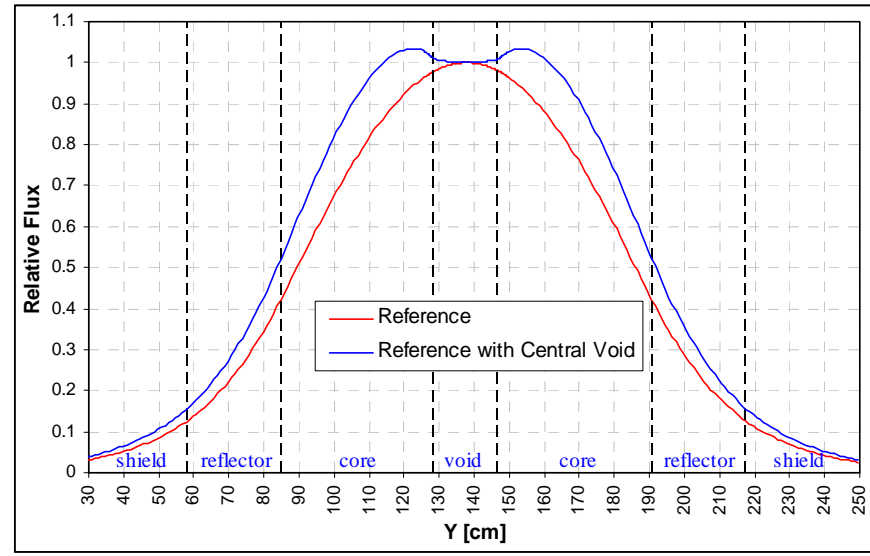

Figure 28. NS Flux Traverse

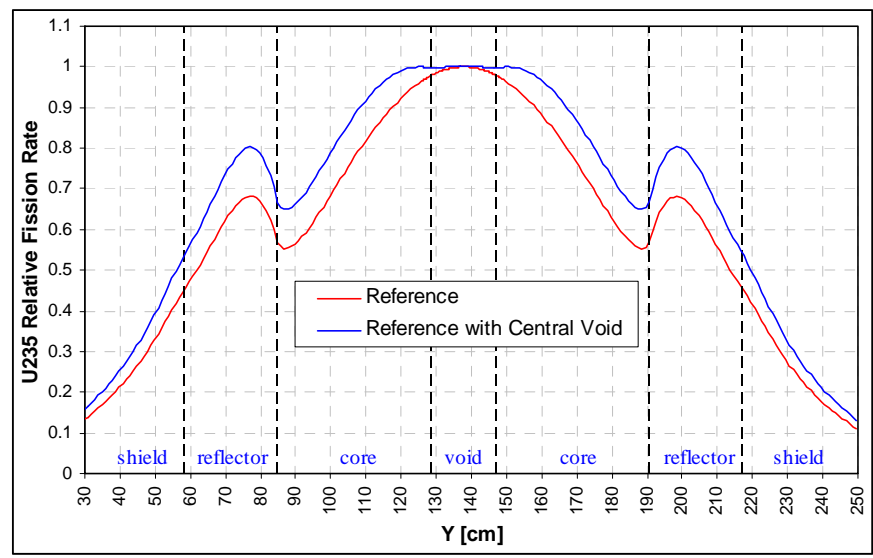

Figure 30. NS U-235 Fission Traverse

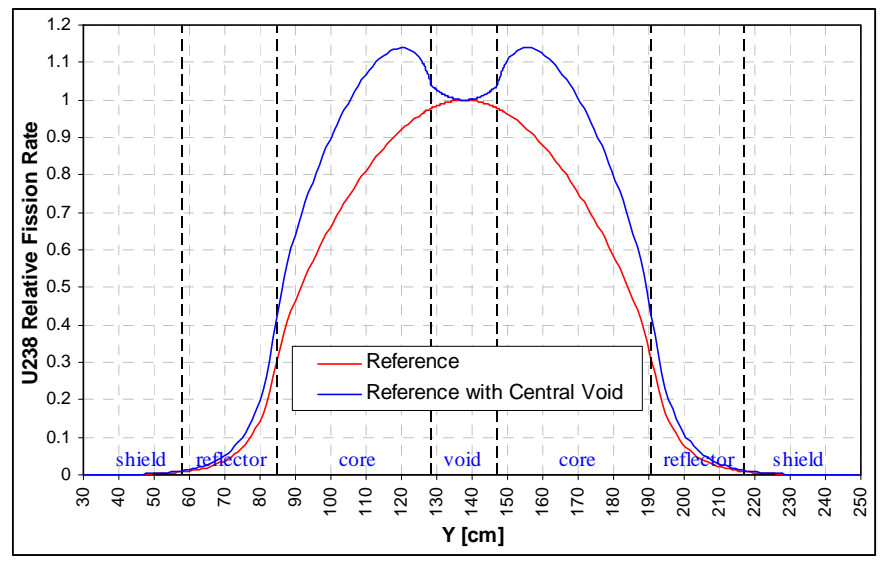

Figure 32. NS U-238 Fission Traverse

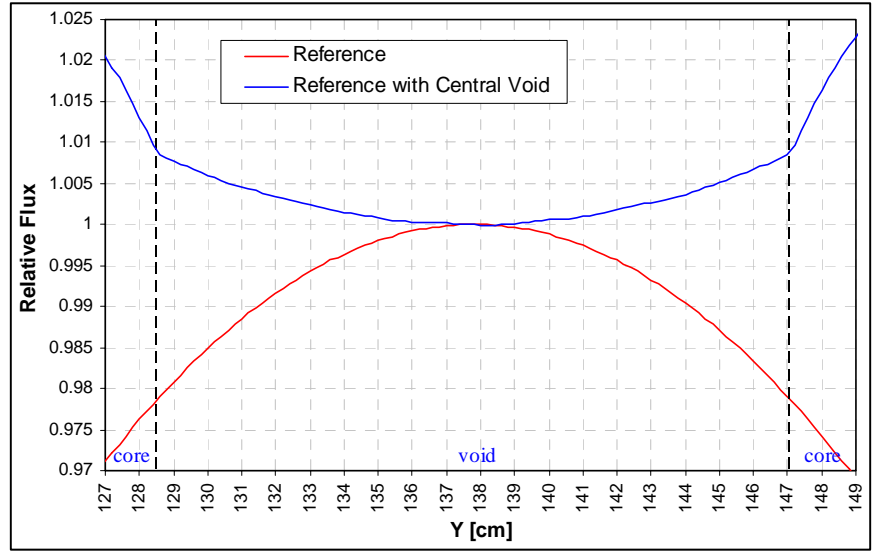

Figure 29. NS Flux Traverse inside the Void Region

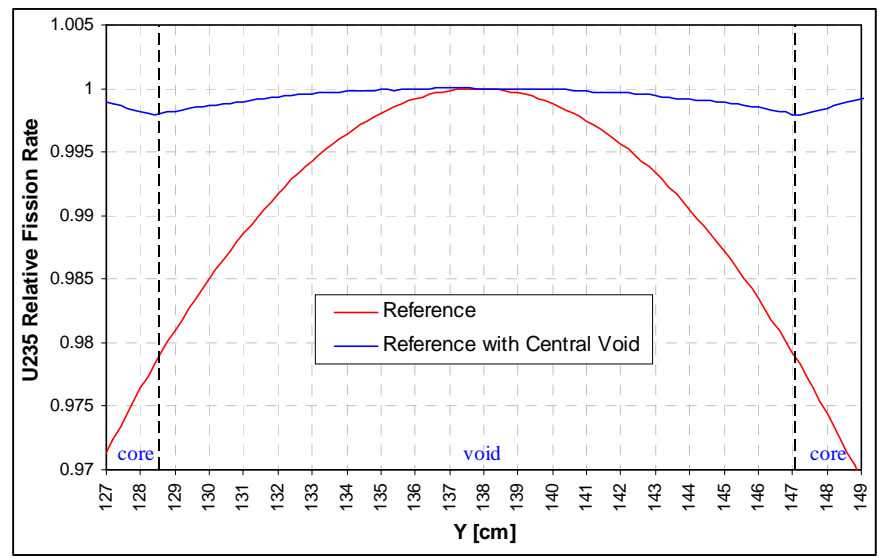

Figure 31. NS U-235 Fission Traverse inside the Void Region

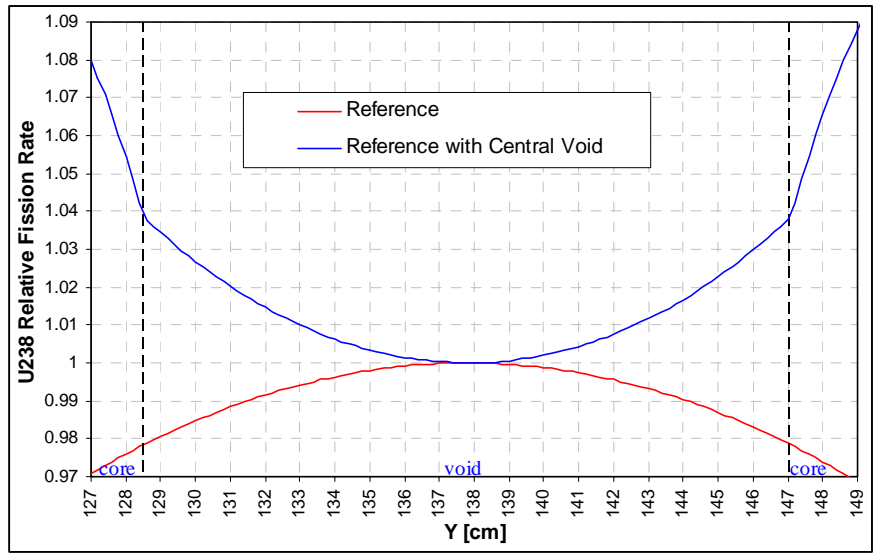

Figure 33. NS U-238 Fission Traverse inside the Void Region 


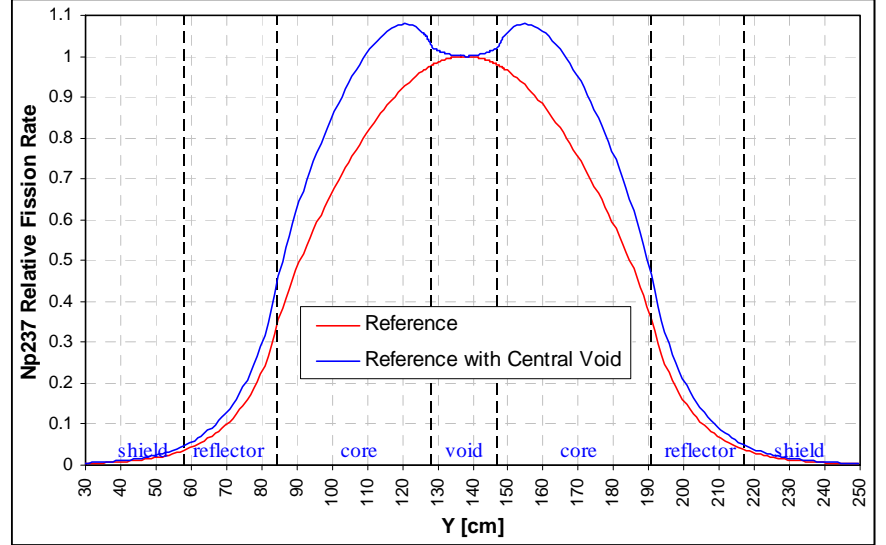

Figure 34. NS Np-237 Fission Traverse

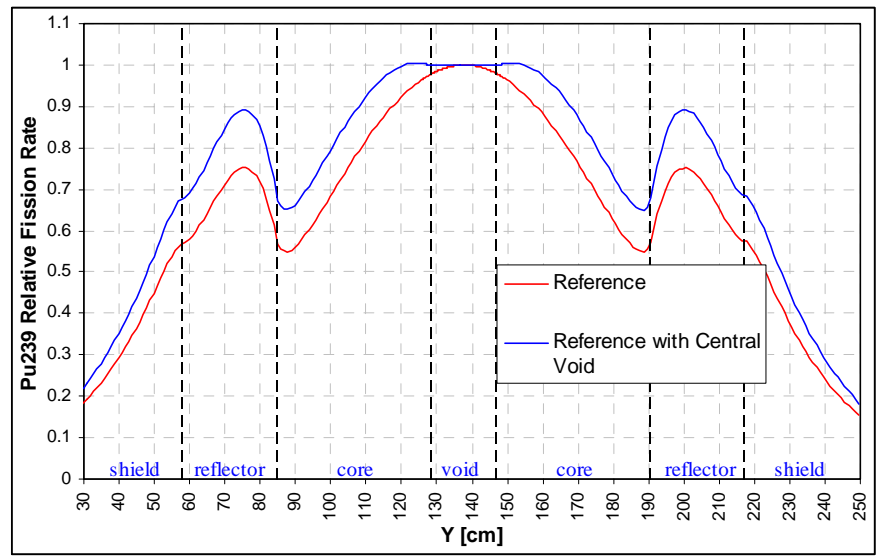

Figure 36. NS Pu-239 Fission Traverse

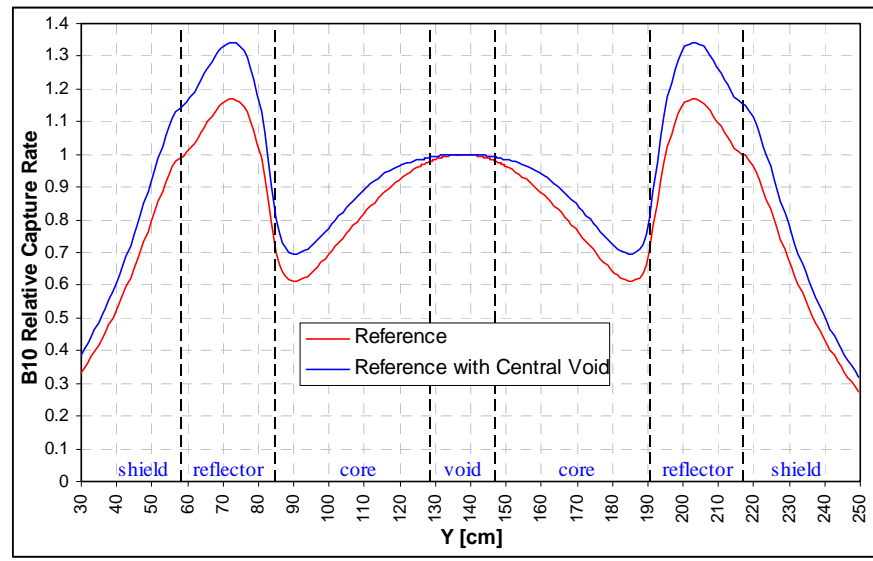

Figure 38. NS B-10 Capture Traverse

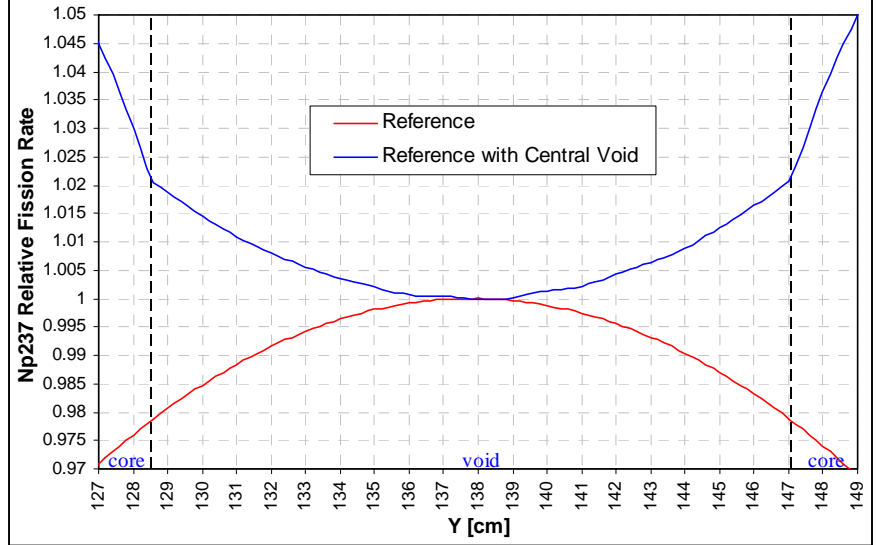

Figure 35. NS Np-237 Fission Traverse Inside the Void Region

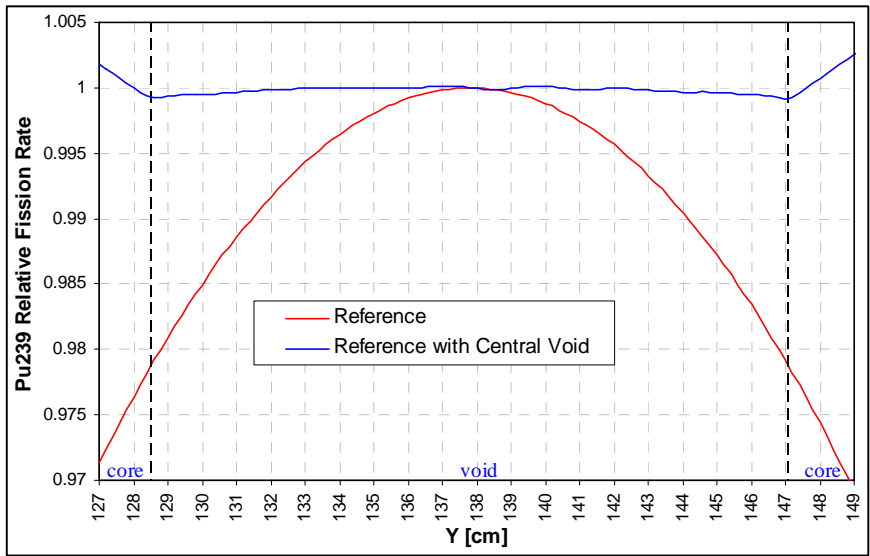

Figure 37. NS Pu-239 Fission Traverse Inside the Void Region

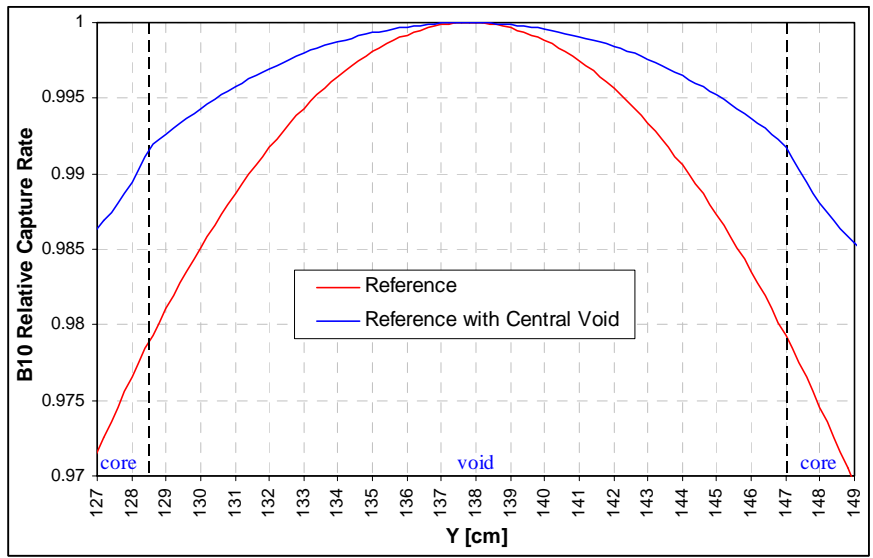

Figure 39. NS B-10 Capture Traverse Inside the Void Region 


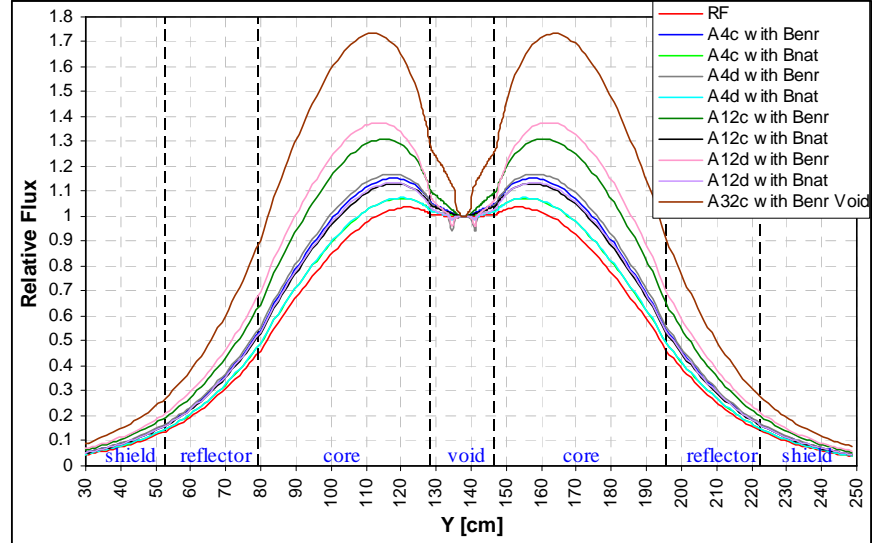

Figure 40. NS Flux Traverse

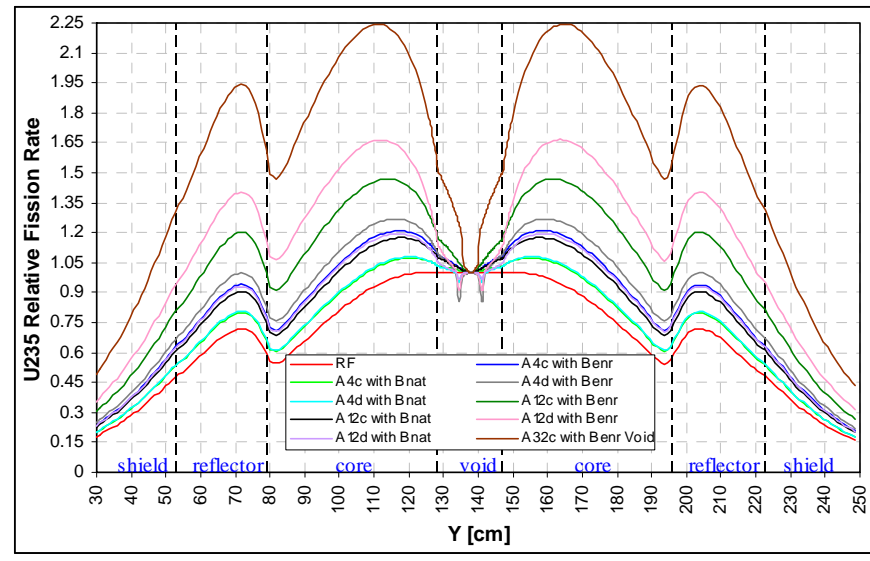

Figure 42. NS U-235 Fission Traverse

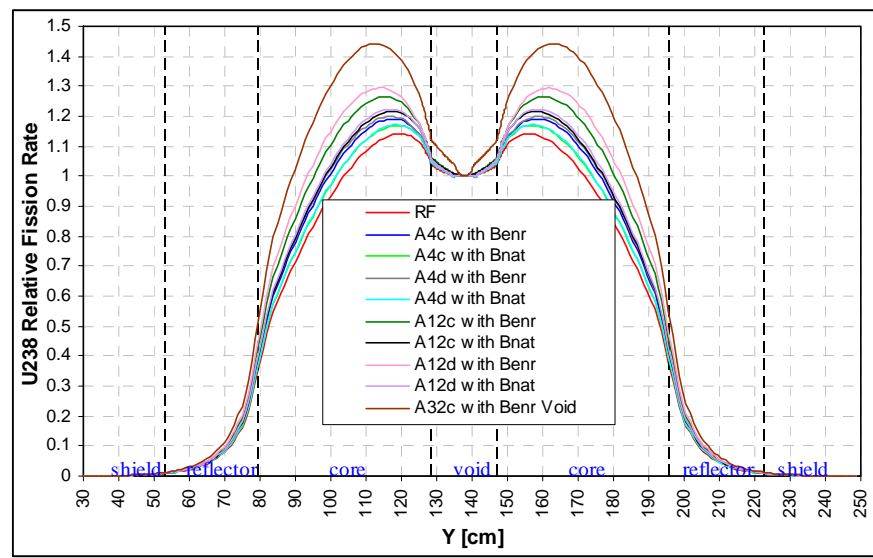

Figure 44. NS U-238 Fission Traverse

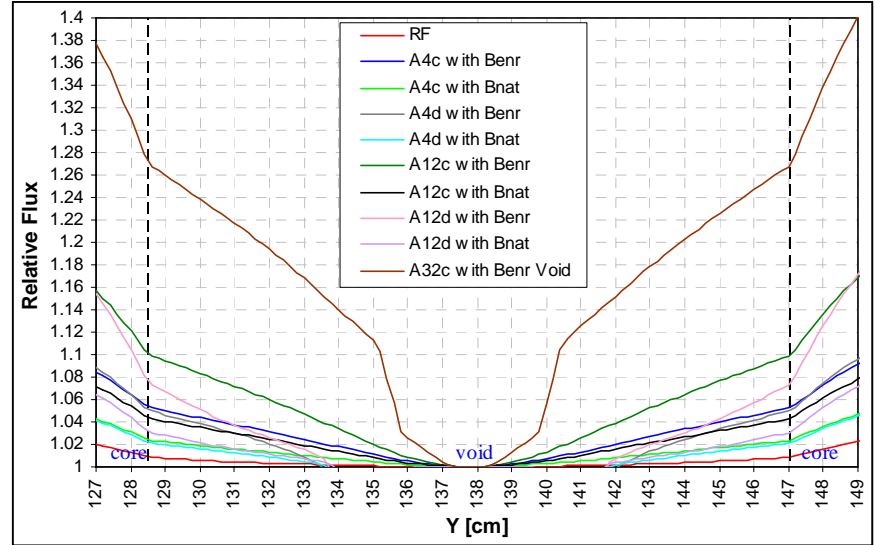

Figure 41. NS Flux Traverse Inside the Void Region

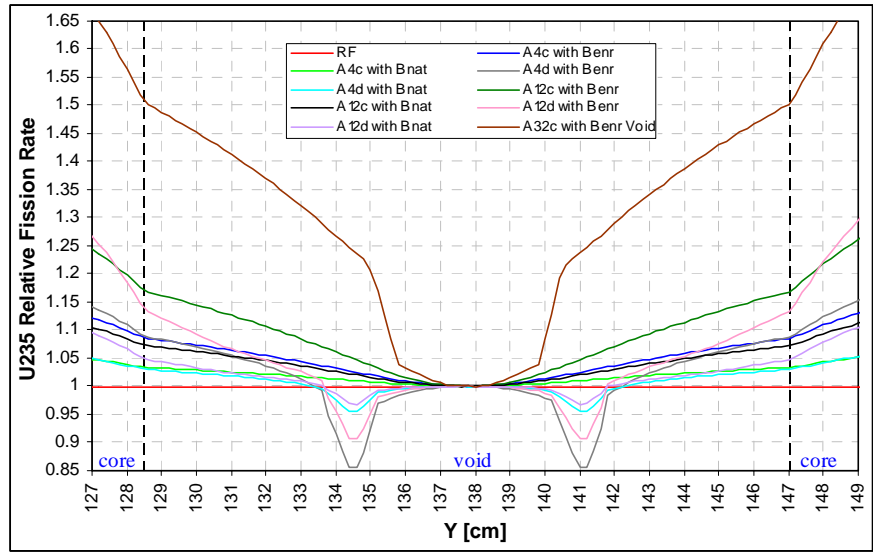

Figure 43. NS U-235 Fission Traverse Inside the Void Region

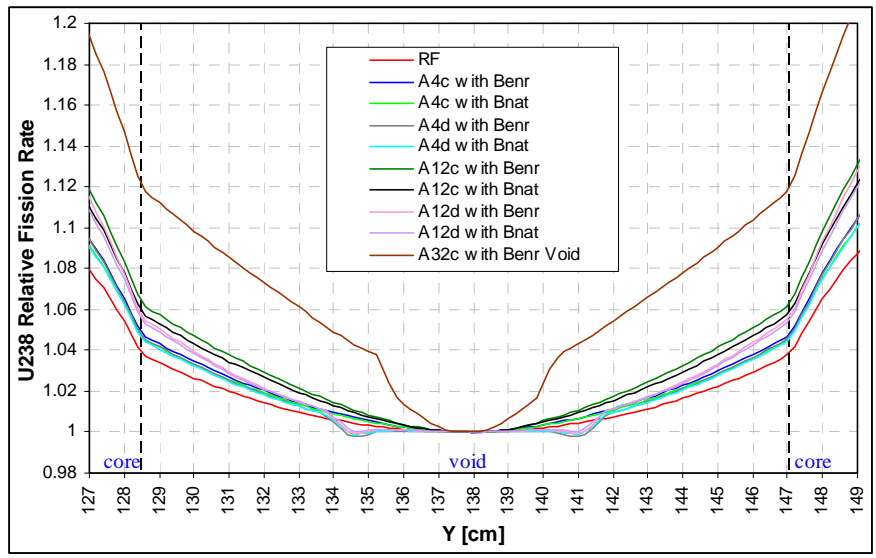

Figure 45. NS U-238 Fission Traverse Inside the Void Region 


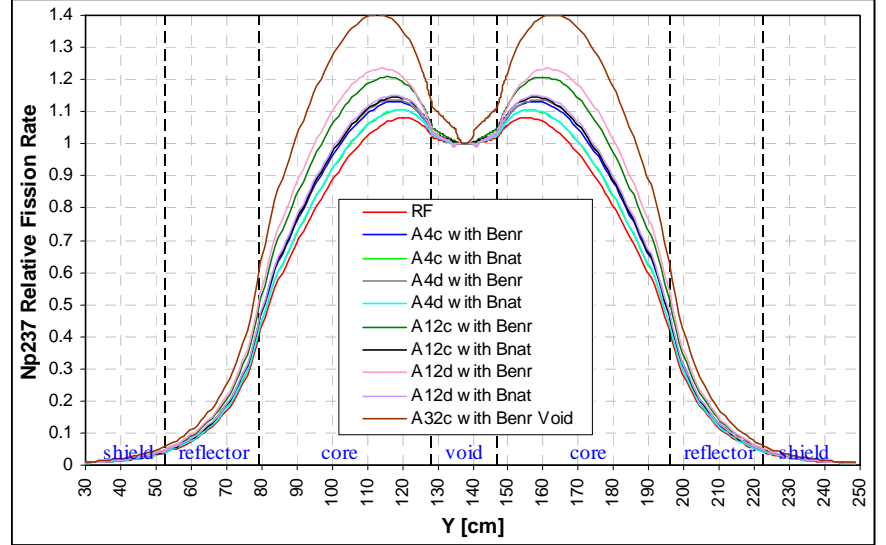

Figure 46. NS Np-237 Fission Traverse

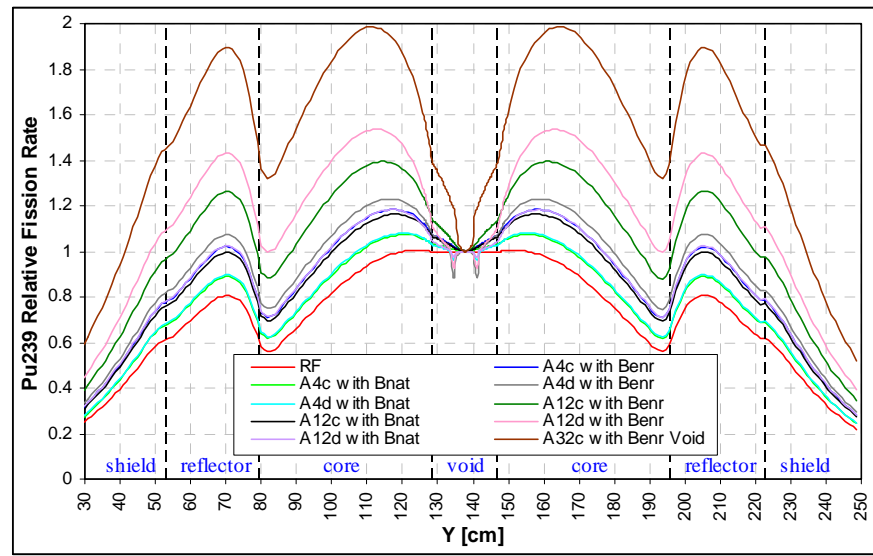

Figure 48. NS Pu-239 Fission Traverse

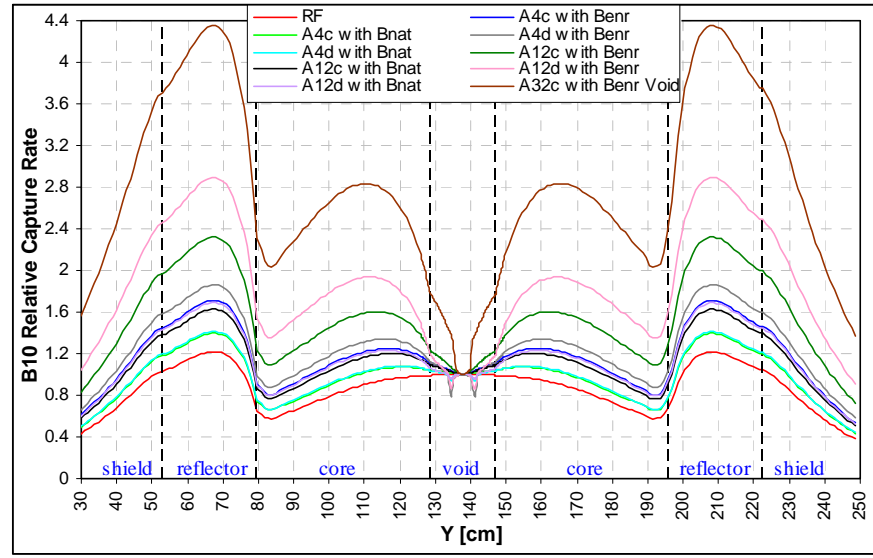

Figure 50. NS B-10 Capture Traverse

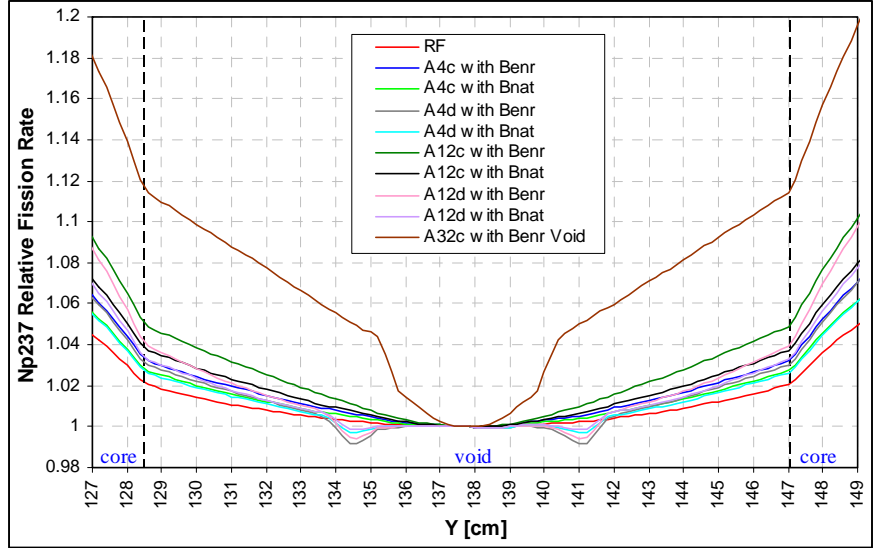

Figure 47. NS Np-237 Fission Traverse Inside the Void Region

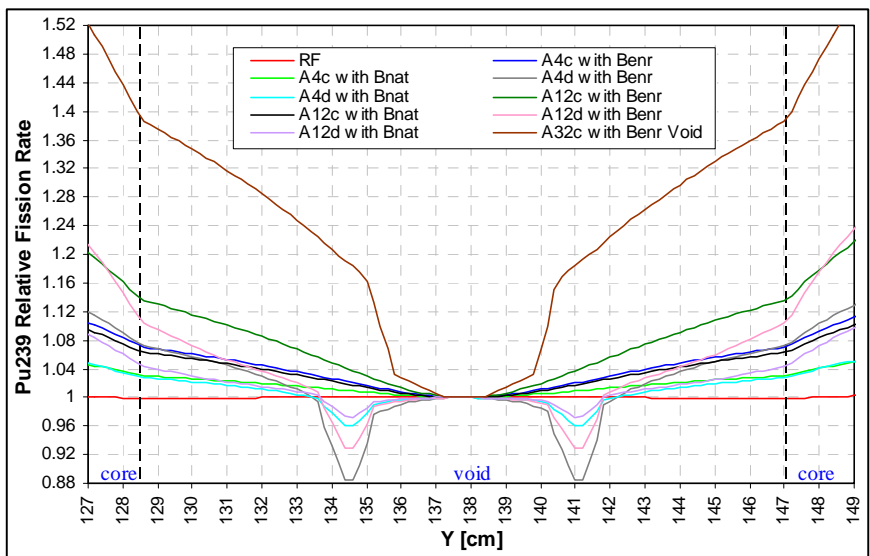

Figure 49. NS Pu-239 Fission Traverse Inside the Void Region

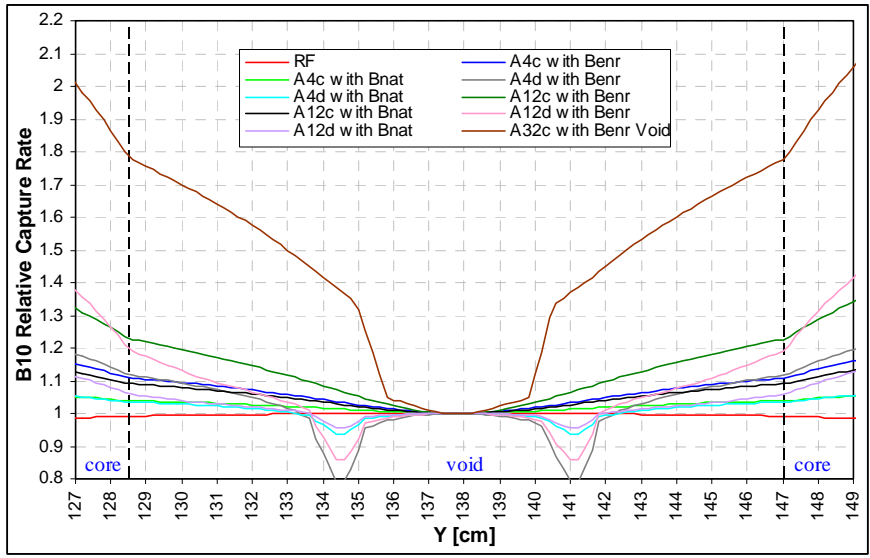

Figure 51. NS B-10 Capture Traverse Inside the Void Region 


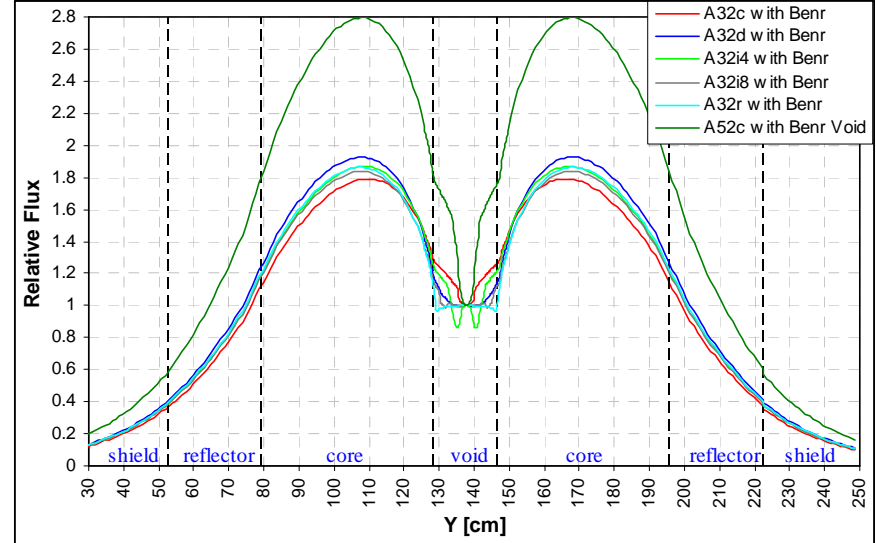

Figure 52. NS Flux Traverse

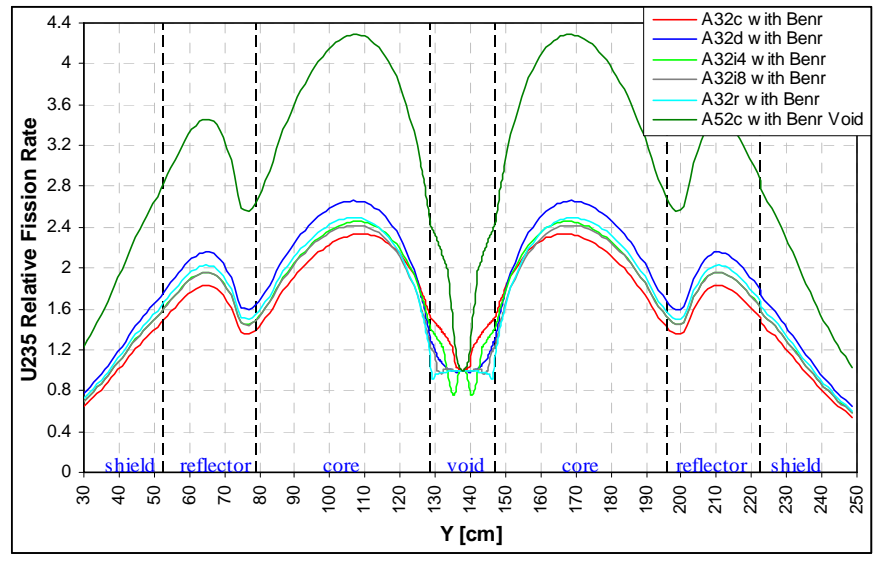

Figure 54. NS U-235 Fission Traverse

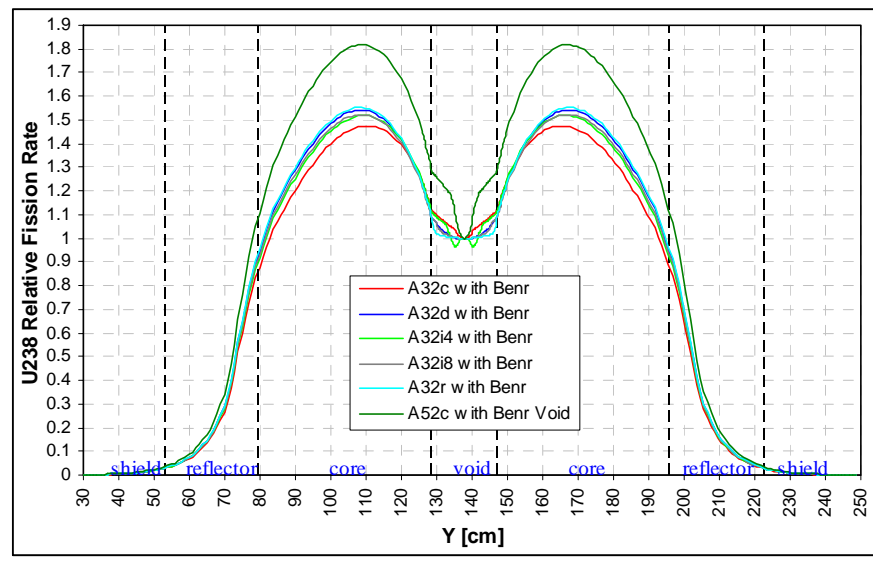

Figure 56. NS U-238 Fission Traverse

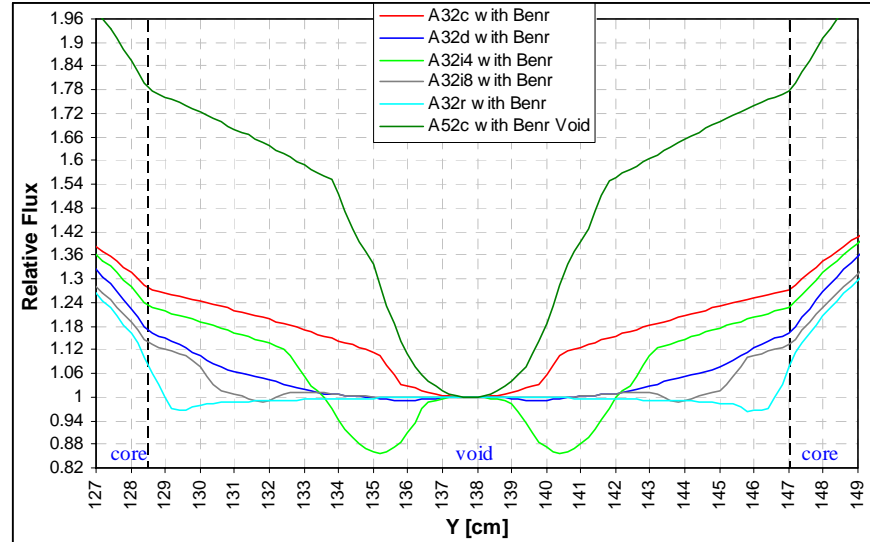

Figure 53. NS Flux Traverse Inside the Void Region

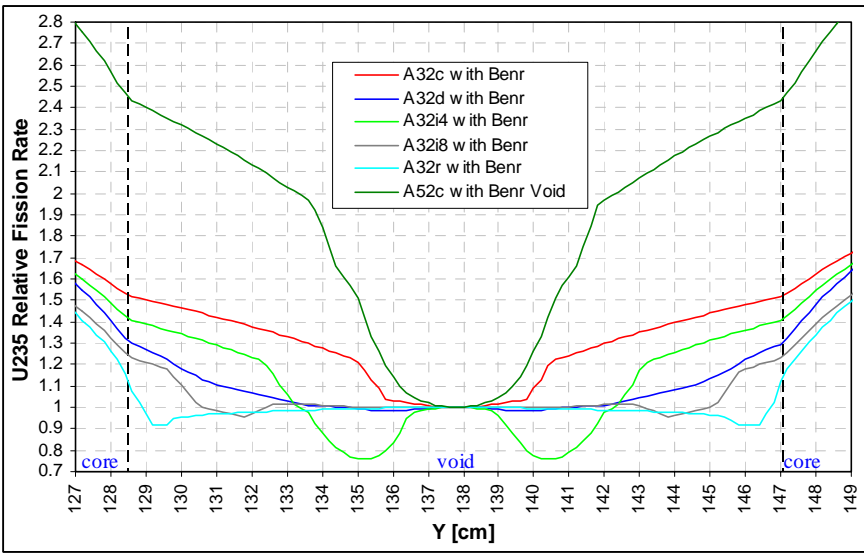

Figure 55. NS U-235 Fission Traverse Inside the Void Region

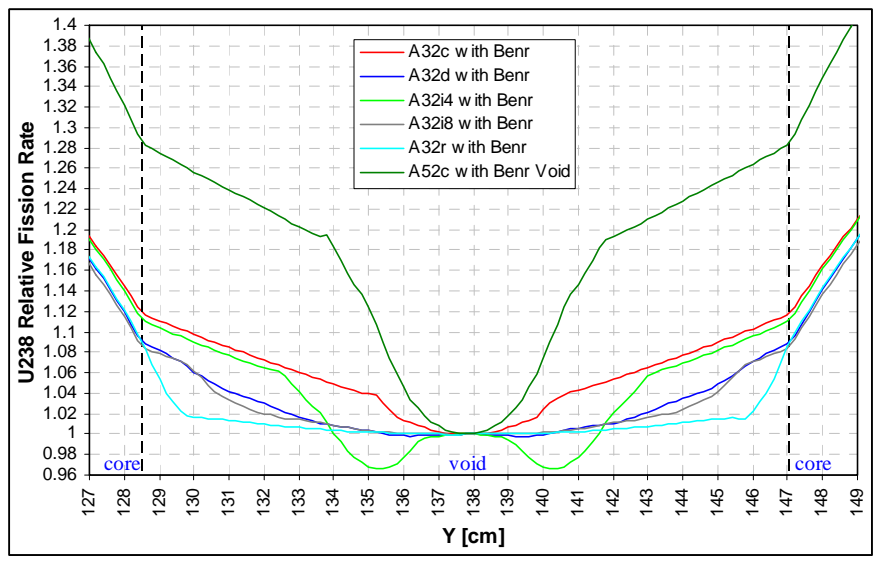

Figure 57. NS U-238 Fission Traverse Inside the Void Region 


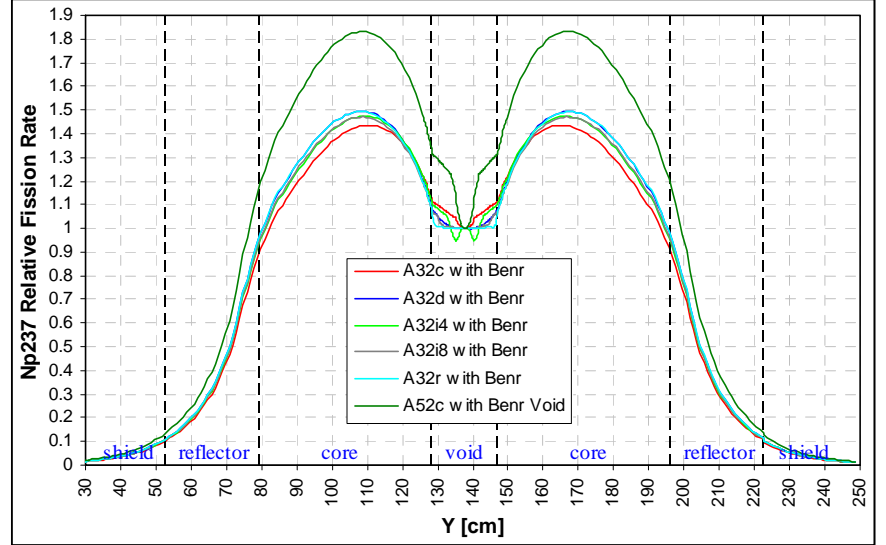

Figure 58. NS Np-237 Fission Traverse

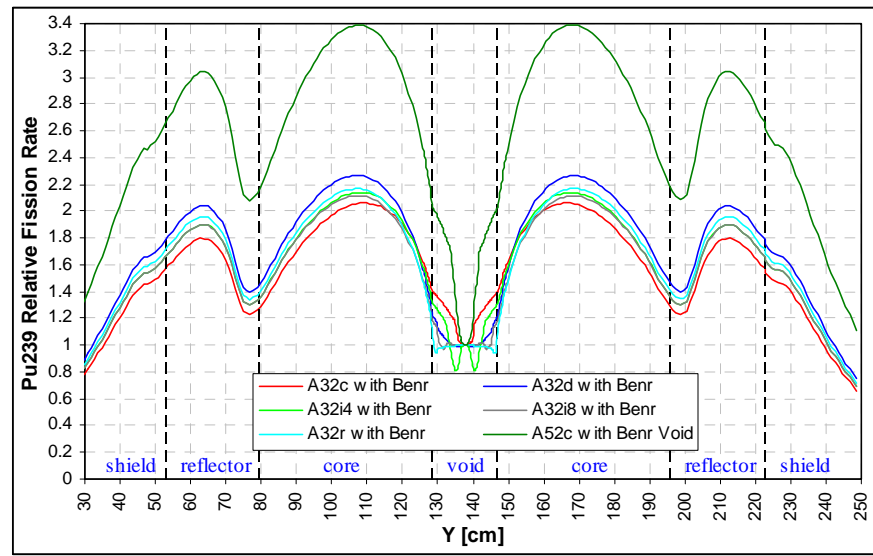

Figure 60. NS Pu-239 Fission Traverse

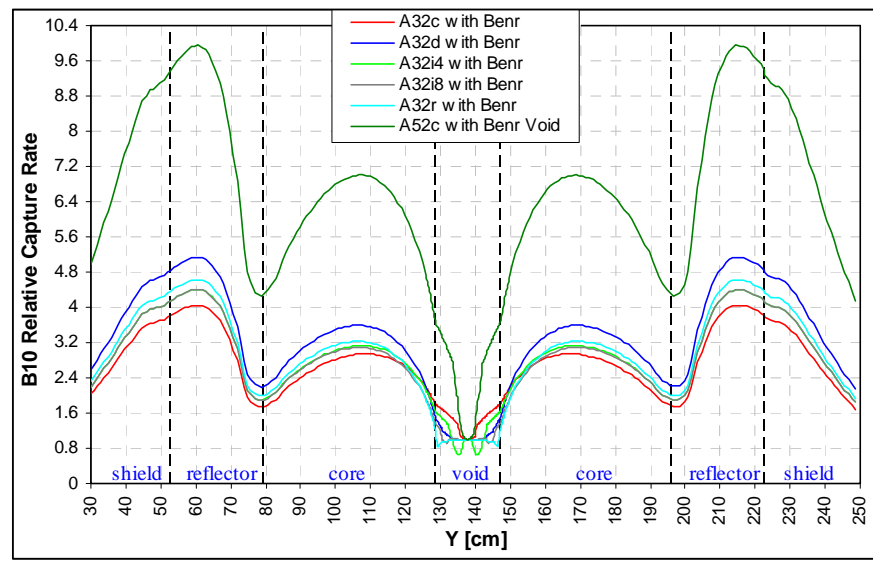

Figure 62. NS B-10 Capture Traverse

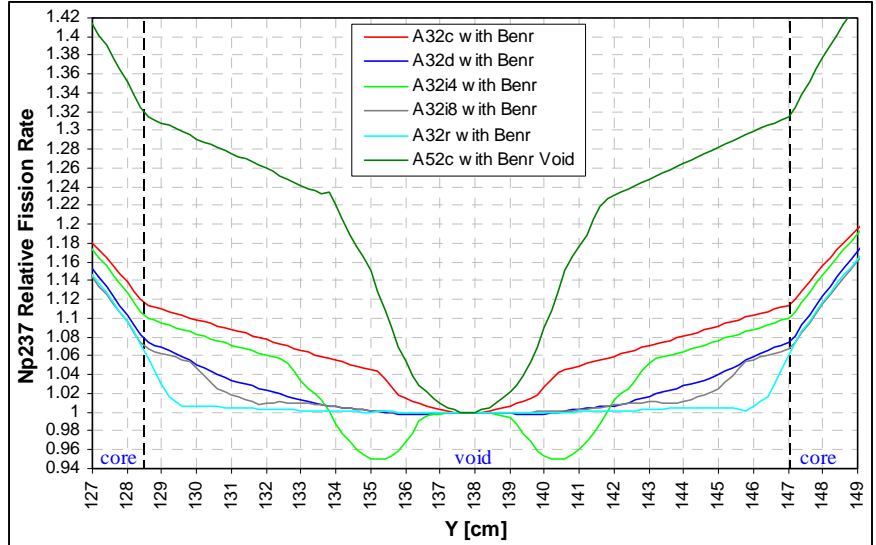

Figure 59. NS Np-237 Fission Traverse Inside the Void Region

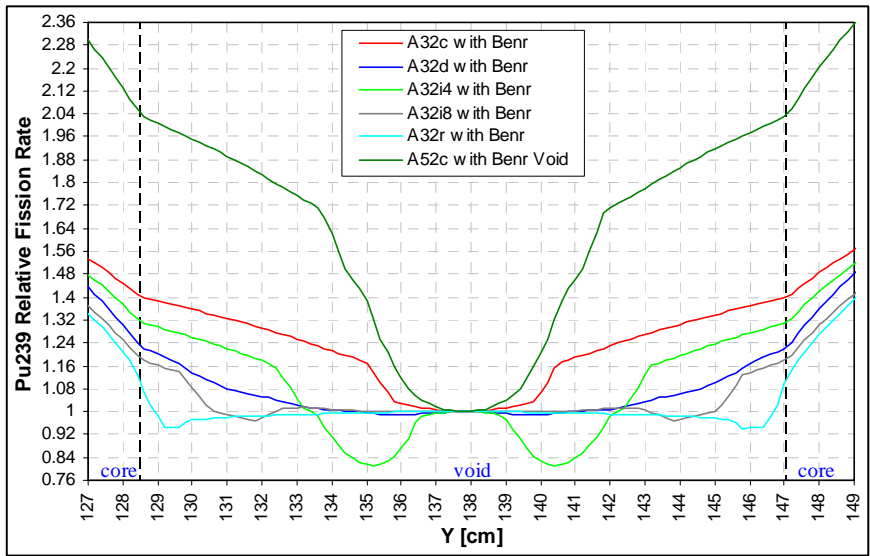

Figure 61. NS Pu-239 Fission Traverse Inside the Void Region

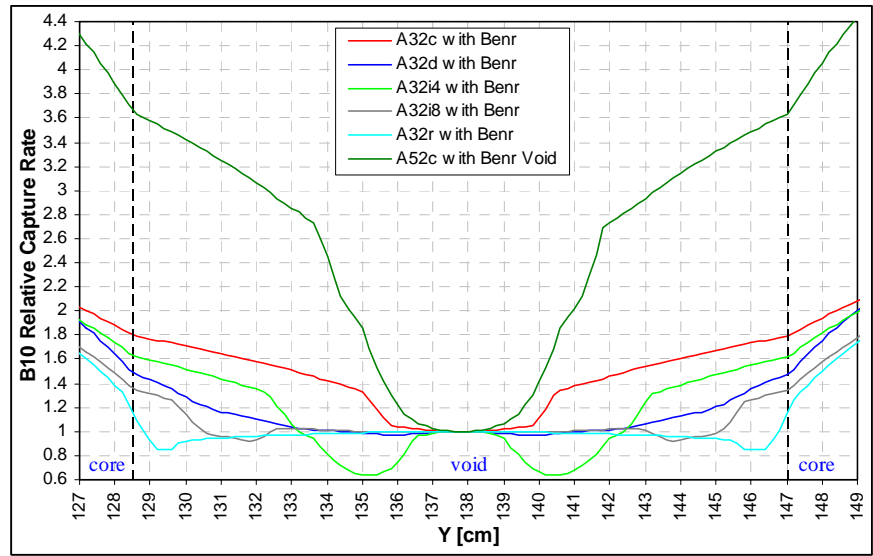

Figure 63. NS B-10 Capture Traverse Inside the Void Region 


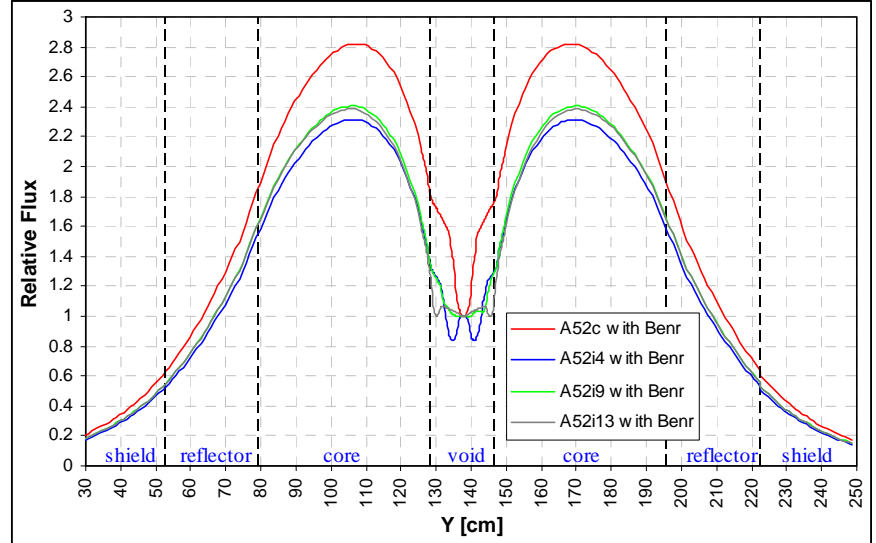

Figure 64. NS Flux Traverse

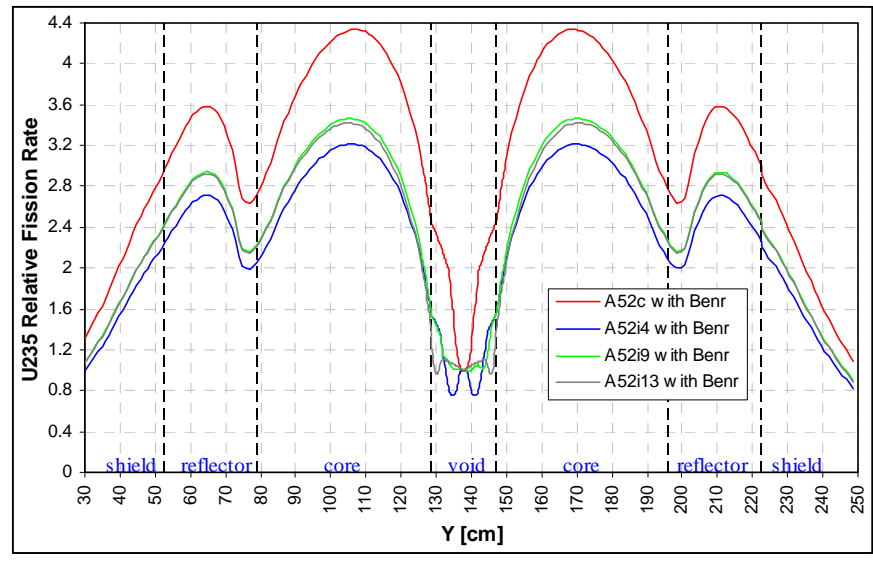

Figure 66. NS U-235 Fission Traverse

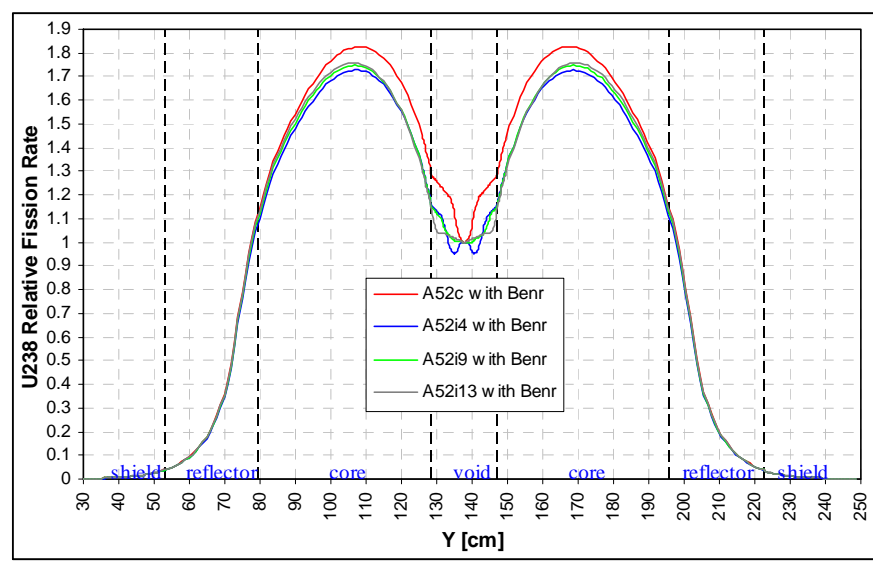

Figure 68. NS U-238 Fission Traverse

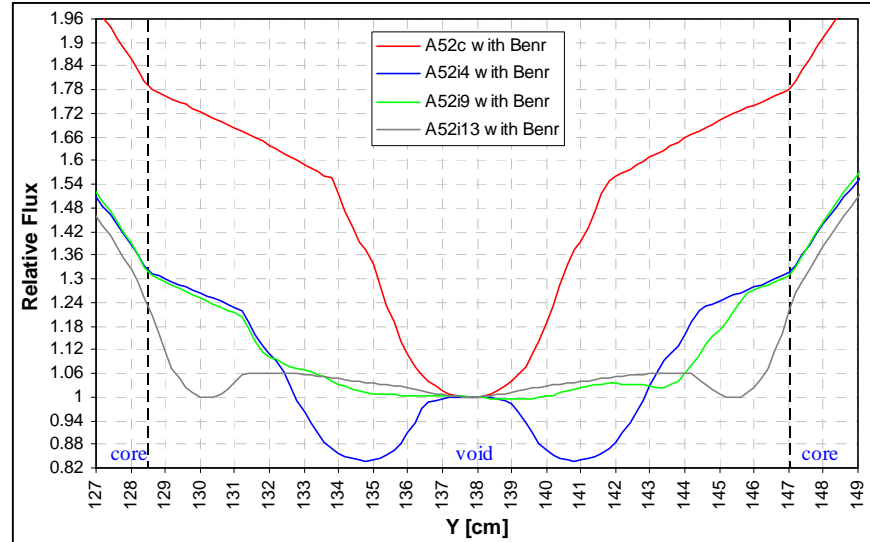

Figure 65. NS Flux Traverse Inside the Void Region

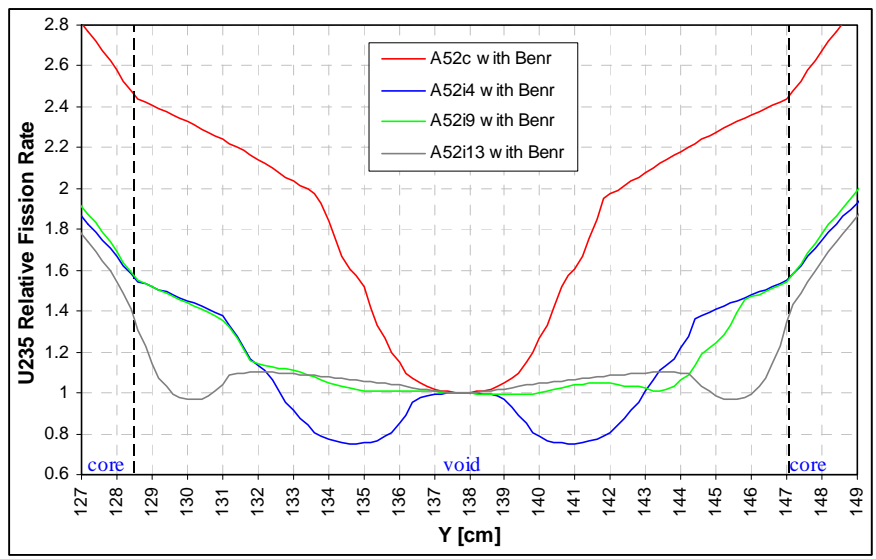

Figure 67. NS U-235 Fission Traverse Inside the Void Region

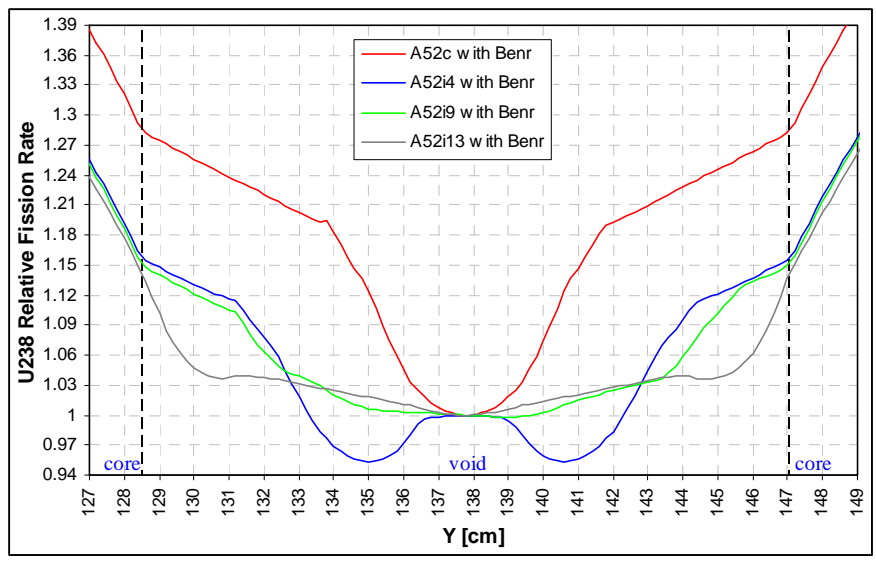

Figure 69. NS U-238 Fission Traverse Inside the Void Region 


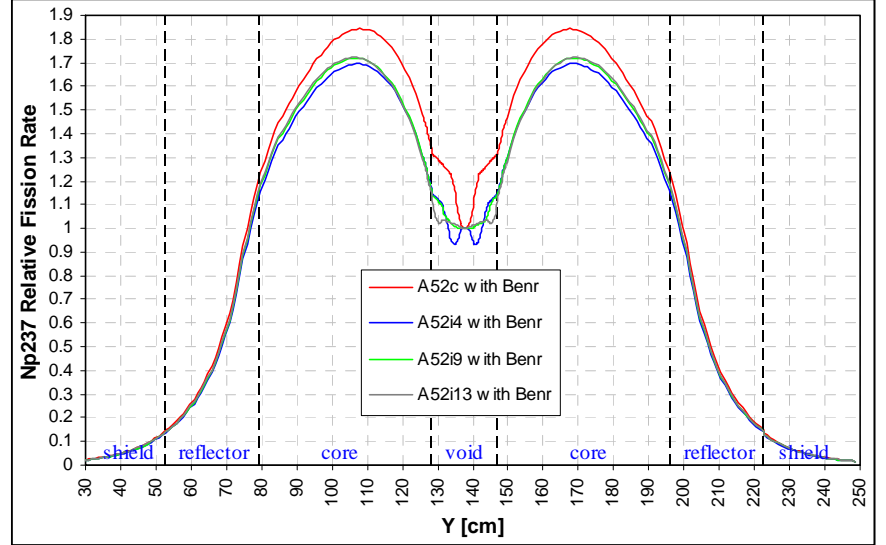

Figure 70. NS Np-237 Fission Traverse

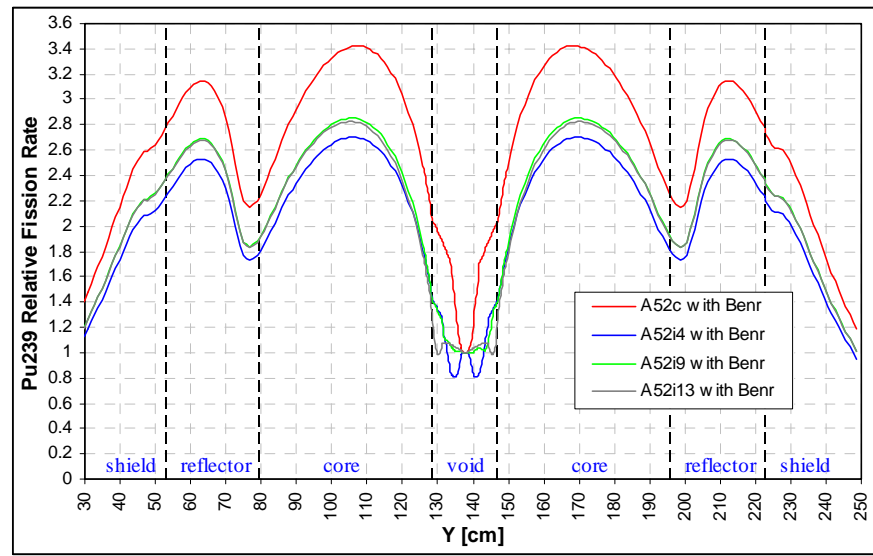

Figure 72. NS Pu-239 Fission Traverse

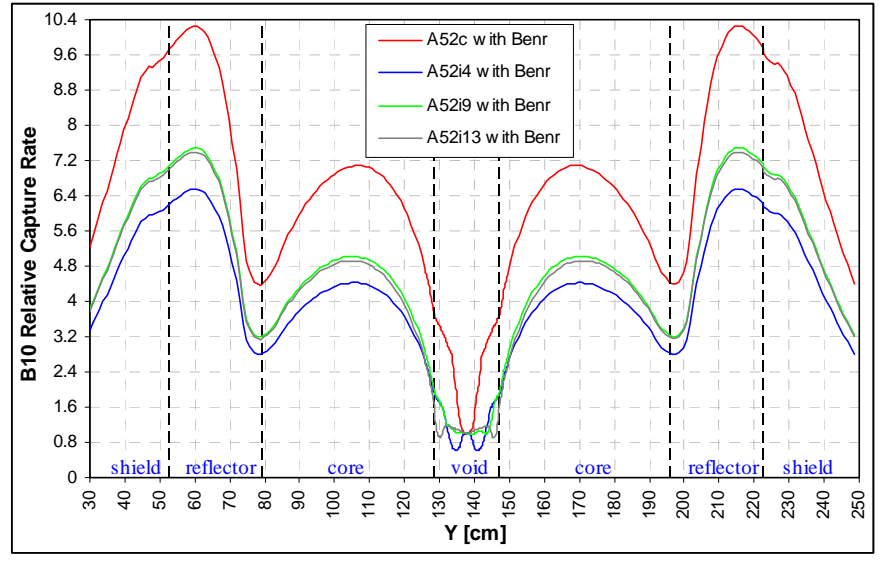

Figure 74. NS B-10 Capture Traverse

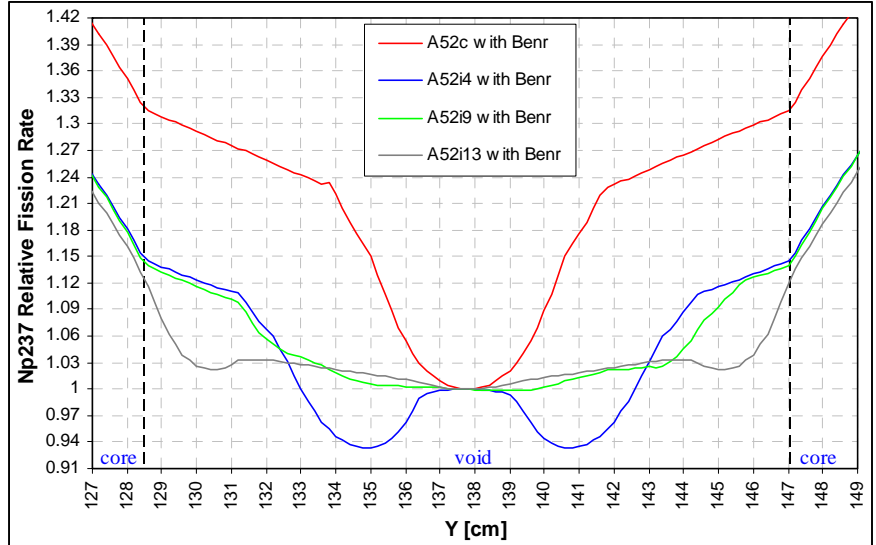

Figure 71. NS Np-237 Fission Traverse Inside the Void Region

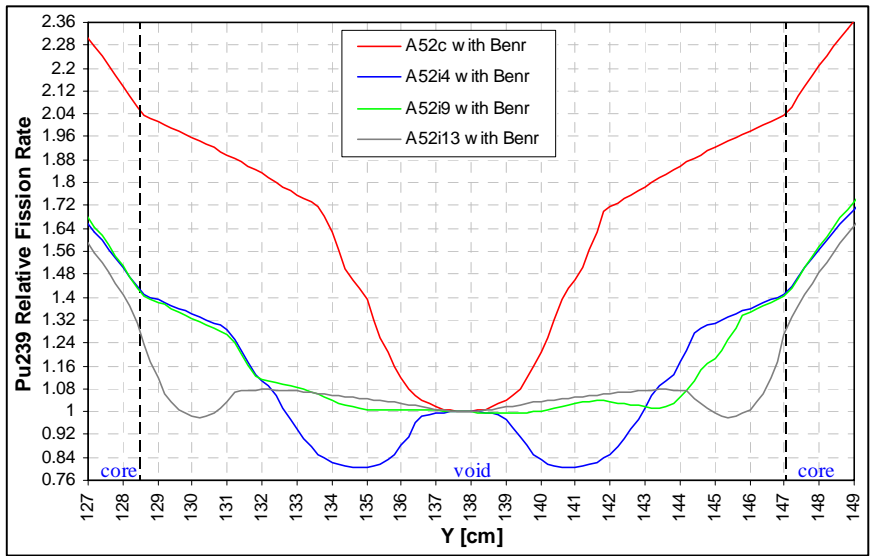

Figure 73. NS Pu-239 Fission Traverse Inside the Void Region

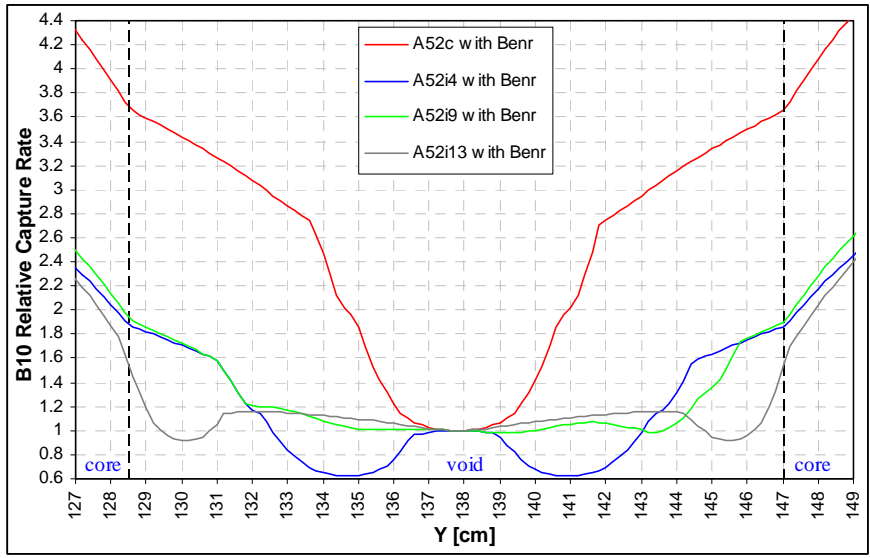

Figure 75. NS B-10 Capture Traverse Inside the Void Region 


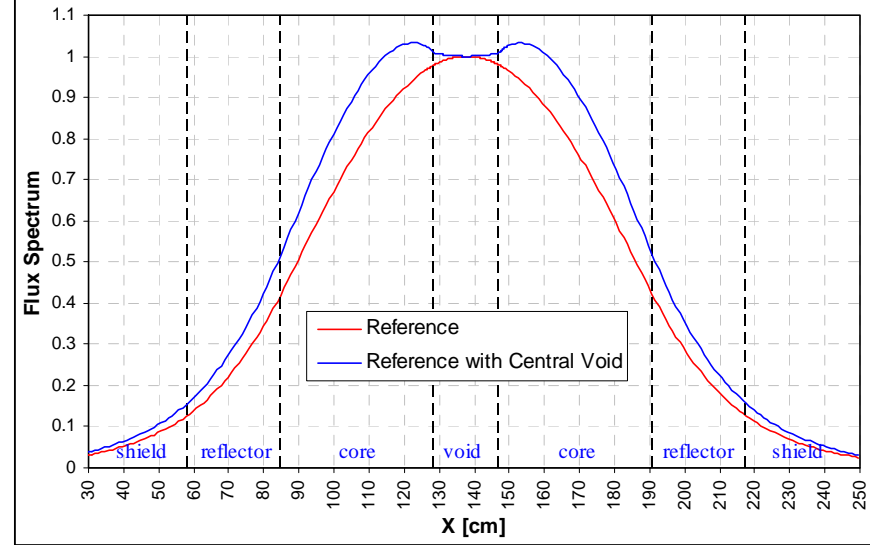

Figure 76. EW Flux Traverse

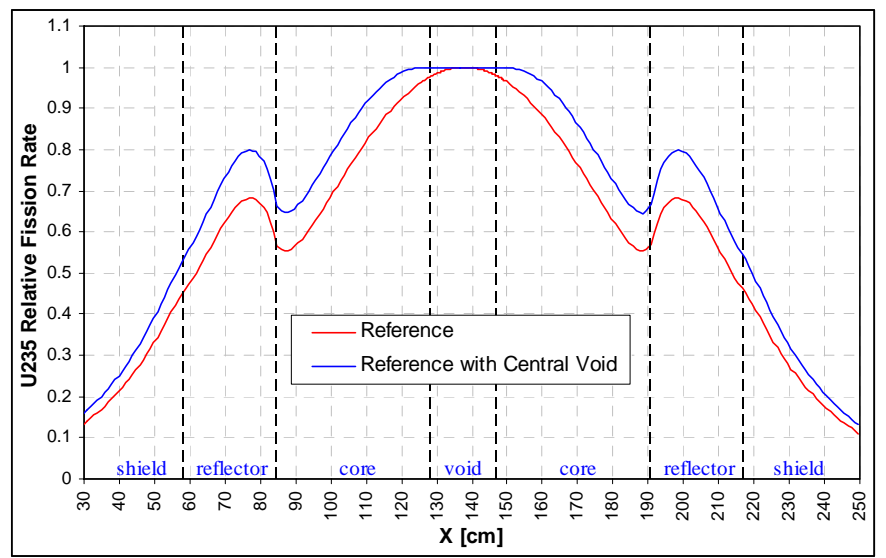

Figure 78. EW U-235 Fission Traverse

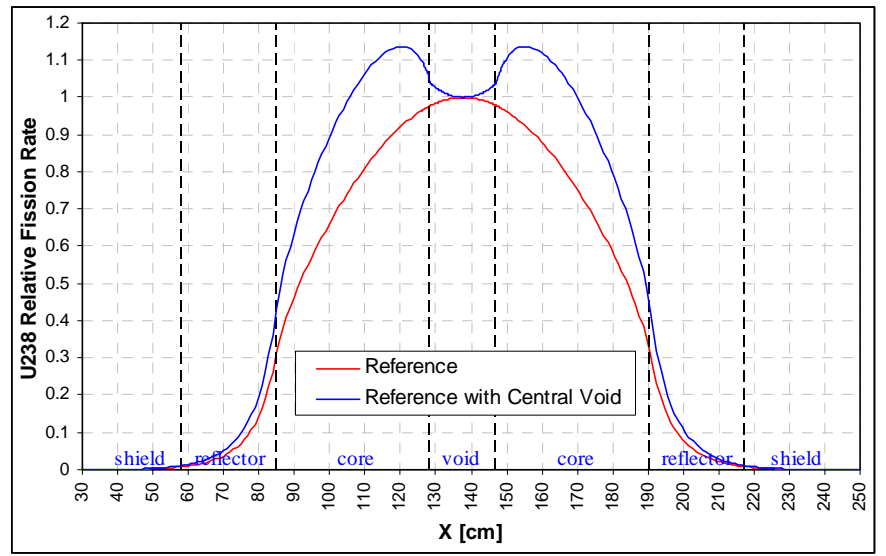

Figure 80. EW U-238 Fission Traverse

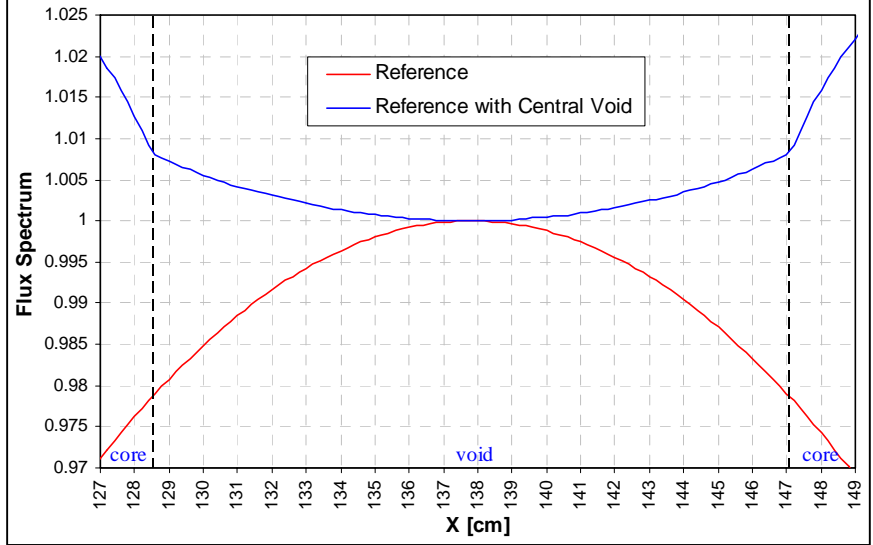

Figure 77. EW Flux Traverse Inside the Void Region

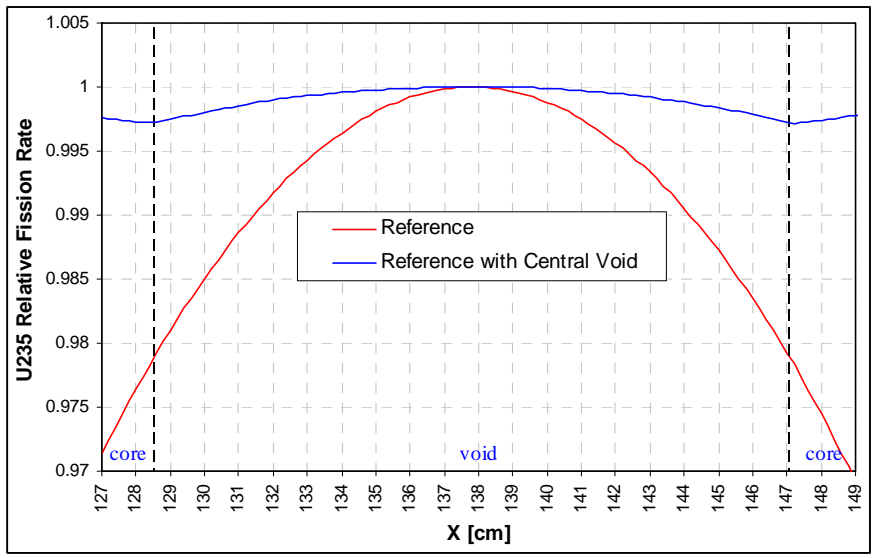

Figure 79. EW U-235 Fission Traverse Inside the Void Region

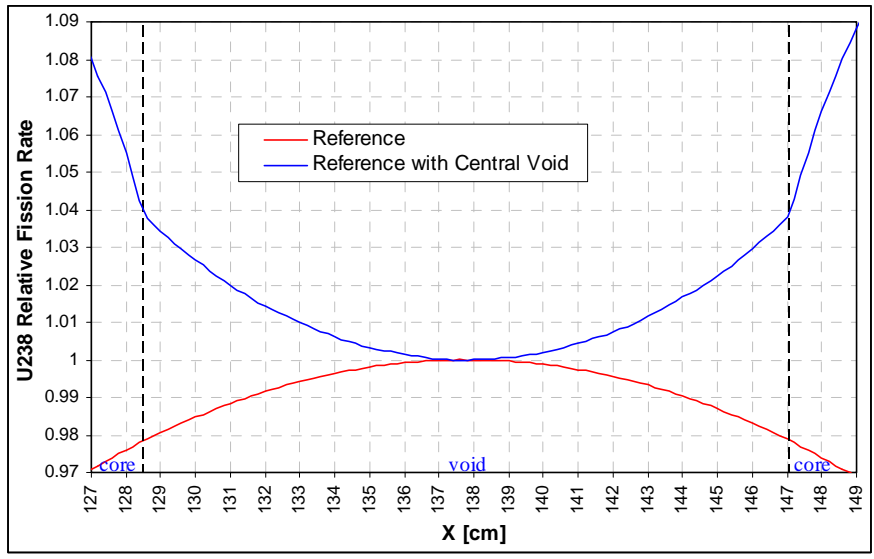

Figure 81. EW U-238 Fission Traverse Inside the Void Region 


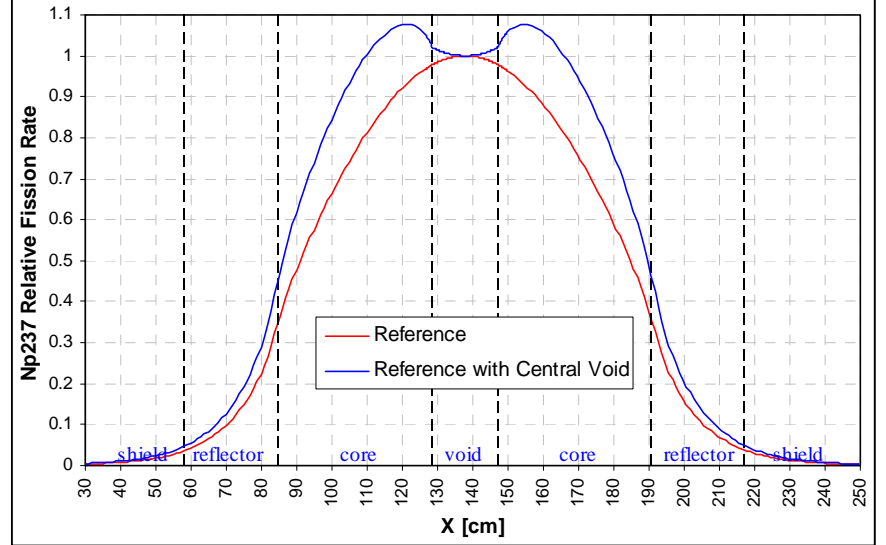

Figure 82. EW Np-237 Fission Traverse

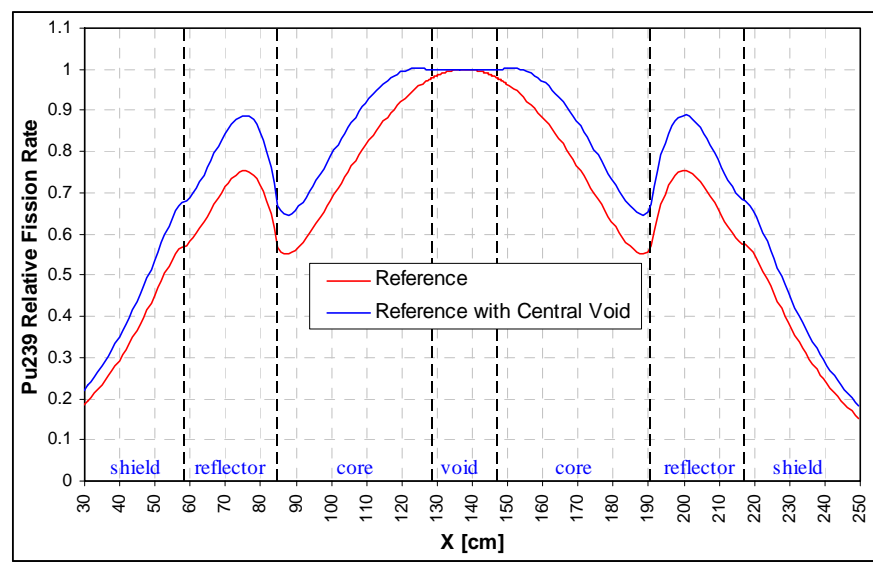

Figure 84. EW Pu-239 Fission Traverse

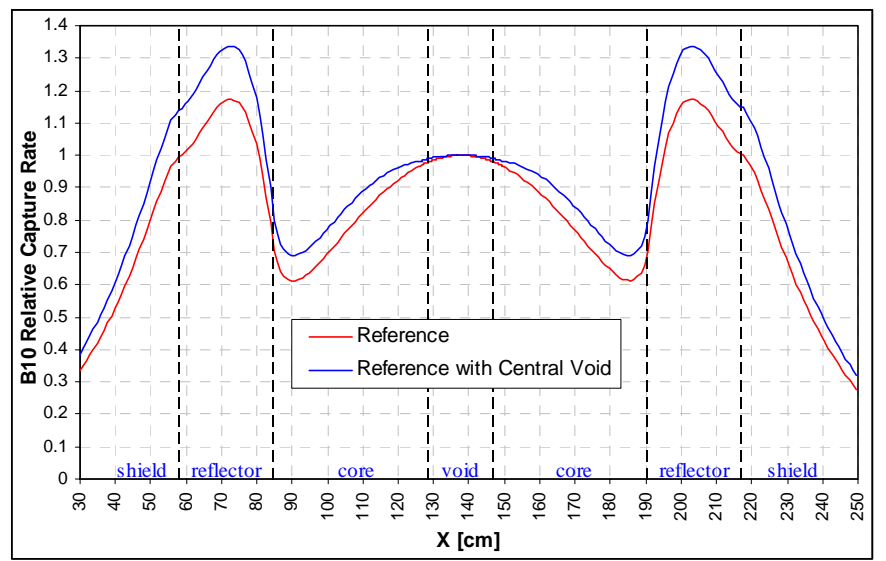

Figure 86. EW B-10 Capture Traverse

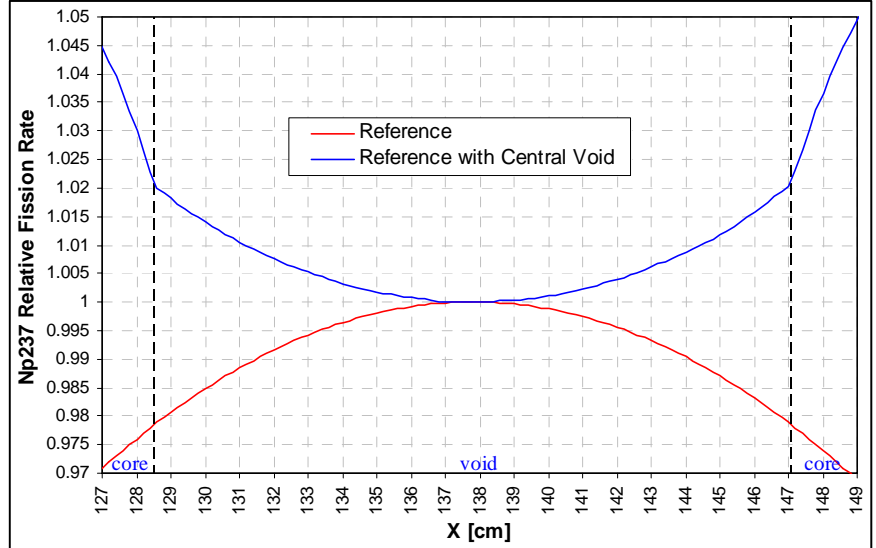

Figure 83. EW Np-237 Fission Traverse Inside the Void Region

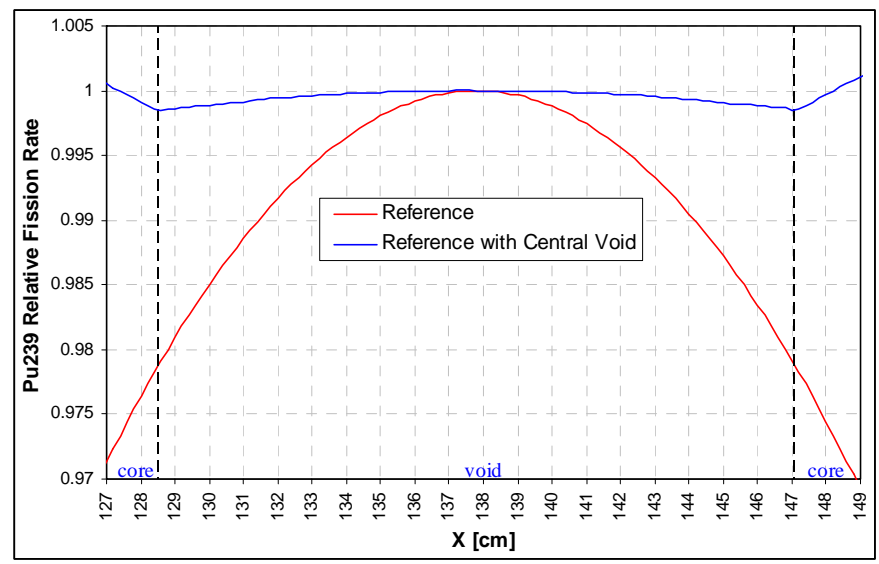

Figure 85. EW Pu-239 Fission Traverse Inside the Void Region

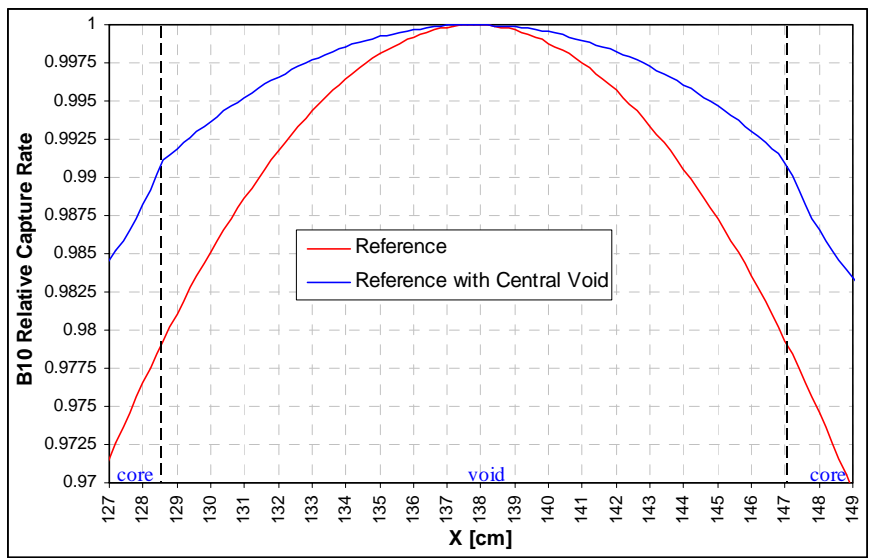

Figure 87. EW B-10 Capture Traverse Inside the Void Region 


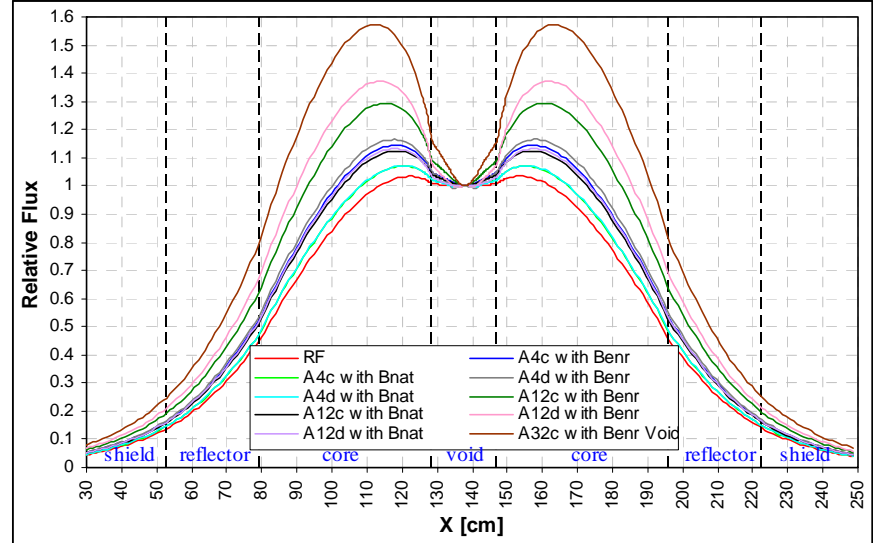

Figure 88. EW Flux Traverse

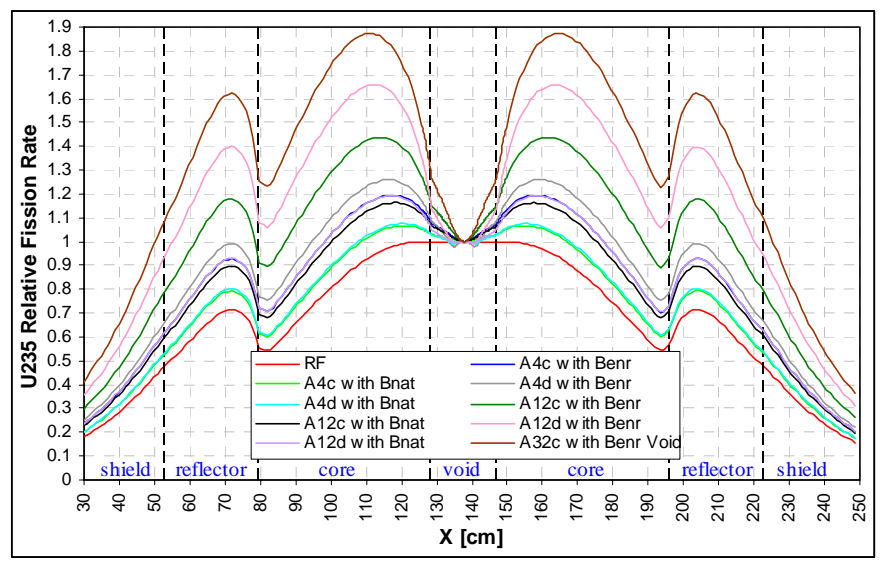

Figure 90. EW U-235 Fission Traverse

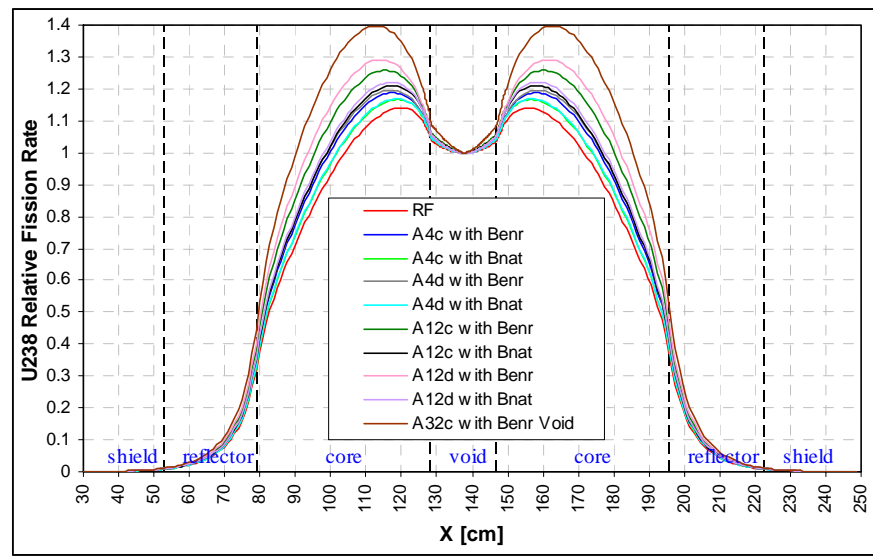

Figure 92. EW U-238 Fission Traverse

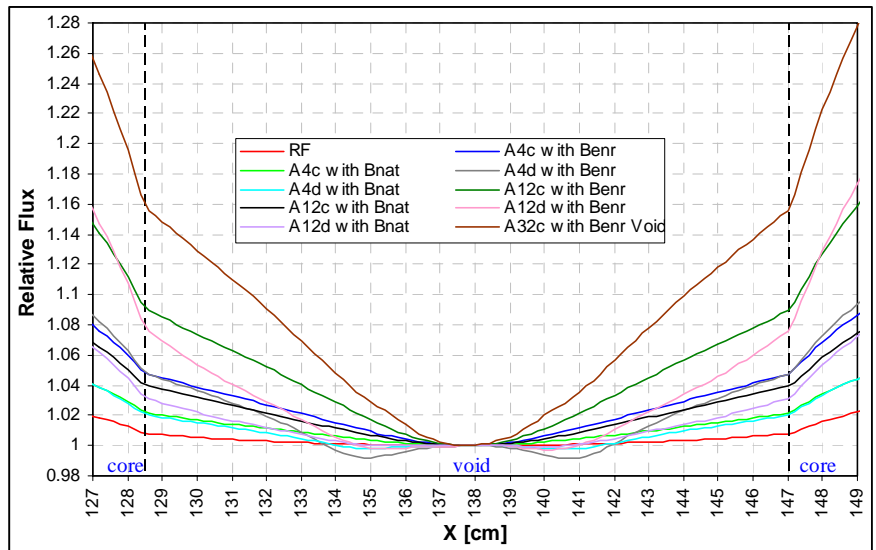

Figure 89. EW Flux Traverse Inside the Void Region

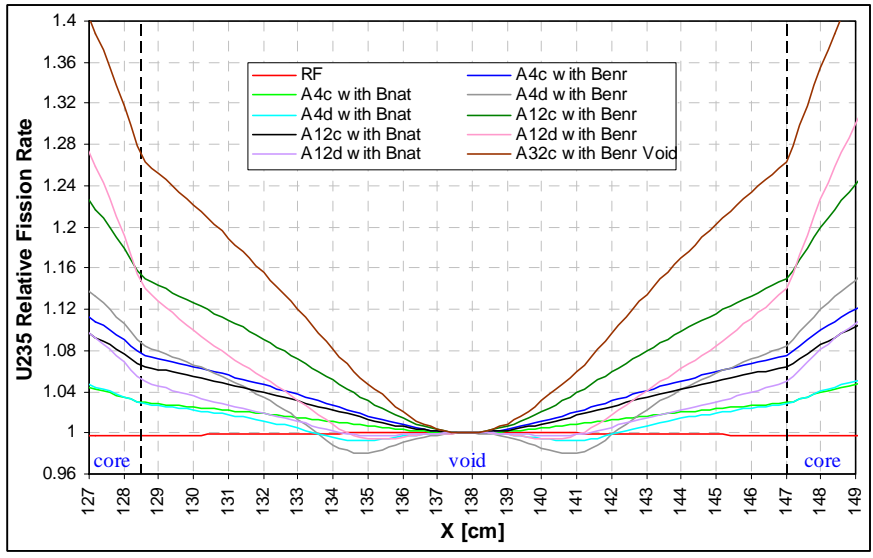

Figure 91. EW U-235 Fission Traverse Inside the Void Region

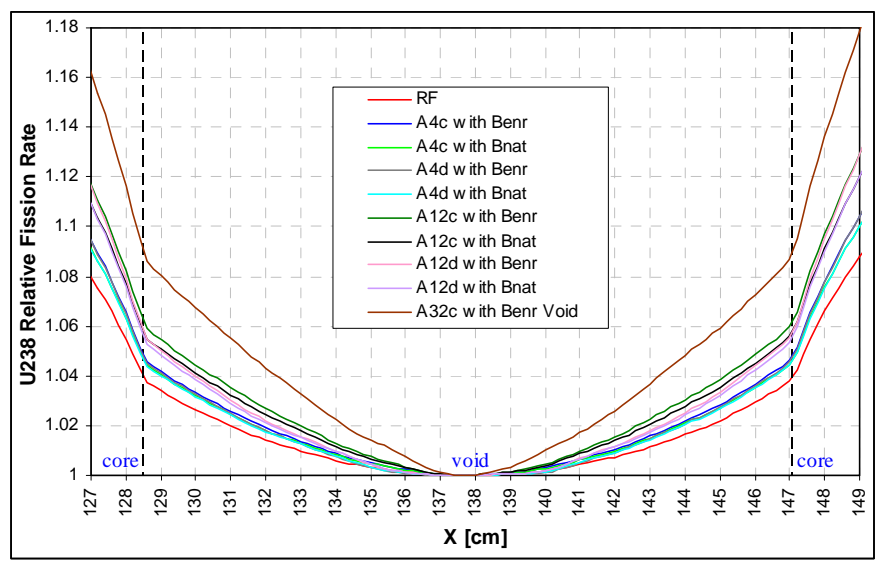

Figure 93. EW U-238 Fission Traverse Inside the Void Region 


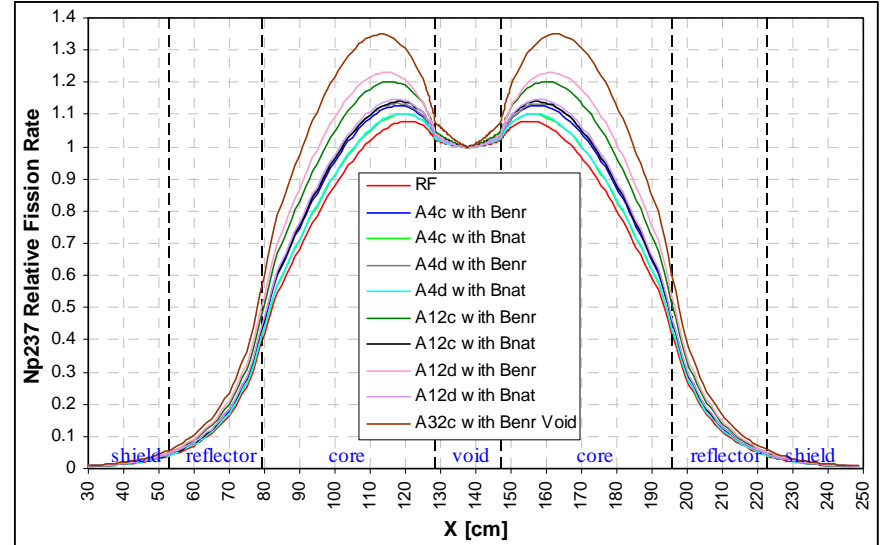

Figure 94. EW Np-237 Fission Traverse

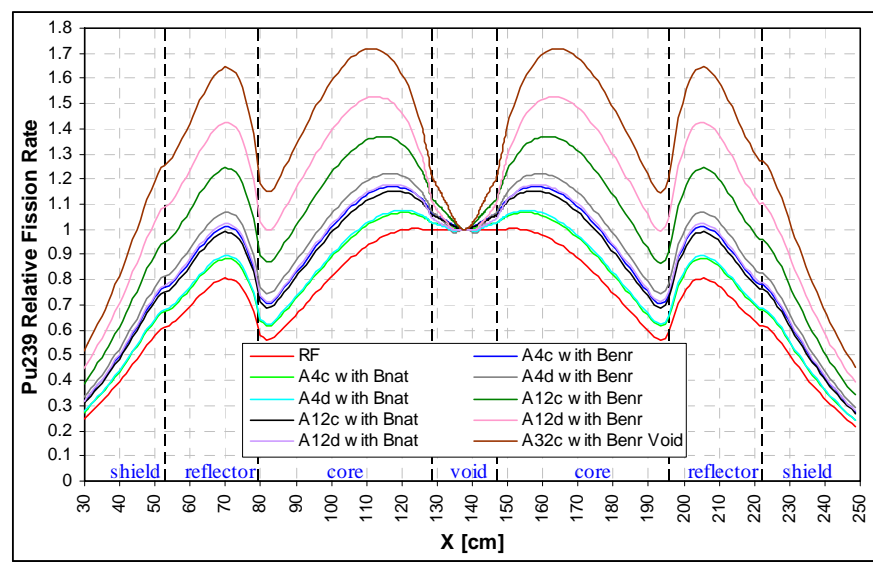

Figure 96. EW Pu-239 Fission Traverse

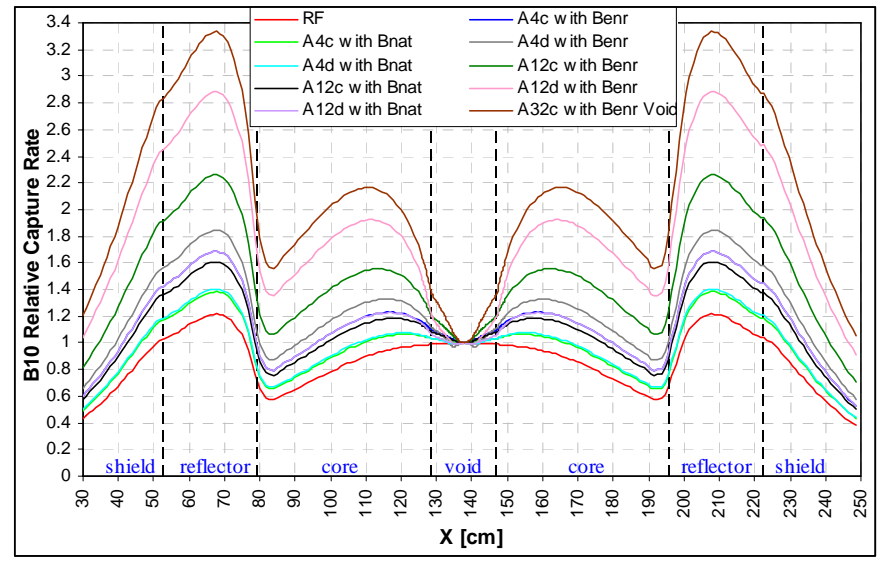

Figure 98. EW B-10 Capture Traverse

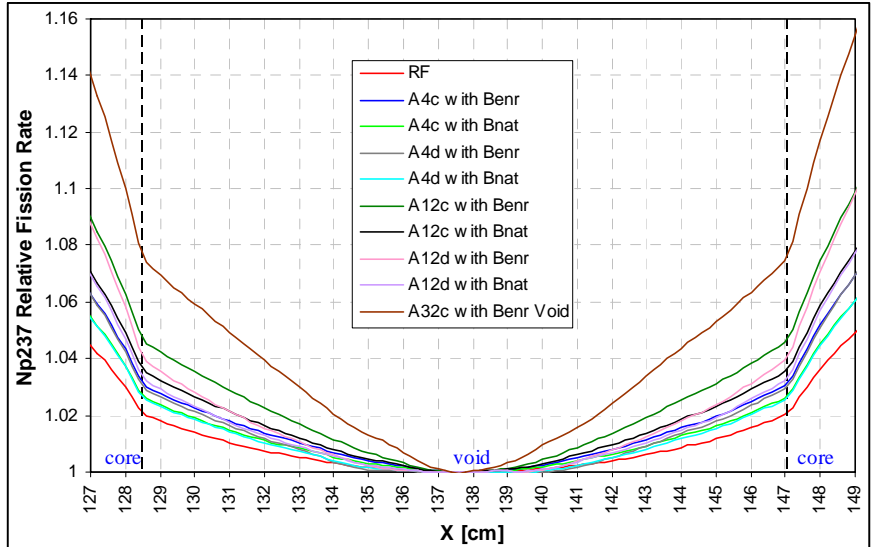

Figure 95. EW Np-237 Fission Traverse Inside the Void Region

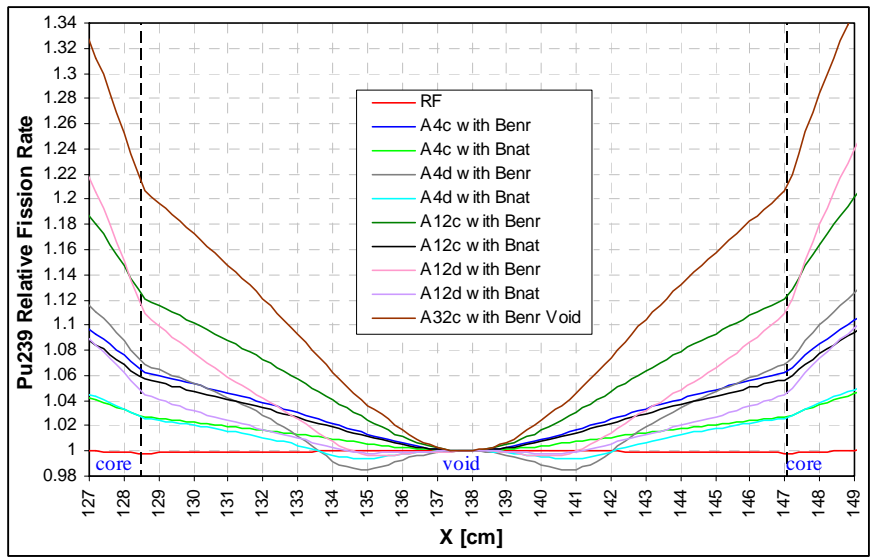

Figure 97. EW Pu-239 Fission Traverse Inside the Void Region

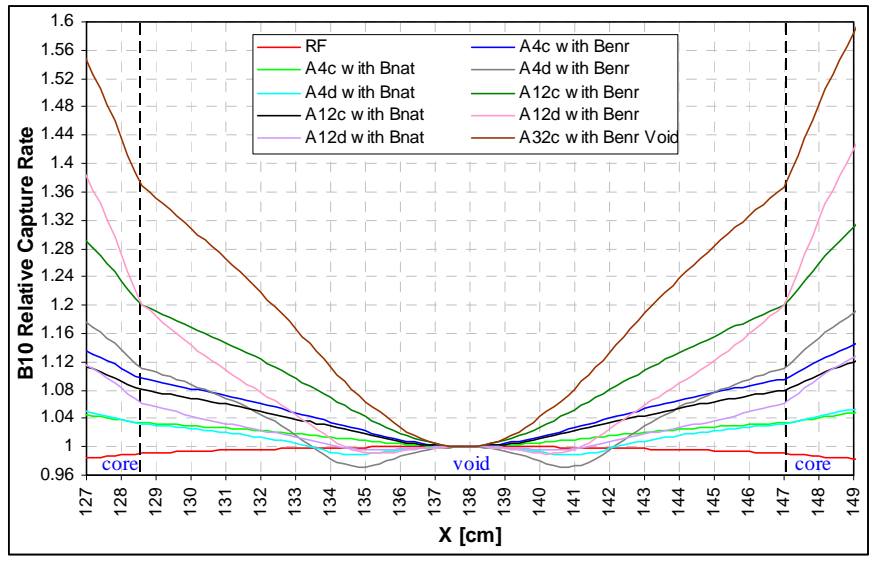

Figure 99. EW B-10 Capture Traverse Inside the Void Region 


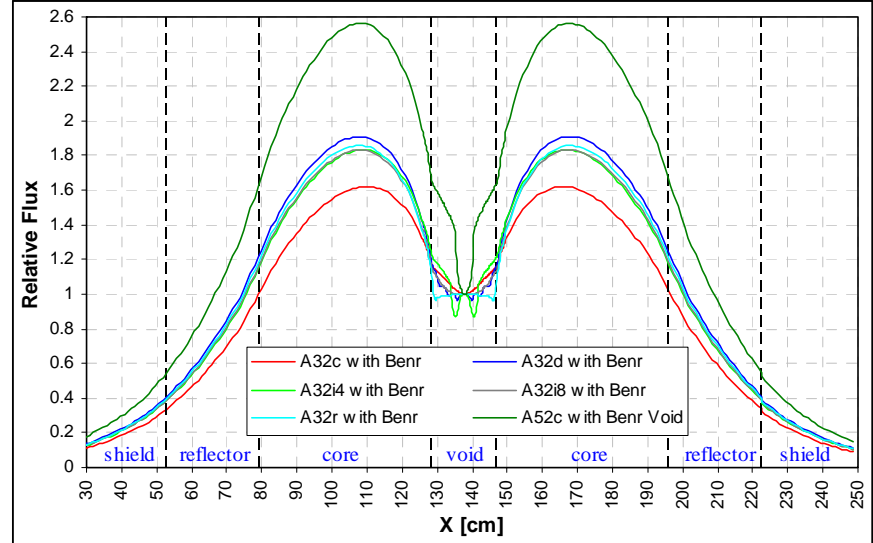

Figure 100. EW Flux Traverse

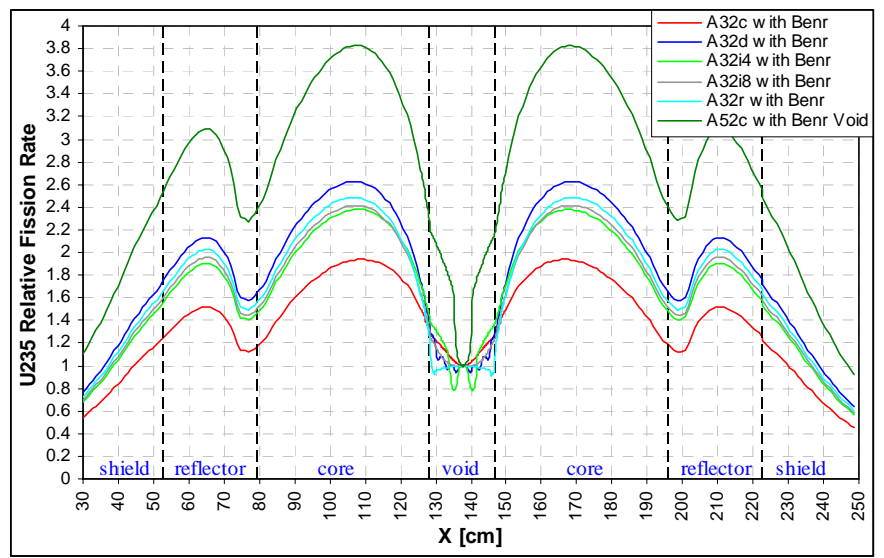

Figure 102. EW U-235 Fission Traverse

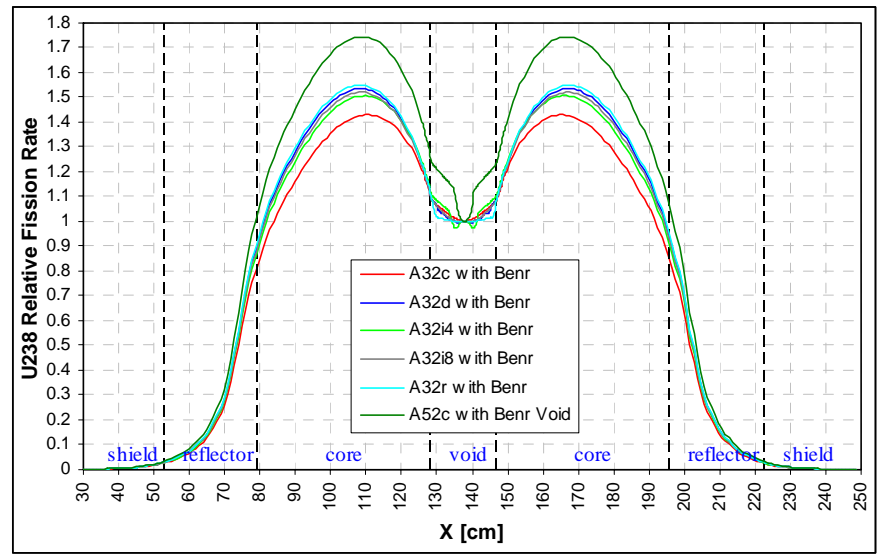

Figure 104. EW U-238 Fission Traverse

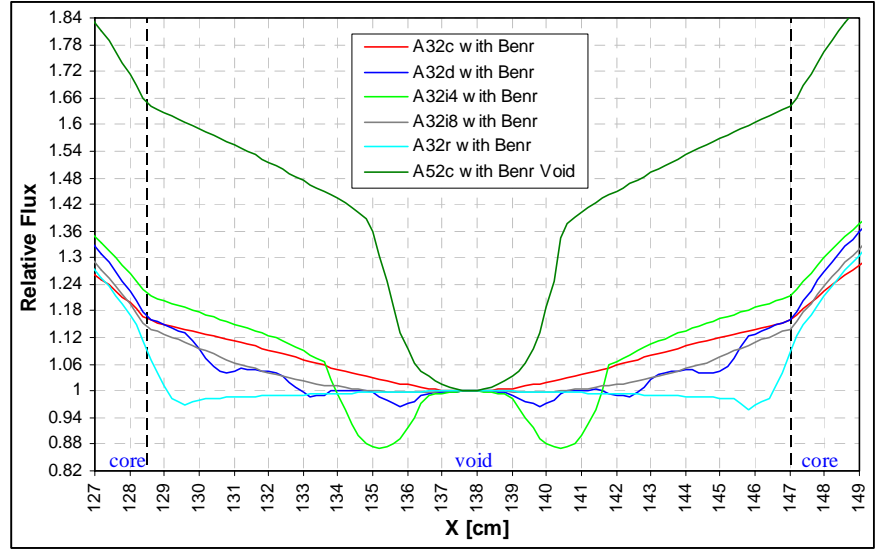

Figure 101. EW Flux Traverse Inside the Void Region

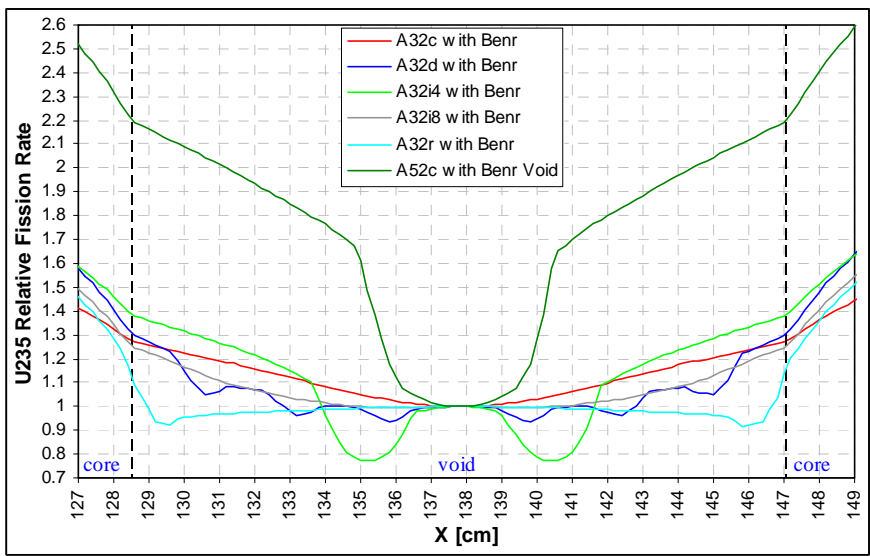

Figure 103. EW U-235 Fission Traverse Inside the Void Region

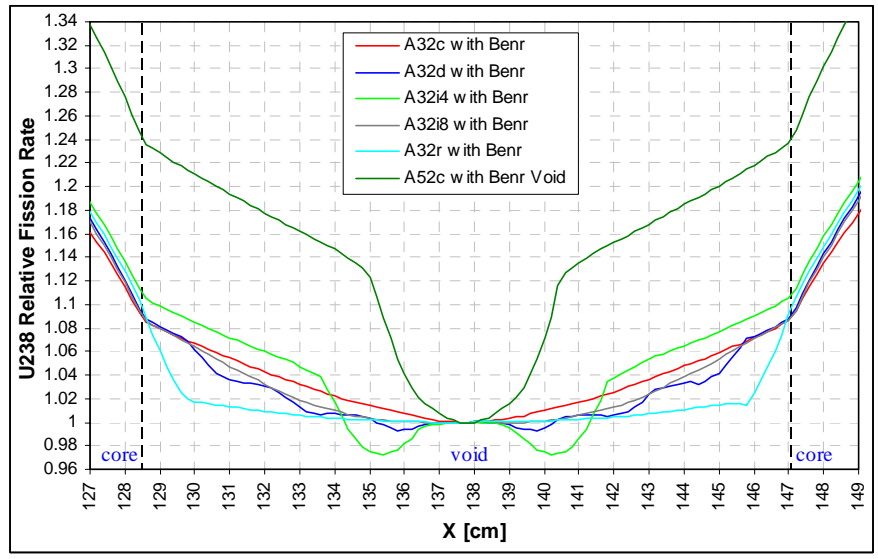

Figure 105. EW U-238 Fission Traverse Inside the Void Region 


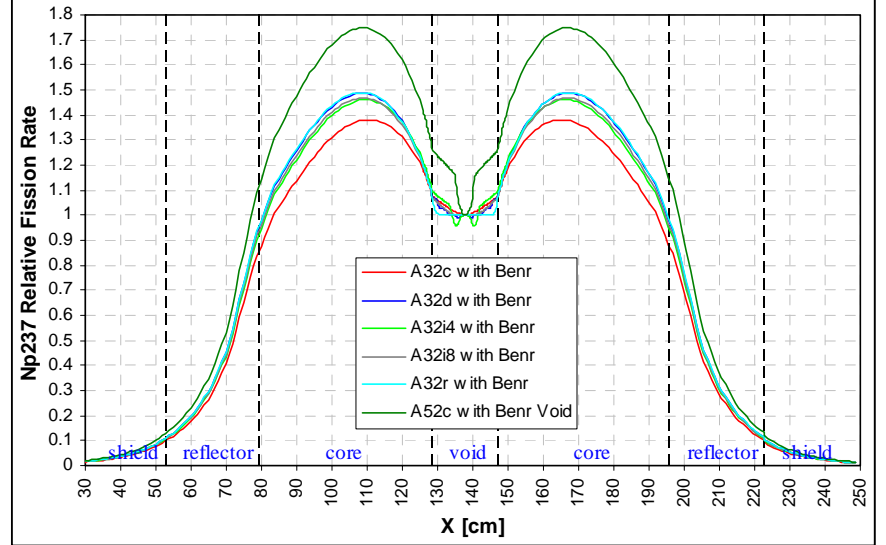

Figure 106. EW Np-237 Fission Traverse

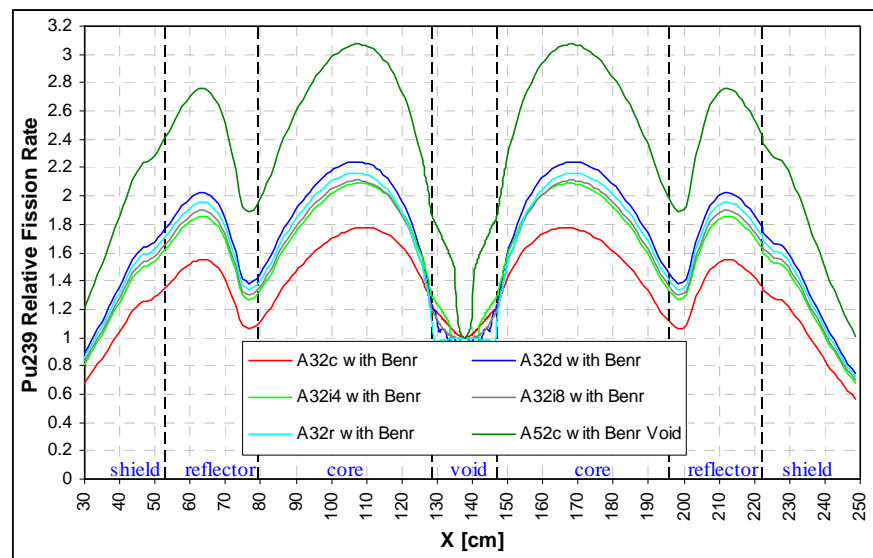

Figure 108. EW Pu-239 Fission Traverse

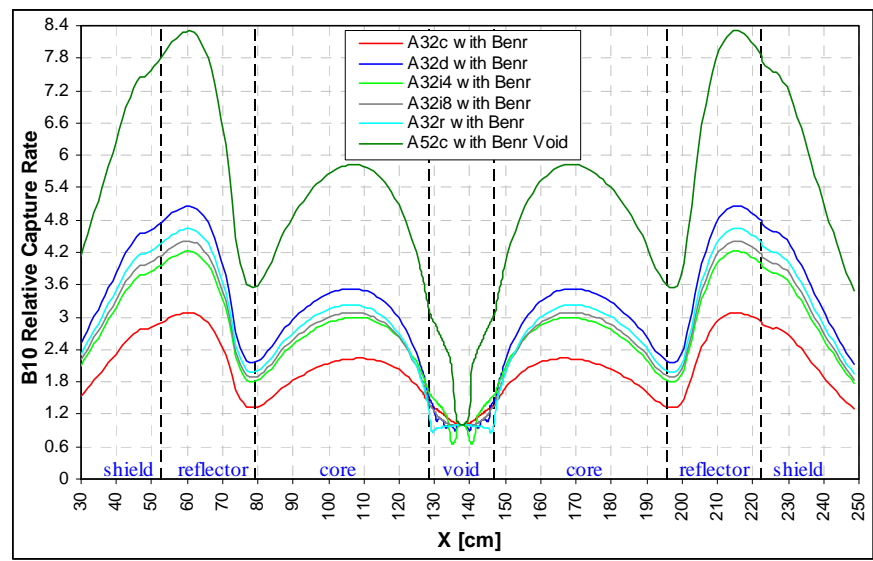

Figure 110. EW B-10 Capture Traverse

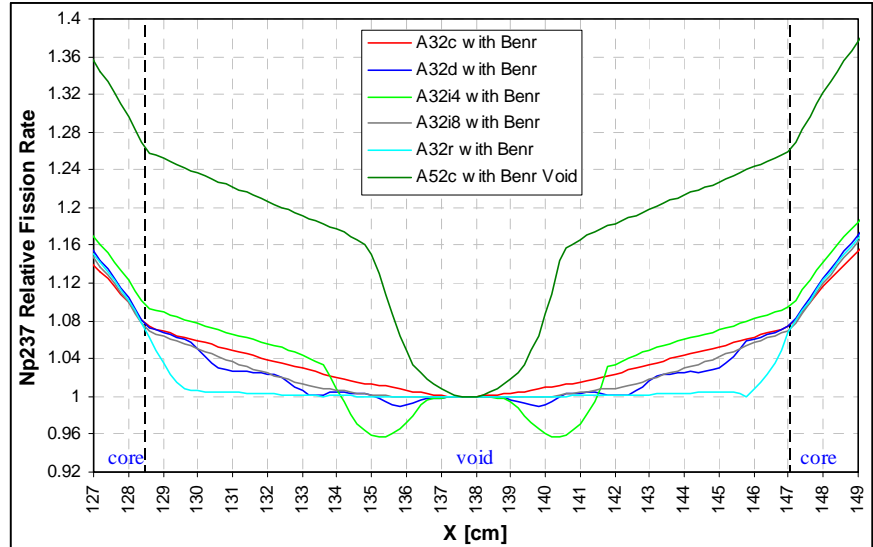

Figure 107. EW Np-237 Fission Traverse Inside the Void Region

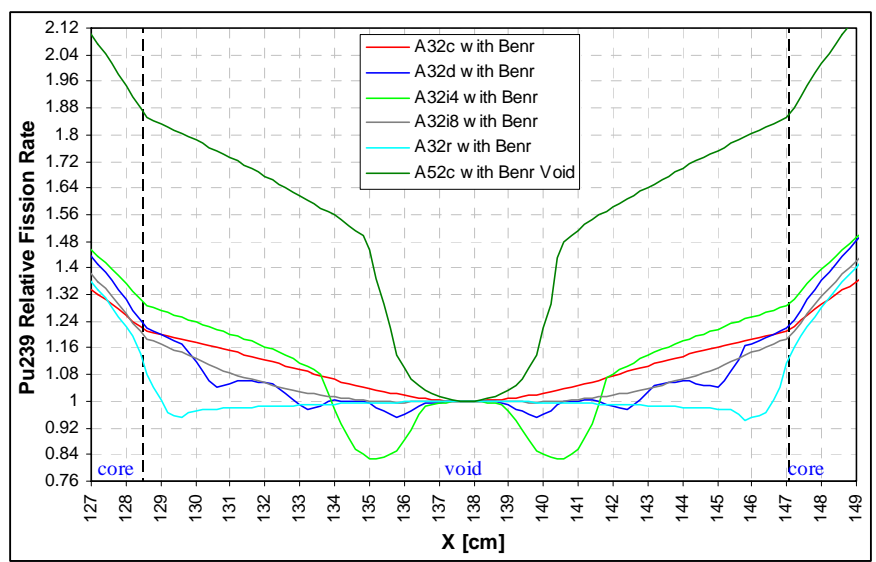

Figure 109. EW Pu-239 Fission Traverse Inside the Void Region

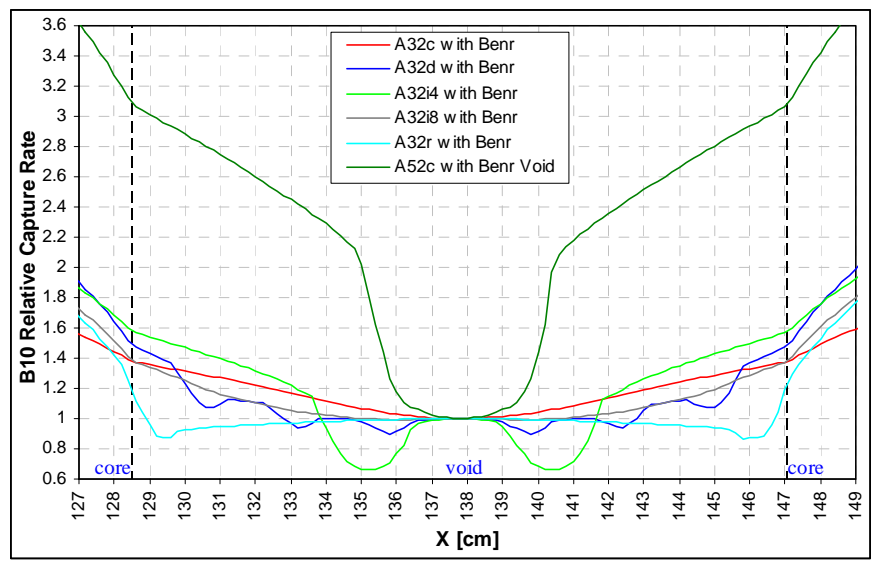

Figure 111. EW B-10 Capture Traverse Inside the Void Region 


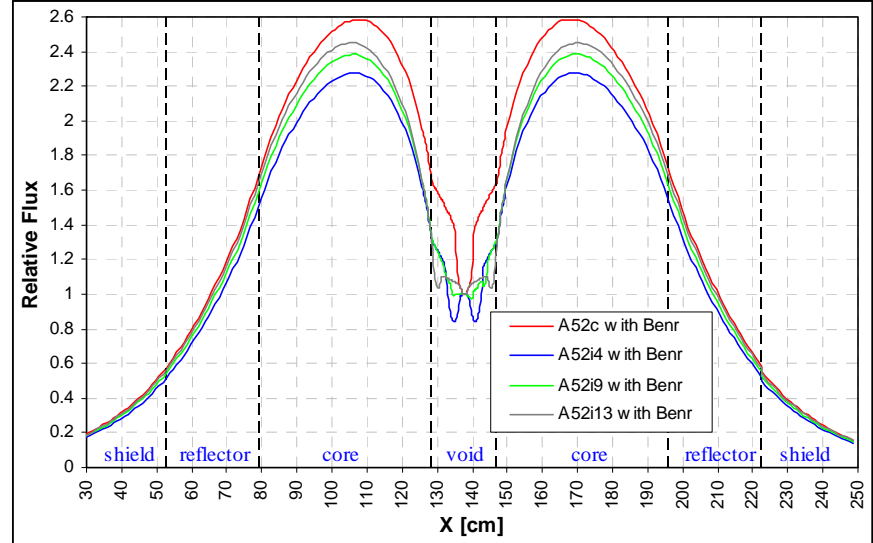

Figure 112. EW Flux Traverse

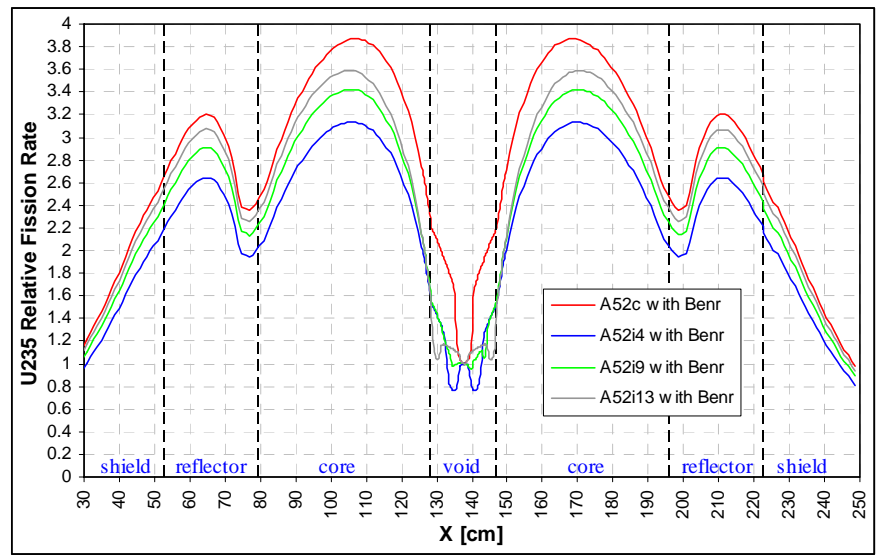

Figure 114. EW U-235 Fission Traverse

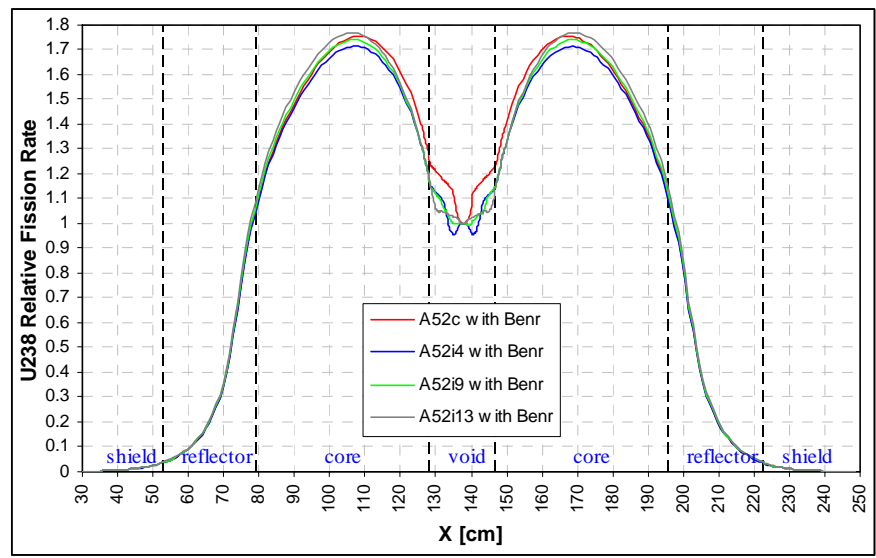

Figure 116. EW U-238 Fission Traverse

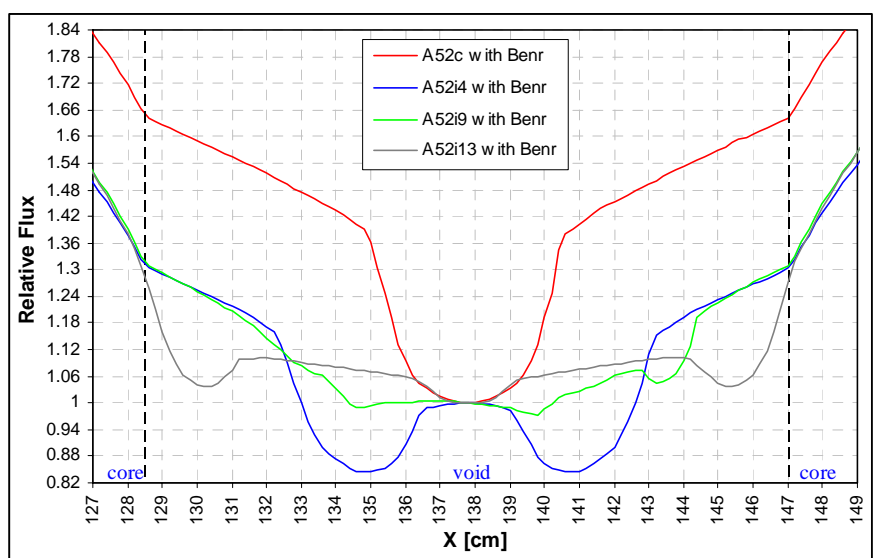

Figure 113. EW Flux Traverse Inside the Void Region

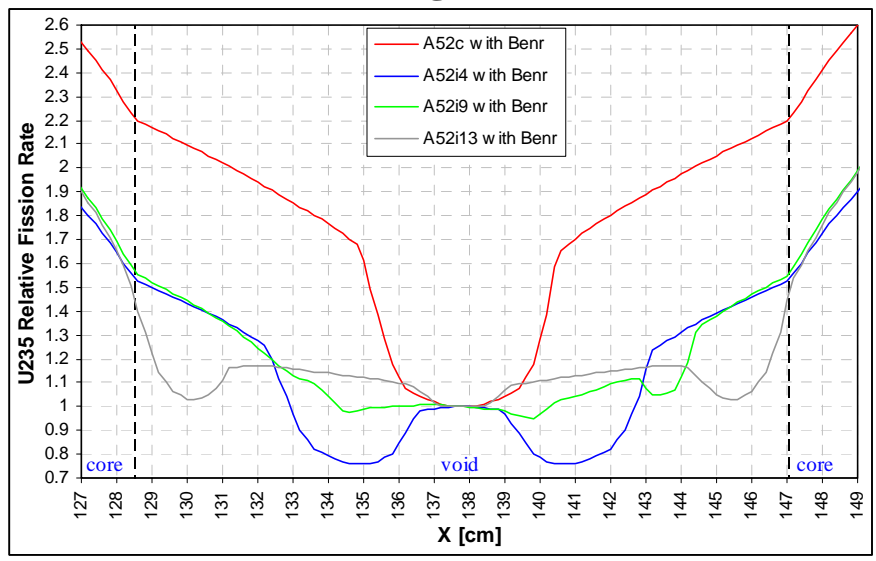

Figure 115. EW U-235 Fission Traverse Inside the Void Region

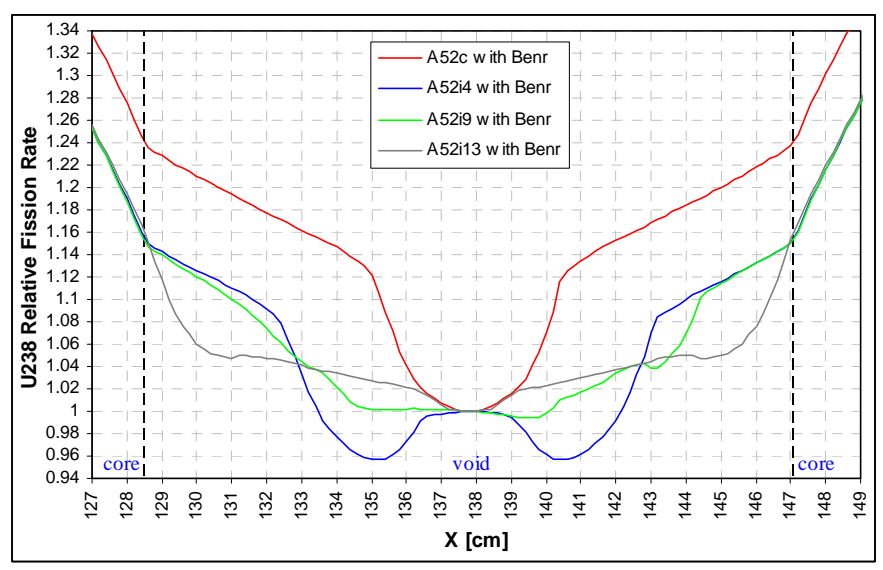

Figure 117. EW U-238 Fission Traverse Inside the Void Region 


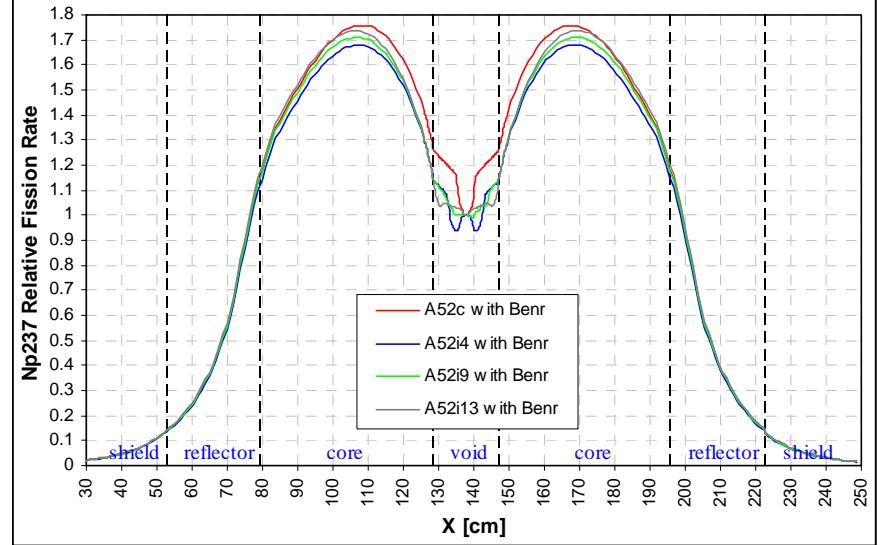

Figure 118. EW Np-237 Fission Traverse

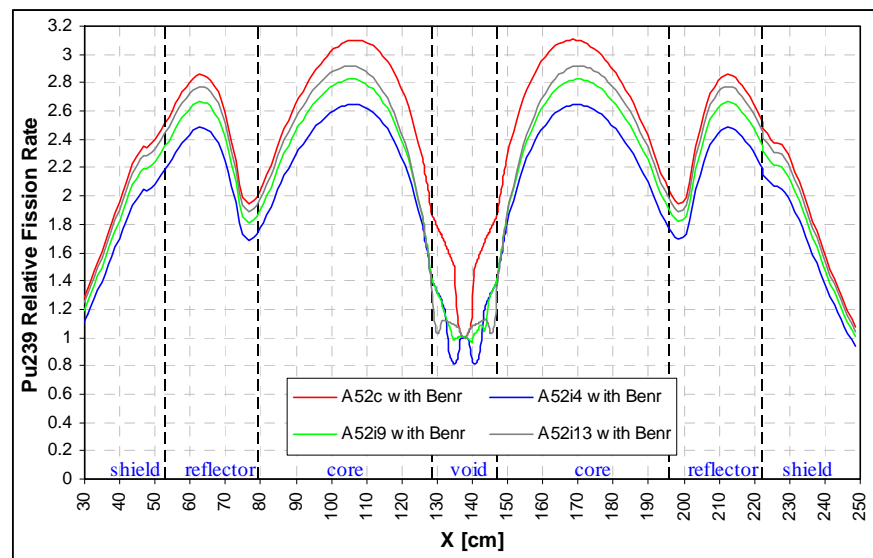

Figure 120. EW Pu-239 Fission Traverse

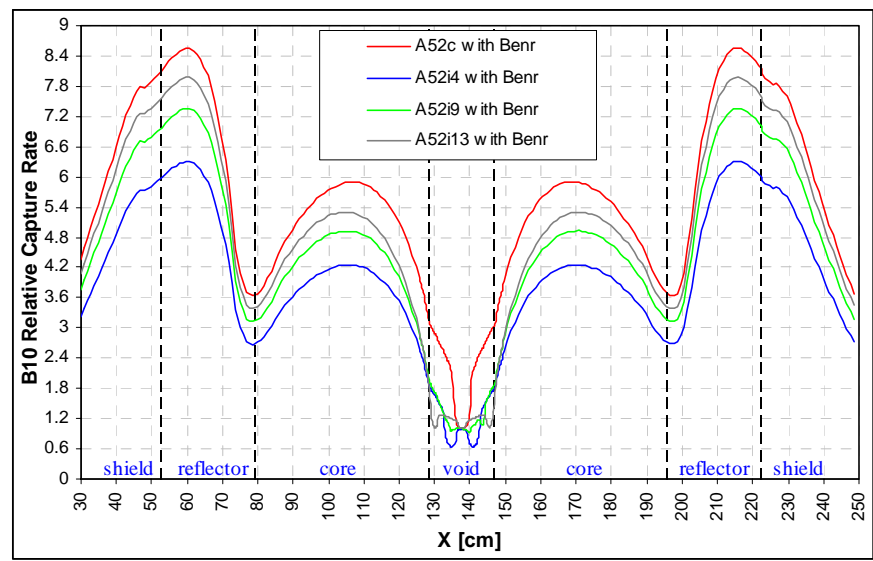

Figure 122. EW B-10 Capture Traverse

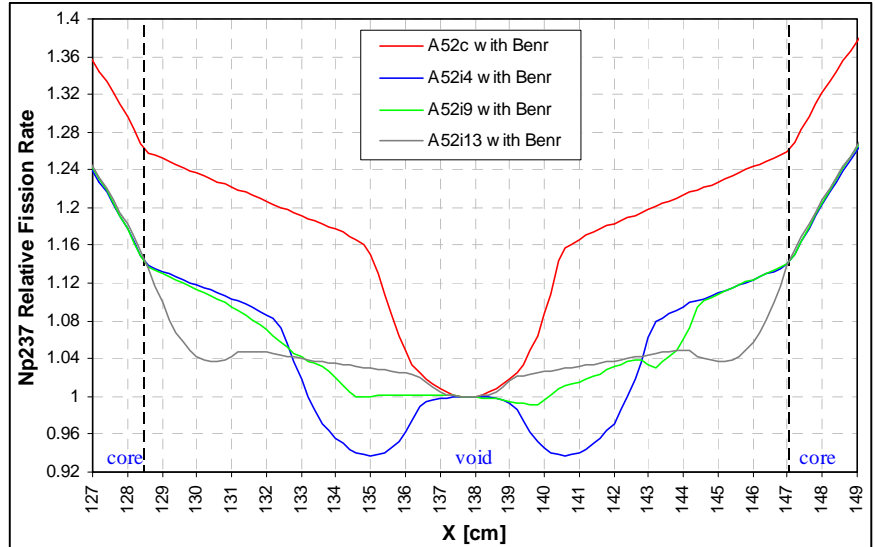

Figure 119. EW Np-237 Fission Traverse Inside the Void Region

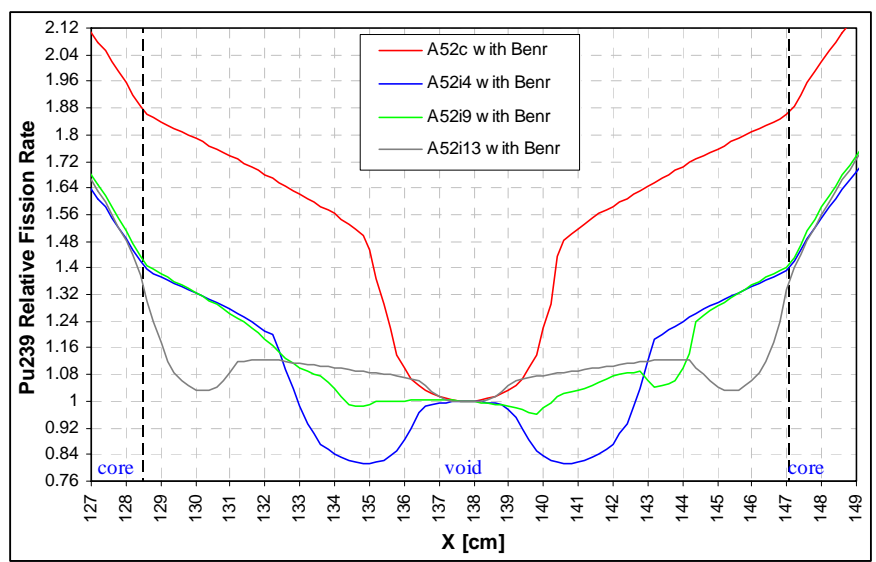

Figure 121. EW Pu-239 Fission Traverse Inside the Void Region

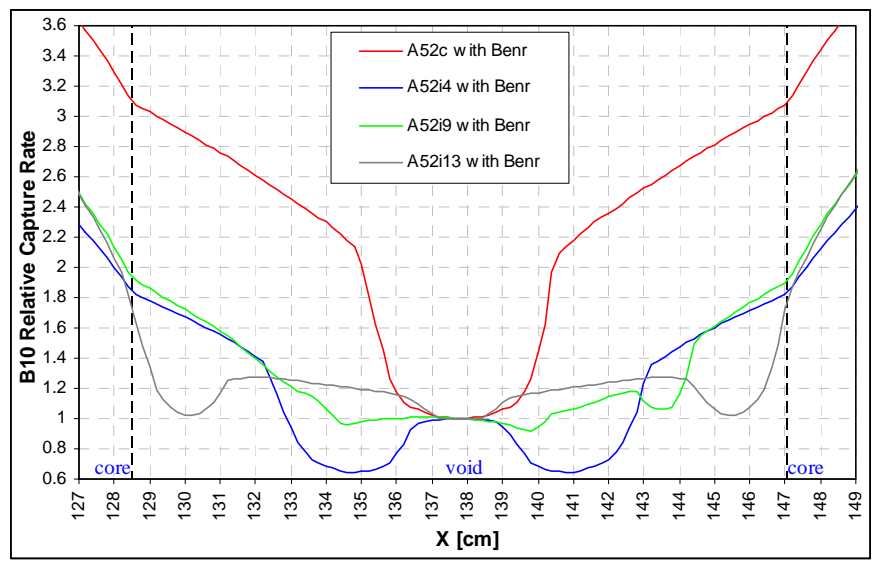

Figure 123. EW B-10 Capture Traverse Inside the Void Region 


\section{Argonne}

Nuclear Engineering Division

Argonne National Laboratory

9700 South Cass Avenue, Bldg. 208

Argonne, IL 60439-4842

www.anl.gov

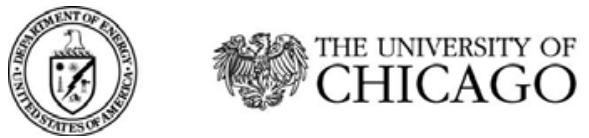

A U.S. Department of Energy laboratory managed by The University of Chicago 